Aus dem Institut für Ethik und Geschichte der Medizin

(Prof. Dr. med. C. Wiesemann)

im Zentrum Psychosoziale Medizin

der Medizinischen Fakultät der Universität Göttingen

\title{
Ärztlich assistierter Suizid - Ein Widerspruch zum ärztlichen Ethos?
}

Eine Darstellung der aktuellen Diskussion in Deutschland

\author{
INAUGURAL - DISSERTATION \\ zur Erlangung des Doktorgrades \\ der Medizinischen Fakultät der \\ Georg-August-Universität zu Göttingen \\ vorgelegt von \\ Kirsti Mehling \\ aus \\ Hof
}

Göttingen 2015 
Dekan:

Prof. Dr. rer. nat. H. K. Kroemer

I. Berichterstatter: apl. Prof. Dr. phil. A. Simon

II. Berichterstatter/in: Prof. Dr. med. M. Quintel

III. Berichterstatter/in: Prof. Dr. hum. biol. M. Schön

Tag der mündlichen Prüfung: $\quad$ 07. Oktober 2015 
Inhaltsverzeichnis:

1 EINLEITUNG 1

2 ÄRZTLICH ASSISTIERTER SUIZID - GRUNDLAGEN DER DISKUSSION 3

2.1 Sterbehilfe - Ein kurzer Überblick 3

2.1.1 Allgemeines zur Sterbehilfe 3

2.1.2 Geschichte der Sterbehilfe 4

2.1.3 Formen von Sterbehilfe 6

2.1.4 Begriffliche Neuordnung 9

2.2 Suizid und ärztliche Hilfe zur Selbsttötung 10

$\begin{array}{lll}2.2 .1 & \text { Allgemeines zum Suizid } & 10\end{array}$

2.2.2 Wunsch nach Suizidhilfe 11

2.2.3 Deutsche Rechtslage $\quad 12$

2.2.4 Rechtslage und Praxis im europäischen Ausland und in den USA 13

$\begin{array}{llr}2.3 & \text { Tabellarische Zusammenfassung } & 16\end{array}$

3 DARSTELLUNG DER AKTUELLEN DISKUSSION ZUM ÄRZTLICH ASSISTIERTEN SUIZID IN DEUTSCHLAND 19

3.1 Anlässe der gegenwärtigen Diskussion 19

$\begin{array}{lll}\text { 3.1.1 Organisierte Sterbehilfe } & 19\end{array}$

3.1.2 Gewerbliche Sterbehilfe 23

3.1.3 Berufsethische und berufsrechtliche Neubewertung der ärztlichen Suizidhilfe 25

$\begin{array}{llr}3.2 & \text { Reaktionen auf die aktuellen Ereignisse } & 27\end{array}$

$\begin{array}{ll}\text { 3.2.1 Nationaler/Deutscher Ethikrat } & 27\end{array}$

$\begin{array}{lll}\text { 3.2.2 Juristische und politische Bestrebungen } & 31\end{array}$

3.2.3 Haltung der deutschen Ärzte 35

3.2.4 Medizinethische und medizinrechtliche Kommentare 38

3.3 Zusammenfassung und Zwischenergebnis $\quad 43$ 
4.1 Grundlegendes zum ärztlichen Ethos $\quad 45$

4.1.1 Zum Verhältnis von Ethos und Ethik in der Medizin 45

4.1.2 Ärztliches Ethos als Standesethos (Hippokratischer Eid und Genfer Ärztegelöbnis) 46

4.1.3 Funktion des ärztlichen Standesethos $\quad 51$

4.2 Das ärztliche Ethos im Kontext der ärztlichen Suizidhilfe 52

4.2.1 Der Wunsch nach Suizidhilfe - Eine Überforderung des traditionellen ärztlichen Ethos? 52

4.2.2 Die Bitte um Suizidhilfe und der „Schwarze Peter“ - Suizidhilfe als ärztliche Aufgabe? 54

4.2.3 Vertrauensverlust durch ärztlich assistierten Suizid? 55

$\begin{array}{lll}4.3 & \text { Zusammenfassung und Zwischenergebnis } & 58\end{array}$

5 ÄRZTLICH ASSISTIERTER SUIZID - EIN WIDERSPRUCH ZUM

ÄRZTLICHEN ETHOS? ZUSAMMENFASSUNG UND AUSBLICK

6 ABKÜRZUNGSVERZEICHNIS

7 LITERATURVERZEICHNIS $\quad 64$ 


\section{EINLEITUNG}

„,Die Zukunft ist etwas, das meistens schon da ist, bevor wir damit rechnen. “ (anonym)

Nach den anfänglichen Sterbehilfedebatten, die sich vornehmlich um den Behandlungsabbruch und die Leidenslinderung drehten (ehemals als passive bzw. indirekte Sterbehilfe bezeichnet), wird die Diskussion seit einigen Jahren immer spezieller und konzentriert sich derzeit vornehmlich auf die Suizidhilfe. Hervorzuheben ist an dieser Stelle, dass es sich um die Hilfe bei einem Suizid handelt, der Ausdruck einer freiverantwortlichen wohlerwogenen Entscheidung und nicht einer psychiatrischen Erkrankung ist. Sicher betrifft das Ersuchen um Suizidhilfe nur einen sehr kleinen Prozentsatz der Patienten, allerdings ist für diese der Wunsch nach einem selbstbestimmten Tod in Würde elementar. Um nicht auf die herkömmlichen Methoden der Selbsttötung zurückgreifen zu müssen, die meist für Angehörige und Sterbewillige schwer zu ertragen oder aus einem körperlichen Unvermögen heraus nicht möglich sind, kommen Ärzte ins Spiel, die mittels der Verschreibung todbringender Medikamente als Helfer zum Sterben auftreten sollen.

Der ärztlich assistierte Suizid ist in Deutschland gegenwärtig aber nicht nur ein kontrovers diskutiertes Thema, sondern er wird bereits praktiziert, sei es im Geheimen im Rahmen einer vertrauensvollen Arzt-Patient-Beziehung oder durch die medienwirksamen Aktivitäten von Sterbehilfevereinen und -organisationen bzw. die Tätigkeit einzelner Ärzte. Obwohl die Debatten bezüglich der (berufs-)ethischen und (berufs-)rechtlichen Einschätzung noch in alle Richtungen offen sind, sind sich Experten wie zum Beispiel der Palliativmediziner Gian Domenico Borasio in einem Interview mit Henckel sicher: „Der assistierte Suizid wird kommen, auch in Deutschland.“ Denn die Zustimmung der Bevölkerung zu dieser Form der Sterbehilfe wird, wie er weiter ausführt, sowohl in Europa als auch in Nordamerika immer größer und die Politik dem irgendwann folgen (Henckel 2012, S. 3). Daher ist es sinnvoll, sich zunächst einen grundlegenden Überblick über die Sterbehilfe und die Selbsttötung zu verschaffen und im Folgenden die aktuelle Debatte nachzuvollziehen, um sich möglichst frühzeitig intensiv mit diesem komplexen und besonders für die Ärzteschaft herausfordernden Thema auseinanderzusetzen, zumal viele Aspekte vor allem der ärztlichen Suizidhilfe noch völlig unklar sind. 
Daher wird in einem einführenden Kapitel in Form eines kurzen Überblicks über die Themen Sterbehilfe und Suizid die Basis für den Fortgang der Arbeit geschaffen. Eine tabellarische Zusammenfassung bildet den Abschluss des Kapitels. Ziel des dritten Kapitels der Arbeit ist, auf Grundlage der gesichteten Literatur herauszuarbeiten, welche konkreten Anlässe es in den vergangenen Jahren waren, die die schon länger geführte innerdeutsche Debatte um die Suizidhilfe wieder in den Fokus der Öffentlichkeit gerückt haben, bis hin zu der Tatsache, dass sich seit Herbst 2014 der Bundestag mit einem Gesetzentwurf Aspekten dieses Problemfelds annehmen möchte. In einer Zusammenschau verschiedener exemplarisch ausgewählter Reaktionen auf die aktuellen Ereignisse um die Suizidhilfe wird dabei klar, dass die Wahl des Arztes als Sterbehelfer die Debatte um die Suizidhilfe verkompliziert und verschärft, denn die deutsche Ärzteschaft betreffen spezifische berufsrechtliche und standesethische Vorgaben. Zudem wird deutlich, dass das ärztliche Ethos ein Kernpunkt, wenn nicht sogar der Kernpunkt der aktuellen Debatte ist, wobei allerdings auffällt, dass die Vorstellungen zu diesem besonderen beruflichen Ethos stark divergieren. Aus diesem Grund soll der Terminus Ethos und dessen Bestimmung im Zentrum des vierten Kapitels der vorliegenden Arbeit stehen. Die detaillierte Betrachtung der ärztlichen Suizidhilfe im Kontext des ärztlichen Ethos und die Prüfung der Fragestellung, ob die ärztliche Suizidhilfe dem ärztlichen Ethos widerspricht, bilden neben der Darstellung der aktuellen Diskussion die zentralen Forschungsaufgaben der vorliegenden Dissertation, die eine Lücke in der bisherigen Literatur zum ärztlich assistierten Suizid füllen sowie die Grundlage für den unabdingbaren weiteren Fortgang der Diskussion in Deutschland bilden soll.

Die Literatur für diese in den Jahren 2012 bis 2015 am Institut für Ethik und Geschichte der Medizin der Medizinischen Fakultät der Georg-August-Universität zu Göttingen unter der Betreuung von Prof. Dr. Alfred Simon entstandene Arbeit wurde weitgehend durch eine Recherche in der Literaturdatenbank ETHMED gewonnen. Die hier unter den Schlagworten [assisted suicide OR euthanasia] gefundenen und nach Relevanz ausgewählten Literaturbeiträge bilden das Fundament der Doktorarbeit. Sie wurden im Laufe des Entstehens der Dissertation durch Literaturrecherchen in der Niedersächsischen Staats- und Universitätsbibliothek und durch im Internet veröffentlichte (qualifizierte) Beiträge ergänzt.

Rein aus Gründen der besseren Lesbarkeit wird zur Bezeichnung gemischtgeschlechtlicher Gruppen durchgehend die männliche Form verwendet. In jedem Fall ist dabei jedoch implizit auch die entsprechende weibliche Person gemeint. 


\section{2 ÄRZTLICH ASSISTIERTER SUIZID - GRUNDLAGEN DER DISKUSSION}

$\mathrm{Zu}$ den schwierigsten Herausforderungen einer Gesellschaft gehören Fragen im Kontext des ärztlichen Handelns am Lebensende, da dieser Bereich verschiedene gesellschaftliche, juristische, medizinische und ethische Probleme umfasst. Das ist ein wesentlicher Grund dafür, dass es bereits seit Jahren in Deutschland einen äußerst vielschichtigen öffentlichen Diskurs über die Sterbehilfe gibt. Hinzu kommt die Erschwernis, dass die verwendete Terminologie dieses ohnehin schon komplizierten Themas nicht immer einheitlich und klar definiert ist. Daher stehen einige allgemeine Ausführungen zur Sterbehilfe am Beginn dieser Arbeit, gefolgt von einer kurzen Darstellung der Geschichte der Sterbehilfe. Überleitend zu den weiteren Ausführungen der Dissertation wird auf die verschiedenen Formen und die begriffliche Neuordnung der Sterbehilfe, den Suizid und auf die ärztlich assistierte Selbsttötung eingegangen, um so die begrifflichen und inhaltlichen Grundlagen für den Fortgang der Arbeit zu schaffen.

\subsection{Sterbehilfe - Ein kurzer Überblick}

\subsubsection{Allgemeines zur Sterbehilfe}

Auf der Suche nach einem menschenwürdigen Lebensende ihrer Patienten stehen Ärzte vor einer Vielzahl an Behandlungsmöglichkeiten, Herausforderungen und Problemen. Durch Patientenverfügungen, Vorsorgevollmachten und Betreuungsverfügungen können Patienten den behandelnden Medizinern in schwierigen Situationen eine Orientierung geben. Diese Unterlagen sind somit von großer Bedeutung, um das Recht der Patienten auf Selbstbestimmung gewährleisten zu können. Allerdings sind die Dokumente inhaltlich und situativ meist unzureichend und können im konkreten Fall nicht angewandt werden. Außerdem besteht in der Gesellschaft, aber auch in der Ärzteschaft eine große Unsicherheit und meist auch Unkenntnis, wo genau die Grenze zwischen erlaubter und strafrechtlich verbotener Sterbehilfe verläuft. Von dem zusätzlich bestehenden berufsrechtlichen Dilemma sei hier 
noch keine Rede. Die stetig wachsende Zahl von Publikationen zeigt, dass kaum ein anderes medizinethisches Thema gesellschaftlich so umstritten ist und derart häufig Anlass für moralische Kontroversen bietet. Bereits beim Bemühen um eine Präzisierung des Begriffs Sterbehilfe gestaltet es sich schwierig, eine genaue Definition zu finden, da dieser Terminus verschiedene mögliche Handlungen am Ende des Lebens impliziert. So wird gemeinhin die Hilfe im Sterben von der Hilfe zum Sterben unterschieden. Die Hilfe im Sterben kann mit Sterbebeistand oder Sterbebegleitung umschrieben werden. Sie besteht in der Unterstützung Sterbender durch Pflege, angemessene Schmerzbehandlung, menschliche sowie ggf. spirituelle Zuwendung und ist als dringendes Erfordernis im Umgang mit Sterbenden unumstritten. Davon abzugrenzen ist die Hilfe zum Sterben, die das Töten oder Sterbenlassen eines schwer kranken oder leidenden Menschen aufgrund seines eigenen, ausdrücklichen oder mutmaßlichen Verlangens bezeichnet. Die Hilfe zum Sterben wird wiederum traditionell in vier verschiedene Formen eingeteilt, wodurch das Verstehen der Sterbehilfe nicht nur für die Bevölkerung, sondern auch für Experten extrem erschwert wird (Hillebrand 2009).

\subsubsection{Geschichte der Sterbehilfe}

Seit vielen Jahrhunderten haben sich Menschen in der abendländischen Geistesgeschichte mit den Themen Tod, Sterbehilfe und Selbsttötung auseinandergesetzt. In den philosophischen Schriften der Denker der griechischen Antike war der Begriff der Euthanasie zentral, der wörtlich übersetzt schöner bzw. guter Tod bedeutet. Die Euthanasie und das Streben danach kamen in manchen Zeiten gar einem Ideal gleich. Bei einigen Philosophenschulen und Gelehrten galten sowohl die Selbsttötung bei Lebensmüdigkeit als auch die Sterbehilfe nicht immer als verwerflich, obwohl es dem (auch heute noch vielfach zitierten) Hippokratischen Eid entgegenstand (Frewer 2001). Auch in den philosophischen Abhandlungen der nachfolgenden Jahrhunderte wurde die Vorstellung eines guten Todes immer wieder thematisiert und ausgeweitet. Im alten Rom wurde die Euthanasie zeitweise gar zum philosophischen Lebensziel, ,indem die Würde des Einzelnen durch selbstbestimmtes Sterben gerettet wird.“ (Kern 2007, S. 289) Dem steht die christliche Lehre von der Unverfügbarkeit des eigenen Lebens strikt gegenüber, weshalb im christlich geprägten Mittelalter Sterbehilfe bzw. Euthanasie meistenteils abgelehnt und die Selbsttötung als Sünde geächtet wurde. Diese Haltung der christlichen Religion war lange Zeit (und zum Teil bis heute) prägend für die 
Auseinandersetzungen um die Sterbehilfe. Das sehr weltzugewandte Menschenbild der Renaissance wiederum ermöglichte einen freieren philosophischen Diskurs zur Euthanasie. Im 18. Jahrhundert schließlich wurde in den ärztlichen Schriften überwiegend eine leidensmindernde Sterbehilfe akzeptiert, die zwar eine Verringerung des Leidens, nicht aber eine Verkürzung des Lebens zum Ziel hatte. In den naturwissenschaftlich geprägten medizinischen Debatten des 19. und 20. Jahrhunderts hatte die Sterbehilfe zunächst wenig Raum, wurde allerdings im Vorfeld des ersten Weltkriegs wieder intensiviert diskutiert und wies zunehmend sozialdarwinistische Tendenzen auf, die sich während des nationalsozialistischen Regimes noch zuspitzten und radikalisierten (op. cit.).

Gegenwärtig ist der Begriff der Euthanasie mit dem der Sterbehilfe eng verbunden und bezeichnet einerseits das Erleichtern des Sterbevorgangs (mit Inkaufnahme seiner Beschleunigung) und andererseits das direkte Herbeiführen eines schnellen Todes. In der internationalen medizinethischen Debatte ist der englische Ausdruck euthanasia durchaus gebräuchlich und steht in der Regel für die Tötung auf Verlangen. In Deutschland hingegen gilt der Begriff als belastet und wird in der aktuellen Debatte eher vermieden, wobei die Ursache hierfür in der deutschen Vergangenheit liegt. Im sog. Dritten Reich (1933-1945) wurden im Rahmen verschiedener Aktionen über 200.000 Menschen, deren Leben aufgrund ihrer Herkunft, einer Krankheit oder einer geistigen/körperlichen Behinderung als lebensunwert betrachtet wurde, systematisch unter dem Vorwand der Rassenhygiene ermordet. Diese Tötungen standen im Zeichen des Irrglaubens der nationalsozialistischen Ideologie, so zum Wohle des Kranken wie auch der Gesellschaft zu handeln und dem Kollektiv die ökonomische Belastung durch die Pflege zu ersparen. Euphemistisch wurden die geplanten und systematisierten Zwangstötungen mit dem Begriff der Euthanasie bezeichnet, was die ursprüngliche Bedeutung des Wortes stark verfälschte (Petermann 2008). Zudem wurde die eindeutig ins Negative weisende Verknüpfung des Wortes Euthanasie mit dem Begriff der Sterbehilfe in der Nachkriegszeit noch intensiviert, indem manche Ärzte ihre in der NS-Zeit unbehelligt betriebenen planmäßigen Kranken- und Kindstötungen nachträglich zur ärztlichen Sterbehilfe erklärten.

Trotz alledem ließ sich nach dem Zweiten Weltkrieg eine Auseinandersetzung mit dem Problemkomplex der Sterbehilfe nicht vermeiden, da durch fortschreitende Erkenntnisse und Therapiemöglichkeiten immer neue medizinethische, das Lebensende betreffende Herausforderungen hinzukamen. Dazu tritt vermehrt die Forderung nach Selbstbestimmung des Patienten. Deshalb ist es erforderlich, mit der Zeit zu gehen und einem ethischen Diskurs zum Thema Sterbehilfe Raum zu geben, denn ,angstvolle Vermeidungen, wie sie die Diskussion 
in Deutschland seit 1945 bestimmen, helfen weder Sterbenden noch den sie behandelnden Ärztinnen und Ärzten.“ (Lunshof u. Simon 2000, S. 246)

\subsubsection{Formen von Sterbehilfe}

Im Bereich der Sterbehilfe werden traditionell vier verschiedene Formen unterschieden, nämlich die aktive, die passive und die indirekte Sterbehilfe sowie die Beihilfe zum Suizid. Im deutschen Strafrecht, das als Teil des Öffentlichen Rechts dem sogenannten Privatrecht gegenübersteht, sind die juristischen Grundlagen zur Sterbehilfe verankert. Im Folgenden werden die unterschiedlichen Arten der traditionellen Unterscheidung kurz erläutert, um anschließend auf die begriffliche Neuordnung des Terminus Sterbehilfe einzugehen. Die bestehenden Begrifflichkeiten wurden in den vergangenen Jahren schrittweise von einer neuen Terminologie ersetzt, mit der Absicht, den tatsächlichen Gegebenheiten der einzelnen Formen der Sterbehilfe mehr zu entsprechen.

\section{$\underline{\text { Aktive Sterbehilfe }}$}

Mit aktiver Sterbehilfe wird die gezielte Tötung eines Patienten durch einen Eingriff bezeichnet, der nicht der Behandlung, der Symptomkontrolle oder dem Behandlungsabbruch dient. Die Tötung auf Verlangen (aktive Sterbehilfe gemäß ausdrücklichem Patientenwunsch) ist von der Tötung ohne ausdrückliches Verlangen (aktive Sterbehilfe gemäß dem mutmaßlichen Patientenwillen oder im Sinne einer sog. Mitleidstötung) zu trennen. Hervorzuheben ist, dass die Tötungshandlung bei der aktiven Sterbehilfe durch einen Sterbehelfer geschieht und explizit nicht durch den Patienten.

Die Sterbehilfe ist hierzulande in keinem eigenen Gesetz geregelt. Lediglich der Umgang mit der aktiven Sterbehilfe ist im Strafgesetzbuch (StGB) expressis verbis festgelegt, indem im $\S 216$ StGB die Tötung auf Verlangen untersagt und in den $\S \S 211$ und 212 StGB die Tötung als solche verboten wird. Folglich berechtigt auch das Selbstbestimmungsrecht des Patienten den Arzt nicht zu einer aktiven, gezielten Sterbehilfe. 


\section{$\underline{\text { Passive Sterbehilfe }}$}

Die aktive Sterbehilfe ist deutlich von der passiven Sterbehilfe zu unterscheiden, die einen Verzicht auf medizinisch indizierte lebenserhaltende Maßnahmen umschreibt und so ein würdevolles Sterben des Patienten zulässt. Die passive Sterbehilfe ist erlaubt, wenn ein entscheidungsfähiger Patient aktuell auf eine lebenserhaltende/ -verlängernde Behandlung verzichtet oder er seine bisher gegebene Zustimmung zurückzieht. Sie ist ferner zulässig, wenn eine wirksame Patientenverfügung mit einem solchen Behandlungsverzicht vorliegt oder dieser dem (mutmaßlichen) Willen des Patienten entspricht, der unabhängig von der Schwere der Erkrankung, der Indikation und den Behandlungsaussichten respektiert werden muss. Dies hat der Bundegerichtshof (BHG) in einem Urteil vom Sommer 2010 herausgearbeitet:

„Sterbehilfe durch Unterlassen, Begrenzen oder Beenden einer begonnenen medizinischen Behandlung (Behandlungsabbruch) ist gerechtfertigt, wenn dies dem tatsächlichen oder mutmaßlichen Patientenwillen entspricht ( $\$$ 1901a BGB) und dazu dient, einem ohne Behandlung zum Tode führenden Krankheitsprozess seinen Lauf zu lassen.“

(BGH 2010)

Der Umstand, dass passive Sterbehilfe sowohl den Verzicht auf die Aufnahme einer lebensverlängernden Maßnahme als auch den Verzicht auf die Weiterführung einer lebensverlängernden Maßnahme umfassen kann, sorgte vielfach für Unklarheit, da beispielsweise der Abbruch einer Beatmung bei infauster Prognose oder das Ziehen einer perkutanen enteralen Ernährungssonde oft fälschlich als aktive Sterbehilfe eingeschätzt wurde (und zum Teil noch wird). Aus diesem Grund betonte der BGH im oben erwähnten Urteil, dass ein Behandlungsabbruch auch durch ein aktives Tun erfolgen könne. Demnach werde eine nur an den Äußerlichkeiten von Tun oder Unterlassen orientierte Unterscheidung der straflosen passiven Sterbehilfe vom strafbaren Töten des Patienten im Sinne einer aktiven Sterbehilfe dem sachlichen Unterschied zwischen der auf eine Lebensbeendigung gerichteten Tötung einerseits und Verhaltensweisen, die dem krankheitsbedingten Sterbenlassen mit Einwilligung des Betroffenen seinen Lauf lassen andererseits, nicht gerecht. Von Strafe bedroht sei jedoch eine über das Sterbenlassen hinausgehende Beschleunigung des Sterbens, denn „gezielte Eingriffe in das Leben eines Menschen, die nicht in einem Zusammenhang mit dem Abbruch einer medizinischen Behandlung stehen, sind einer Rechtfertigung durch Einwilligung nicht zugänglich.“(op. cit.) 


\section{$\underline{\text { Indirekte Sterbehilfe }}$}

In Abgrenzung zur aktiven Sterbehilfe ist bei der sogenannten indirekten Sterbehilfe die Lebensverkürzung nicht intendiert, sondern primär Nebenwirkung der notwendigen und gebotenen Symptomkontrolle/Schmerztherapie. Die palliative Maßnahme steht im Vordergrund, die Lebensverkürzung wird als mögliche Nebenfolge in Kauf genommen. Nach Ansicht deutscher Gerichte hat die Leidenslinderung sogar klaren Vorrang vor einer bloßen Lebensverlängerung, daher sollen und müssen die Möglichkeiten der Palliativmedizin genutzt werden. Folglich kann eine unzureichende Leidensminderung durchaus (im Sinne einer Körperverletzung) gesetzeswidrig sein. Grundsätzlich aber ist indirekte Sterbehilfe zulässig, wenn sie medizinisch indiziert ist, ein entsprechender oder mutmaßlicher Patientenwille vorliegt und keine Tötungsabsicht besteht.

Eine fehlende detaillierte juristische Regelung der passiven und indirekten Sterbehilfe macht es der Ärzteschaft bei ihrer Entscheidungsfindung nicht leicht. So kann der ärztliche Entschluss über den Behandlungsabbruch in den Tatbestand der vorsätzlichen Tötung, also des Totschlags führen, während umgekehrt die Fortsetzung der Behandlung bei Unklarheit des Willens des Patienten den Vorwurf der vorsätzlichen Körperverletzung heraufbeschwört (Ulsenheimer 2008). Deshalb ist es unbedingt erforderlich, dass Ärzte bei schwierigen Abwägungen in den Grenzbereichen zwischen Leben und Tod nach Möglichkeit weitere Beteiligte wie Kollegen, Pflegekräfte, vor allem aber Betreuer und Bevollmächtigte in ihre Entscheidungen mit einbeziehen. Dadurch kann ein Höchstmaß an Objektivität erreicht und zugleich die Last der Verantwortung verteilt und reduziert werden. Multidisziplinäre Ethikkomitees können im klinischen Alltag beim Prozess einer gemeinsamen Entscheidungsfindung helfen.

\section{$\underline{\text { Beihilfe zur Selbsttötung }}$}

Unter Beihilfe zur Selbsttötung wird die Mitwirkung beim Suizid eines Menschen verstanden. Das kann vor allem durch die Beschaffung tödlich wirksamer Medikamente, aber auch durch das Nichtverhindern eines Suizids oder das Unterlassen der Rettung eines Suizidenten geschehen. Die Beihilfe zum Suizid ist also in verschiedenen Weisen möglich, wobei der Begriff Beihilfe juristisch eigentlich unzutreffend ist, da dieser die Strafbarkeit des Handelns voraussetzt, was aber im Fall des Suizids bzw. des Suizidversuchs nicht der Fall ist. Zutreffender ist es demnach, eher von Hilfe zum Suizid zu sprechen. 


\subsubsection{Begriffliche Neuordnung}

In der Debatte um die Sterbehilfe sind sich die meisten Experten dahingehend einig, dass die herkömmliche Terminologie missverständlich ist. Die Abgrenzung zwischen den unterschiedlichen Arten der Sterbehilfe sowie die Fehleinschätzung oder das Uminterpretieren vieler Handlungen bereitet ständig wiederkehrende Probleme, wie eine Studie durch die Befragung von über 1.500 deutschen Ärzten und von mehr als 1.200 deutschen Vormundschaftsrichtern herausstellte. Hier bewerteten beispielweise $36 \%$ der Richter und sogar $42 \%$ der Ärzte die Beendigung einer künstlichen Beatmung fälschlicherweise als aktive Sterbehilfe (Oorschot u. Simon 2008). Aus diesem Grund haben bereits verschiedene Gremien versucht, neue Begrifflichkeiten zu finden, um die bestehenden Unklarheiten zu beheben, zumal diese die ohnehin schon diffizile Auseinandersetzung mit dem Thema Sterbehilfe noch zusätzlich verkomplizieren. Im Folgenden seien beispielhaft die Vorschläge des Nationalen Ethikrats kurz vorgestellt.

Der Nationale Ethikrat (Vorläufer des heutigen Deutschen Ethikrates) hat in seiner 2006 herausgegebenen Stellungnahme Selbstbestimmung und Fürsorge am Lebensende vorgeschlagen, die missverständliche und irreführende Terminologie der aktiven, passiven und indirekten Sterbehilfe aufzugeben und stattdessen die Begriffe Sterbebegleitung, Therapie am Lebensende, Sterbenlassen, Beihilfe zur Selbsttötung und Tötung auf Verlangen als angemessenere Beschreibungen für die Entscheidungen und Handlungen am Lebensende $\mathrm{zu}$ verwenden. Mit Sterbebegleitung sollen Maßnahmen zur Pflege und Betreuung von Todkranken und Sterbenden bezeichnet werden, aber auch menschliche Zuwendung und seelsorgerischer Beistand. $\mathrm{Zu}$ den Therapien am Lebensende zählen alle medizinischen oder palliativen Maßnahmen, die das Ziel haben, Leben zu verlängern und Leiden in der letzten Lebensphase zu mildern. Dazu gehören dem Vorschlag entsprechend zugleich Maßnahmen, bei denen die Möglichkeit besteht, dass der natürliche Prozess des Sterbens ungewollt verkürzt wird. Der Begriff des Sterbenlassens soll den Terminus der passiven Sterbehilfe ersetzen. Auch die Maßnahme einer je nach Fall und Bedarf unterschiedlich tiefen palliativen Sedierung soll unter diese Kategorie fallen, allerdings nur, wenn während der Sedierung auf lebenserhaltende Maßnahmen verzichtet wird. Andernfalls würde man sie unter den Begriff Therapien am Lebensende subsumieren. Unter Beihilfe zur Selbsttötung wird die Beschaffung eines todbringenden Mittels oder eine anderweitige Unterstützung bei der Vorbereitung oder Durchführung einer eigenverantwortlichen Selbsttötung verstanden. Die Tötung auf Ver- 
langen wiederum beschreibt das Töten des Sterbewilligen auf dessen ernsthaften Wunsch hin. Der Nationale Ethikrat ist sich allerding durchaus bewusst, dass die von ihm favorisierte Terminologie die Schwierigkeiten die es bereitet, medizinische Maßnahmen und Entscheidungen am Lebensende angemessen zu beschreiben, nicht restlos zu beseitigen vermag (Nationaler Ethikrat 2006).

\subsection{Suizid und ärztliche Hilfe zur Selbsttötung}

\subsubsection{Allgemeines zum Suizid}

Ein Suizid ist gemäß seiner Wortherkunft aus dem Lateinischen (von lat. sui, dt. sich und lat. caedere, dt. töten) ein Akt der Selbsttötung. Die synonym gebrauchten Bezeichnungen Selbsttötung, Freitod oder Selbstmord sind jedoch unterschiedlich konnotiert. Als Mord wird im deutschen Strafrecht eine Tötung aus niederen Beweggründen bezeichnet, womit der Ausdruck Selbstmord immer einen negativen Beigeschmack erhält. Es gilt deshalb, im Gespräch mit dem Patienten und dessen Angehörigen von der Verwendung dieses Begriffs sowie von Schuldzuweisungen und undifferenzierten moralischen Bewertungen des Suizid(wunsch)es dringend Abstand zu nehmen. Der eher euphemistische Begriff des Freitodes geht auf Friedrich Nietzsches Überschrift der 22. Rede Zarathustras Vom freien Tode zurück (Kluge 2002). Weitgehend wertneutral sind hingegen der bildungssprachliche Begriff Suizid und der amtssprachliche Ausdruck Selbsttötung. Daher werden lediglich diese beiden Termini im Fortgang der Arbeit verwendet, um eine sachliche Darstellung des Themas zu gewährleisten.

Das Statistische Bundesamt verzeichnet, dass trotz eines seit Jahrzehnten rückläufigen Sterblichkeitsniveaus bei Suiziden heutzutage dennoch jeder hundertste Mensch in Deutschland freiwillig aus dem Leben scheidet. Zudem liegt die Anzahl der Suizidversuche um ein vielfaches höher als die Zahl der tatsächlich durchgeführten Suizide mit tödlichem Ausgang (Rübenach 2007). Risikofaktoren für Suizide sind unter anderem psychische Erkrankungen (hierunter besonders Depressionen), soziale Isolation, höheres Lebensalter, männliches 
Geschlecht sowie verschiedene Persönlichkeitsfaktoren (Schmidtke 2012). Zum Beispiel kann sich das Gefühl der Hoffnungslosigkeit bis hin zum Suizidversuch oder der tatsächlichen Selbsttötung verdichten, wobei ein Großteil der Suizidversuche als Zeichen einer Hilf- bzw. Perspektivlosigkeit des Suizidenten verstanden werden muss (Neitzke et al. 2013). Bei diesem Ruf nach Hilfe als Ausdruck einer verzweifelten Krisensituation sollte eine moralische Pflicht zur Hilfeleistung bestehen und dem Suizidenten in seiner scheinbar aussichtslosen Lage mit viel Empathie und Geduld begegnet werden.

Wichtig ist es, den krankhaft bedingten Suizid vom statistisch deutlich seltener vorkommenden Bilanzsuizid zu differenzieren. Bilanzsuizide sind gründlich überlegte Suizidhandlungen, bei denen kein Zweifel besteht, dass der Sterbewillige über längere Zeit hinweg selbstbestimmt das Für und Wider des Suizids gründlich abgewogen hat. Solche Suizide sind meist detailliert geplant und werden oft am Ende einer schweren Krankheit oder in hohem Lebensalter, also nach einer längeren rationalen Abwägung der Lebensumstände in Betracht gezogen. In solche Selbsttötungen einzugreifen ist, wie der deutsche Philosoph Dieter Birnbacher schreibt, „eine vielleicht verständliche, aber doch kaum zu rechtfertigende Anmaßung.“" (Birnbacher 2000, S. 179)

\subsubsection{Wunsch nach Suizidhilfe}

Da manche Menschen nicht nur die Umstände, sondern auch den Zeitpunkt ihres Todes bestimmen möchten, äußern einzelne Patienten den Wunsch nach einem Suizid mit ärztlicher Hilfe. Dieses Anliegen wird durch verschiedene Motive gestärkt, wobei es in erster Linie psychische Beweggründe sind, die weit vor physischen Motiven, wie zum Beispiel Dyspnoe, Fatigue oder Schmerzen stehen. Vorrangig für das Suizidbegehren ist der Wunsch des Patienten nach der Kontrolle über die Umstände des Todes, die Aussicht auf eine künftige niedrige Lebensqualität, die Angst vor Schmerzen, das Unvermögen in Zukunft für sich selbst zu sorgen, der Verlust der Unabhängigkeit sowie der Wunsch zu Hause zu sterben, wie eine amerikanische Studie zeigte (Ganzini et al. 2009). Hinzu kommt der Wunsch nach einem würdevollen, schnellen und vor allem schmerzfreien Tod, wie es bei dem häufig gewählten Tod durch Erhängen, dem Sprung vor einen Zug oder ähnlichen Suizidarten meist nicht gegeben ist. Zudem werden auf diese Weise oft Dritte (wie beispielsweise Zugführer) 
traumatisiert, die den Suizidenten dann auffinden oder unfreiwillig aktiv am Geschehen beteiligt sind.

Letztendlich ist es unstrittig, dass ein respektvoller Umgang mit Todeswünschen von Patienten unbedingt zu den ärztlichen Aufgaben gehört und dabei versucht werden sollte, mit dem betroffenen Patienten, seinen Angehörigen und dem behandelnden Team die palliativmedizinischen Möglichkeiten zu erörtern und zu versuchen, einen gemeinsamen Weg zu finden. Im Umgang mit den betroffenen Patienten ist es wichtig anzuerkennen, dass ein Todeswunsch nicht als ausschließlich, absolut oder endgültig zu sehen ist. Er kann, wie die Deutsche Gesellschaft für Palliativmedizin (DGP) in ihren Reflexionen zum ärztlich assistierten Suizid betont, Ausdruck einer Ambivalenz zweier durchaus nebeneinander existenten Motive sein, die einerseits die Hoffnung auf ein baldiges Ende des Lebens und andererseits auf mehr Lebensqualität beinhalten. Daher ist es bedeutsam, die Äußerung von Sterbewünschen (auch im behandelnden Team) trotz aller Zurückhaltung nicht zu tabuisieren, sondern vielmehr als Zeichen des Vertrauens zu sehen. Zudem sollte man sich dessen bewusst sein, dass ein Gespräch mit dem Patienten über dieses, für ihn sehr zentrale Thema, sowohl eine große Entlastung für den Patienten, als auch eine Bereicherung für die ArztPatient-Beziehung bedeuten kann. Alternativen für den Patienten und dessen Umfeld können, neben anderen Vorgehensweisen, die palliative Sedierung oder die Begleitung bei einem freiwilligen Verzicht auf Nahrung und Flüssigkeit sein, wobei beides in Deutschland strafund berufsrechtlich zulässig ist (DGP 2014).

\subsubsection{Deutsche Rechtslage}

Der Versuch sich selbst zu töten und der durchgeführte Suizid stellen nach deutschem Recht keinen Straftatbestand dar. Demnach ist die Hilfe zum Suizid ebenfalls straffrei, denn nach juristischer Dogmatik kann nur die (Bei-)Hilfe zu einer strafbaren Handlung strafbar sein. Dennoch ist die Hilfe bei der Selbsttötung für den Arzt nicht unproblematisch. Ihm kommen als Suizidhelfer eine besondere Rolle und Verantwortung zu, denn für einen Arzt besteht ein Strafbarkeitsrisiko, wenn er die Rettung eines handlungsunfähigen Suizidenten unterlässt. Den Hintergrund hierfür bildet die sogenannte Garantenstellung des Arztes, der aufgrund seiner beruflichen Stellung in besonderer Weise für das Leben und die Gesundheit seines 
Patienten verantwortlich ist (BGH 1984). Die Rechtsprechung der letzten Jahre geht allerdings zunehmend auf die konkreten Umstände des Einzelfalles und eine mögliche Eigenverantwortlichkeit des Suizidenten ein. Die Gerichte haben anerkannt, dass es keine Rechtsverpflichtung zur Erhaltung eines erlöschenden Lebens um jeden Preis gibt (Ulsenheimer 2008). Das am 1. September 2009 in Kraft getretene Gesetz zur Änderung des Betreuungsrechts spricht ausdrücklich für den Wegfall der allgemeinen Pflicht, freiverantwortliche Suizide zu verhindern. Dennoch sind ärztlich lebensrettende Interventionen verboten, wenn sie gegen den mutmaßlichen oder zuvor geäußerten Willen eines (nunmehr einwilligungsunfähigen) Patienten erfolgen. Wie der Vorsitzende Richter am BGH a. D. Klaus Kutzer herausstellt, ist es mit dieser juristisch angeordneten Rechtslage nicht zu vereinbaren, dass ein erkennbar freiverantwortlicher Suizid als Unglücksfall anzusehen ist, der Ärzte zur Hilfeleistung verpflichtet. Sie dürfen vielmehr unter Beachtung des erklärten Patientenwillens dem freiverantwortlichen Selbsttötungsversuch seinen Lauf lassen. Für die Beurteilung des ärztlich assistierten Suizids ist diese Rechtsauffassung von großer Bedeutung, wenn der behandelnde Arzt weiß, dass der Schwerstkranke in Kenntnis der Irreversibilität des weiteren Krankheitsverlaufs eine wohlüberlegte und andauernde Entscheidung zum Suizid getroffen hat (Kutzer 2012).

\subsubsection{Rechtslage und Praxis im europäischen Ausland und in den USA}

Die Suizidhilfe ist in Europa in den Niederlanden, Luxemburg und in der Schweiz erlaubt. Bei der Sterbehilfediskussion in Deutschland wird oft auf diese Länder sowie den amerikanischen Bundesstaat Oregon verwiesen, wo der ärztlich assistierte Suizid gesetzlich geregelt und zulässig ist. Im Folgenden soll kurz die der Suizidhilfepraxis in diesen Ländern dargestellt werden, da viele Argumente der Debatte sich auf deren Daten und Erfahrungswerte beziehen. 


\section{$\underline{\text { Niederlande }}$}

Im April 2002 wurden erstmals in den Niederlanden die Ärzte formell durch das Gesetz über die Kontrolle der Lebensbeendigung auf Verlangen und die Hilfe bei der Selbsttötung von der Strafbarkeit der Tötung auf Verlangen und der Suizidhilfe ausgenommen. Damit legalisierte der Staat eine seit den 1970er Jahren bereits von den niederländischen Gerichten unter bestimmten Auflagen tolerierte ärztliche Suizid- und Sterbehilfe, die eigentlich bis dato gemäß den Artikeln 293 und 294 des niederländischen Strafgesetzbuchs grundsätzlich illegal war. Gemäß dem Gesetz von 2002 sind nur Ärzte, die unter bestimmten Voraussetzungen handeln, nicht strafrechtlich belangbar. Zu diesen Voraussetzungen gehört erstens die Pflicht, die Selbsttötung einer regionalen Kontrollkommission zu melden und zweitens die Einhaltung bestimmter gesetzlich vorgeschriebener Sorgfaltskriterien. Nach diesen Sorgfaltskriterien muss der Arzt:

„a) zu der Überzeugung gelangt sein, dass der Patient seine Bitte freiwillig und nach reiflicher Überlegung geäußert hat,

b) zu der Überzeugung gelangt sein, dass keine Aussicht auf Besserung besteht und der Patient unerträglich leidet,

c) den Patienten über dessen Situation und über die medizinische Prognose aufgeklärt haben,

d) mit dem Patienten zu der Überzeugung gelangt sein, dass es für dessen Situation keine andere annehmbare Lösung gab,

e) mindestens einen anderen, unabhängigen Arzt zu Rate gezogen haben, der den Patienten untersucht und schriftlich zur Einhaltung der unter a) bis d) genannten Sorgfaltskriterien Stellung genommen hat und

f) die Lebensbeendigung oder Hilfe bei der Selbsttötung fachgerecht durchgeführt haben.“

(Regionale Kontrollkommissionen 2012, S. 9)

Die Zahl der Sterbehilfefälle steigt in den Niederlanden von Jahr zu Jahr. Im Berichtsjahr 2012 wurden der Kontrollkommission insgesamt 4.188 Sterbehilfehandlungen gemeldet, darunter 3.965 Fälle von Lebensbeendigung auf Verlangen, 185 Fälle von Hilfe zur Selbsttötung und in 38 Fällen handelte es sich um eine Kombination aus beidem. In einem Großteil der Fälle wurde die Sterbehilfe durch den Hausarzt zuhause durchgeführt und zwar bei Patienten, die meistens an Tumorerkrankungen litten (op. cit.). Der Vergleich mit landesweiten früheren Studienergebnissen lässt allerdings vermuten, dass nur etwa die Hälfte der tatsächlichen Sterbehilfehandlungen gemeldet wurde. Zudem wird immer wieder über Fälle von Sterbehilfe bei Alzheimerpatienten und schwerst geschädigten Neugeborenen berichtet. Auf Initiative der niederländischen Vereinigung für ein freiwilliges Lebensende, der mit nach 
eigenen Angaben 130.000 Mitgliedern weltgrößten Sterbehilfeorganisation, wurde 2012 die weltweit erste Sterbehilfeklinik in Den Haag eröffnet. Zudem werden seit dem Frühjahr 2012 sogenannte ambulante Sterbehilfeteams eingesetzt, die aus je einem Arzt und einer ausgebildeten Pflegekraft bestehen, die den Betroffenen zu Hause aufsuchen und dort ggf. die lebensbeendenden Maßnahmen durchführen.

\section{$\underline{\text { Schweiz }}$}

In der Schweiz ist die Hilfe zum Suizid nur dann strafbar, wenn sie aus selbstsüchtigen Motiven geleistet wird (Schweizerisches StGB, Artikel 115). Seit vielen Jahren leisten die Ärzte dort Suizidhilfe, ohne standesrechtlich verfolgt zu werden, da die standesrechtlichen Vorgaben liberaler als in Deutschland sind. In ihren Richtlinien zur Betreuung von Patienten am Lebensende von 2004 stellte die Schweizerische Akademie der Medizinischen Wissenschaften (SAMW) zwar fest, dass die Suizidhilfe nicht Teil der ärztlichen Aufgaben ist, weist aber zugleich darauf hin, dass der Arzt den Patientenwillen zu achten habe und im Einzelfall eine Hilfeleistung zur Selbsttötung als ärztliche Gewissensentscheidung zu respektieren sei (SAMW 2004). Zudem müssen folgende Mindestanforderungen für die ärztliche Suizidhilfe, wie ein gemäß der Krankheit nahes Lebensende als auch alternative Hilfsmöglichkeiten mit dem Patienten erörtert worden sein. Außerdem muss der urteilsfähige Patient seine Entscheidung zur Selbsttötung wohlerwogen und ohne äußeren Druck gefasst haben, was von einer unabhängigen Person zu überprüfen ist. Dennoch erhalten in der Schweiz immer wieder Menschen, die nicht terminal erkrankt sind, bis hin zu psychiatrischen Patienten Suizidassistenz (KNA/aerzteblatt.de 2008).

Bei den hauptsächlich in der Schweiz, aber auch in Deutschland tätigen Sterbehilfeorganisationen kann die Suizidhilfe unter Einbeziehung nicht-ärztlicher Mitarbeiter erfolgen. Das Wirken dieser Vereine ist nicht ganz unproblematisch, denn durch das Fehlen von gesetzlichen Regelungen liegt die Handlungsfreiheit ganz bei den handelnden Personen und Organisationen. So besteht bislang keine Möglichkeit der Kontrolle und dadurch die Gefahr des Missbrauchs. Anders als etwa in den Niederlanden gibt es in der Schweiz zudem keine zentrale Meldestelle für assistierte Suizide, sodass bis heute keine offiziellen Daten verfügbar sind. Schätzungen gehen von ca. 450 assistierten Suiziden jährlich aus (Bosshard 2012). 


\section{Oregon}

Die Praxis und gesetzliche Regelung der Sterbehilfe in dem US-Bundesstaat Oregon wird von Befürwortern der ärztlichen Suizidhilfe vielfach als positives Beispiel einer gelungenen juristischen Regelung und Kontrolle der Sterbehilfe dargestellt. Seit 1998 ist der ärztlich assistierte Suizid unter Einhaltung genauer Regelungen zugelassen. Gesetzliche Grundlage ist der am 27. Oktober 1997 in Kraft getretene Oregon Death with Dignity Act, der es einem einsichtsfähigen erwachsenen Einwohner von Oregon erlaubt, sein Leben mit ärztlicher Hilfe selbst zu beenden. Bei Zweifeln an der Urteilsfähigkeit des Antragstellers wird die Suizidassistenz abgelehnt. Der sterbewillige Patient muss einen schriftlichen Antrag stellen und der behandelnde und beratende Arzt eine terminale Erkrankung bestätigen, bevor er dem Patienten ein Rezept für ein entsprechendes Medikament ausstellt. Außerdem muss ein weiterer unabhängiger Arzt die terminale Erkrankung sowie eine Lebenserwartung von maximal sechs Monaten attestieren. Die Kontrolle erfolgt durch die staatliche Gesundheitsbehörde und das Vorgehen sowie die Statistiken werden streng protokolliert und veröffentlicht. Im Jahr 2008 bzw. 2009 wurde ein nach dem Vorbild Oregons gestaltetes Gesetz auch in den Bundesstaaten Washington und Montana verabschiedet, in Vermont folgte 2013 eine vergleichbare Regelung.

Eine Vielzahl von Auflagen ermöglicht größtmögliche Transparenz. In den ersten neun Jahren wurden insgesamt 292 Fälle von ärztlich assistiertem Suizid beschrieben, was lediglich $0,32 \%$ aller Todesfälle von Patienten mit den gleichen Grunderkrankungen in Oregon entspricht. Das Durchschnittsalter der Suizidenten lag bei 70 Jahren. Von 1998 bis 2006 wurden lediglich $64 \%$ der verschriebenen Rezepte eingelöst. Folglich reicht vielen Patienten allein das Wissen, dass es einen Ausweg gibt, um ihnen ihre leidvolle Situation zu erleichtern. Bis März 2007 wurde kein einziger Fall von Missbrauch bekannt und die Zahlen sprechen gegen eine starke Zunahme von ärztlich assistierten Suiziden im Sinne eines Dammbruchs, der von Gegnern der Suizidhilfe oft beschworen wird (Petermann 2008).

\subsection{Tabellarische Zusammenfassung}

Mit der nachfolgenden Tabelle werden die verschiedenen Formen der Sterbehilfe und ihre (berufs-)rechtliche Bewertung in einer Tabelle zusammengefasst. 


\begin{tabular}{|c|c|c|c|c|}
\hline & Beschreibung & Strafrechtliche Bewertung & Berufsrechtliche Bewertung & Anmerkung \\
\hline $\begin{array}{c}\text { Tötung auf } \\
\text { Verlangen } \\
\text { (ehemals aktive } \\
\text { Sterbehilfe) }\end{array}$ & $\begin{array}{c}\text { Gezielte Tötung des } \\
\text { Patienten auf dessen } \\
\text { ausdrücklichen Wunsch }\end{array}$ & $\begin{array}{c}\underline{\text { strafbar }} \\
\text { vgl. § } 216 \text { StGB } \\
\text { Tötung auf Verlangen: } \\
\text { „(1) Ist jemand durch das ausdrückliche } \\
\text { und ernstliche Verlangen des Getöteten zur } \\
\text { Tötung bestimmt worden, so ist auf } \\
\text { Freiheitsstrafe von sechs Monaten bis zu } \\
\text { fünf Jahren zu erkennen.“ }\end{array}$ & $\begin{array}{c}\text { berufsrechtlich verboten } \\
\text { vgl. § } 16 \mathrm{MBO} \text { : } \\
\text { „Es ist ihnen [ ̈̈rzten] verboten, } \\
\text { Patientinnen und Patienten auf deren } \\
\text { Verlangen zu töten“ }\end{array}$ & $\begin{array}{c}\text { Tötung ohne ausdrückliches } \\
\text { Verlangen ist als Tötung bzw. } \\
\text { Mord (vgl. §§ } 211 \text { und } 216 \text { StGB) } \\
\text { ebenfalls unzulässig! }\end{array}$ \\
\hline $\begin{array}{c}\text { Therapieziel- } \\
\text { änderung/ } \\
\text { Therapie- } \\
\text { verzicht/ } \\
\text { Therapie- } \\
\text { abbruch/ } \\
\text { Sterben } \\
\text { zulassen } \\
\text { (ehemals } \\
\text { passive } \\
\text { Sterbehilfe) }\end{array}$ & $\begin{array}{c}\text { Unterlassen, Begrenzen } \\
\text { oder Beenden } \\
\text { lebenserhaltender } \\
\text { Maßnahmen } \\
\text { gemäß (mutmaßlichem) } \\
\text { Patientenwillen }\end{array}$ & $\begin{array}{l}\qquad \underline{\text { straflos }} \\
\text { vgl. BGH 2010: } \\
\text { „Sterbehilfe durch Unterlassen, Begrenzen } \\
\text { oder Beenden einer begonnenen } \\
\text { medizinischen Behandlung (Behandlungs- } \\
\text { abbruch) ist gerechtfertigt, wenn dies dem } \\
\text { tatsächlichen oder mutmaßlichen } \\
\text { Patientenwillen entspricht und dazu dient, } \\
\text { einem ohne Behandlung zum Tode } \\
\text { führenden Krankheitsprozess seinen Lauf } \\
\text { zu lassen.“ }\end{array}$ & $\begin{array}{c}\text { berufsrechtlich zulässig } \\
\text { vgl. BÄK 2011, Präambel der } \\
\text { Grundsätze: } \\
\text { „Ein offensichtlicher Sterbevorgang } \\
\text { soll [...] nicht künstlich in die Länge } \\
\text { gezogen werden. Darüber hinaus darf } \\
\text { das Sterben durch Unterlassen, } \\
\text { Begrenzen oder Beenden einer } \\
\text { begonnenen med. Behandlung } \\
\text { ermöglicht werden, wenn dies dem } \\
\text { Willen des Patienten entspricht.“ }\end{array}$ & $\begin{array}{l}\text { Therapiezieländerung ist eine } \\
\text { gezielte Korrektur hinsichtlich } \\
\text { des Einsatzes einer Therapie, } \\
\text { meint aber nicht den } \\
\text { grundsätzlichen Verzicht auf alle } \\
\text { therapeutischen Maßnahmen; } \\
\text { Patientenwille ist wesentlich } \\
\text { (eigenmächtige Begrenzung einer } \\
\text { indizierten Behandlung durch den } \\
\text { Arzt ist strafbar!) }\end{array}$ \\
\hline
\end{tabular}




\begin{tabular}{|c|c|c|c|c|}
\hline & Beschreibung & Strafrechtliche Bewertung & Berufsrechtliche Bewertung & Anmerkung \\
\hline $\begin{array}{c}\text { Behandlung am } \\
\text { Lebensende } \\
\text { (ehemals } \\
\text { indirekte } \\
\text { Sterbehilfe) }\end{array}$ & $\begin{array}{c}\text { Schmerztherapie/ } \\
\text { Symptomkontrolle } \\
\text { mit unbeabsichtigter, } \\
\text { aber in Kauf } \\
\text { genommener Lebens- } \\
\text { verkürzung }\end{array}$ & $\begin{array}{c}\underline{\underline{\text { straflos }}} \\
\text { (unzureichende Leideslinderung } \\
\text { kann allerdings strafbar sein) } \\
\text { (vgl. BGH 1996) }\end{array}$ & $\begin{array}{c}\text { berufsrechtlich zulässig } \\
\text { vgl. B̈̈K 2011, Grundsätze zur ärztl. } \\
\text { Sterbebegleitung: „Bei Sterbenden } \\
\text { kann die Linderung des Leidens so } \\
\text { im Vordergrund stehen, dass eine } \\
\text { möglicherweise dadurch bedingte } \\
\text { unvermeidbare Lebensverkürzung } \\
\text { hingenommen werden darf.“ }\end{array}$ & $\begin{array}{c}\text { palliative Maßnahme steht im } \\
\text { Vordergrund! }\end{array}$ \\
\hline Suizid & $\begin{array}{l}\text { Akt der vorsätzlichen } \\
\text { Selbsttötung }\end{array}$ & $\begin{array}{c}\quad \underline{\text { straflos }} \\
\text { kein Straftatbestand }\end{array}$ & keine berufsrechtliche Wertung & $\begin{array}{l}\text { früher Garantenpflicht für Ärzte } \\
\text { zur Rettung von Suizidenten (vgl. } \\
\text { BGH 1984); heute wird Ärzten } \\
\text { ein eigenverantwortliches } \\
\text { Abwägungsermessen zugestanden } \\
\text { (vgl. DJT 2006) }\end{array}$ \\
\hline $\begin{array}{c}\text { Hilfe zur } \\
\text { Selbsttötung }\end{array}$ & $\begin{array}{l}\text { Mitwirkung bei der } \\
\text { Selbsttötung eines } \\
\text { Menschen (vor allem } \\
\text { durch Beschaffung } \\
\text { tödlich wirkender } \\
\text { Medikamente) }\end{array}$ & $\begin{array}{l}\underline{\text { straflos }} \\
\text { da es an einer tatbestandsmäßigen und } \\
\text { rechtswidrigen Haupttat fehlt }\end{array}$ & $\begin{array}{c}\text { berufsrechtlich verboten } \\
\text { vgl. § } 16 \text { MBO: „Sie [Ärzte] dürfen } \\
\text { keine Hilfe zur Selbsttötung leisten.“ } \\
\text { (abweichende Regelungen in den } \\
\quad \text { BOen einzelner LÄKen!) }\end{array}$ & $\begin{array}{c}\text { Sterbewilliger muss den } \\
\text { entscheidenden Akt des Suizids } \\
\text { selbst vollziehen; } \\
\text { Problem des berufsrechtlichen } \\
\text { Verbots einer in Deutschland } \\
\text { strafrechtlich erlaubten Handlung }\end{array}$ \\
\hline
\end{tabular}




\section{DARSTELLUNG DER AKTUELLEN DISKUSSION ZUM ÄRZTLICH ASSISTIERTEN SUIZID IN DEUTSCHLAND}

Eine grundlegende Sichtung der Literatur der vergangenen Jahre zeigt, dass im Wesentlichen drei neue Ausgangspunkte die Thematik stärker ins Licht der Öffentlichkeit gerückt haben und Impuls dafür sind, bislang weniger beachtete Aspekte der Suizidhilfe, insbesondere der ärztlichen Suizidhilfe, kritisch zu hinterfragen. Vorgestellt werden sollen deshalb im Folgenden sowohl die organisierte Sterbehilfe durch Sterbehilfeorganisationen als auch das Problemfeld der gewerblichen Sterbehilfe sowie die durch die Bundesärztekammer (B̈̈K) 2011 vorgenommene berufsrechtliche und berufsethische Neubewertung der ärztlichen Suizidhilfe. Im Anschluss daran geht es um aktuelle Reaktionen und Argumentationen verschiedener Meinungsträger und um die juristischen und politischen Bestrebungen auf diesem Gebiet. Am Ende des Kapitels wird ein Zwischenergebnis aus der aktuellen Diskussion gezogen.

\subsection{Anlässe der gegenwärtigen Diskussion}

\subsubsection{Organisierte Sterbehilfe}

Ausgehend von wenigen Begebenheiten haben die Aktivitäten verschiedener Sterbehilfeorganisationen in der Schweiz in den letzten Jahrzehnten sehr rasch und kontinuierlich zugenommen. Deren Tätigkeit hat sich zu einer rechtlich und gesellschaftlich geduldeten Praxis etabliert. Die kritische Berichterstattung über das Wirken dieser Sterbehilfeorganisationen ist seit vielen Jahren ein Bestandteil der innerdeutschen Diskussion um die Suizidhilfe.

In der Schweiz wurden 1982 die Gesellschaften EXIT-Romandie und EXIT-Deutsche Schweiz gegründet, die nach eigenen Angaben aktuell ca. 18.500 bzw. 70.000 Mitglieder haben. Die anfängliche Tätigkeit dieser Vereinigungen umfasste noch nicht direkt die Suizidhilfe, sondern konzentrierte sich mehr auf die Verbreitung von Informationen über einen schmerz- 
losen und sicheren Suizid und die öffentliche Bekanntmachung der Möglichkeiten von Patientenverfügungen und ggf. deren rechtliche Durchsetzung. Ab Ende der 1980er Jahre führten Mitglieder von EXIT-Deutsche Schweiz erste Suizidbegleitungen durch. Kurz darauf begann auch die ärztliche Mitbeteiligung an den Suiziden. Diese wurden mittels einer ausdrücklich zur Selbsttötung rezeptierten letalen Dosis des Barbiturats Natriumpentobarbital durchgeführt. Im Mai 2012 haben die beiden Sterbehilfeorganisationen mit der Ankündigung für Aufsehen gesorgt, sich für den sogenannten Altersfreitod zu engagieren. Dabei handelt es sich um eine Suizidbegleitung bei nicht terminal erkrankten, eher lebensmüden älteren Menschen, die beispielsweise vor dem Eintritt in ein Pflegeheim stehen. Die Kriterien Endstadium einer Krankheit oder Lebensende scheinen den Vereinigungen zu strikt für die Bedürfnisse der heutigen Gesellschaft und das durch chronische Krankheiten verursachte dauerhafte Leiden. Außerdem soll den Menschen, die an einem Altersfreitod interessiert sind, auch die medizinische Abklärung des Sterbewillens erleichtert werden (KNA/aerzteblatt.de 2014).

Von der Öffentlichkeit eher weniger bemerkt ist seit Ende der 1990er Jahre der Verein EXITInternational tätig, der derzeit etwa 700 Mitglieder hat. Er wurde von dem Begründer von EXIT-Deutsche Schweiz, dem Pfarrer Rolf Sigg, im Jahr 1997 gegründet, um Suizidhilfe auch für Nicht-Schweizer zu ermöglichen. Dies geschah auf Initiative des deutschen Arztes Julius Hackethal, dem mittlerweile verstorbenen Schirmherrn von EXIT-International, der hierzulande Mitte der 1980er Jahre für die ärztliche Suizidhilfe und die Tötung auf Verlangen eintrat und dadurch oft im Fokus der Medien stand. Jährlich vermittelt dieser Verein rund 25 Ausländern, vor allem aus Deutschland und Frankreich, Suizidhilfe in der Schweiz (Meier 2012).

Hervorzuheben ist, dass alle drei Organisationen nicht gewinnorientiert arbeiten, von ihren Mitgliedern allerdings eine finanzielle Entschädigung für ihre Bemühungen im Einzelfall verlangen.

Neben den drei EXIT-Organisationen gibt es die 1998 von dem Rechtsanwalt Ludwig A. Minelli gegründete Sterbehilfeorganisation DIGNITAS, die mit ungefähr 5.000 Mitgliedern eine kleinere Schweizer Sterbehilfeorganisation ist. Sie wurde 1998 in der Nähe von Zürich ins Leben gerufen und verfolgt nach eigenen Angaben keinerlei kommerzielle Interessen. Im Gegensatz zu EXIT können bei DIGNITAS auch Personen, die nicht in der Schweiz wohnen und keine Schweizer Bürger sind, Mitglied werden. Diese ausländischen Mitglieder wenden sich mit ihrem Sterbewunsch an die Organisation, die wiederum mit Schweizer Ärzten zu- 
sammenarbeitet und so den Kontakt zwischen dem Sterbewilligen und einem Arzt herstellt, der nach einer genauen Prüfung des Sterbewunsches im gegebenen Falle das entsprechende Rezept ausstellt. Zuvor wird ein schriftliches Ersuchen des Antragstellers geprüft und ein Vorgespräch mit einem DIGNITAS-Mitarbeiter geführt. Wenn alle Prüfungen stattgefunden haben und keine Bedenken mehr bestehen, kann ein Termin für die Suizidbegleitung mit zwei Mitgliedern des Vereins vereinbart werden. DIGNITAS ist bemüht, im Vorfeld eines Suizids auch die Familie des Patienten einzubeziehen. Der finale Akt der Selbsttötung muss allerdings vom Suizidenten von eigener Hand ausgeführt werden. Dieser Schritt und eine vorherige Willenserklärung werden von zwei Vereinsmitgliedern gefilmt, um die im Anschluss an einen Suizid (der in der Schweiz als außergewöhnlicher Todesfall gilt und von den Vereinsmitgliedern gemeldet werden muss) stattfindenden polizeilichen Ermittlungen abzukürzen und den Ausschluss selbstsüchtiger Beweggründe für die Suizidhilfe nachweisen zu können.

Am 26. September 2005 erfolgte in Hannover die Gründung des Vereins DIGNITASDeutschland e. V. . Den ersten Vorsitz führt, wie auch in der Schweiz, Ludwig A. Minelli, den zweiten Vorsitz die Sozialpädagogin Sabine Laube. Ein erklärtes Ziel des Vereins ist es, die derzeitige Rechtslage zur Suizidhilfe in Deutschland zu ändern und insbesondere gemäß dem Grundgesetz ein Leben und Sterben in Würde zu verwirklichen sowie die Patientenselbstbestimmung in der täglichen Praxis zu gewährleisten. Weiterhin sollen die von den deutschen Bürgern verfassten Patientenverfügungen durchsetzbar und einklagbar werden, wobei der Verein in diesem Punkt die 2009 verabschiedete gesetzliche Regelung der Verbindlichkeit von Patientenverfügungen bereits als großen Erfolg ansieht. Zusätzlich sieht sich der Verein als Berater für Ärzte, Krankenhäuser und Pflegeheime (DIGNITAS-Deutschland 2013). Mitglied bei DIGNITAS-Deutschland können volljährige Personen mit Wohnsitz in Deutschland, aber auch Menschen mit ausländischer Staatsbürgerschaft werden. Deutsche Mitglieder haben aufgrund einer Vereinbarung der DIGNIATS-Vereine das Recht, auch vom Schweizer Verein beraten und unterstützt zu werden. Dies bezieht sich auch auf die Suizidhilfe, die allerdings nur auf Schweizer Staatsgebiet durchgeführt wird. Die Mitgliedsbeiträge sind eher gering (Aufnahmegebühr 120 Euro, Monatsbeitrag 20 Euro), eine Suizidbegleitung kostet allerdings mehrere Tausend Euro, denn alleine für die Vorbereitungen einer Sterbebegleitung (ohne die Garantie darauf, dass die Suizidhilfe vom Verein bewilligt wird) wird bereits ein besonderer Beitrag von ca. 2.400 Euro fällig. Außerdem werden zwei eingehende Arztbesuche in der Schweiz mit ca. 800 Euro berechnet und die Kosten für die konkrete Suizidbegleitung betragen dann noch einmal 2.400 Euro. Alles in allem wird für Mitglieder, die verbindlich einen Termin zur Suizidbegleitung vereinbaren, von DIGNITAS 
ein Betrag von ca. 8.400 Euro in Vorauskasse verlangt, wenn sich der Verein auch um die Bestattungsfragen kümmert. Zwar gibt es Ermäßigungen für Bedürftige, aber die Kostenaufstellung zeigt, dass eine von diesem Verein geleistete Suizidhilfe für Deutsche Mitglieder eine doch recht große finanzielle Aufwendung ist. Insgesamt gibt sich der DIGNITAS-Verein auch in seiner Informationsbroschüre sehr kämpferisch, zeichnet in polemischen Worten ein eher einseitiges Bild der Sterbehilfesituation in Deutschland und bezeichnet das deutsche Recht gar als ,pervers“ (op. cit., S. 3).

In der Schweiz und auch hierzulande hat der Verein DIGNITAS immer wieder für negative Schlagzeilen gesorgt. So wurden beispielsweise 2007 von ehemaligen Mitgliedern des Vereins Vorwürfe erhoben, sterbewilligen Personen, vor allem aus dem Ausland, werde im Sinne einer Schnellabfertigung zu rasch Suizidhilfe gewährt. Anwohner von Häusern und Appartements, in denen der Verein die Suizidhilfe durchführt, setzen immer wieder juristische Mittel ein, um dem Handeln des Vereins in ihrer Nähe Einhalt zu gebieten. In den Jahren 2008 und 2010 wurden vermehrt Stimmen laut, die DIGNITAS eine unsachgemäße oder illegale Entsorgung menschlicher Überreste unterstellten. Auch für die Anfang 2008 (versuchsweise) durchgeführte Suizidhilfe mittels des rezeptfrei erhältlichen Gases Helium wurde DIGNITAS wiederholt stark kritisiert.

Die Eröffnung einer Zweigstelle einer Sterbehilfeorganisation in Deutschland hat hierzulande die Diskussion um die Suizidbegleitung sehr angeheizt. Bisher hat man das Problem der organisierten Suizidhilfe eher aus der Ferne im Nachbarland betrachten können. Nun findet sich das Problem quasi vor der eigenen Haustür. Dieser Fakt, zusammen mit dem äußerst kämpferischen Auftreten des Vereins, hat eine Vielzahl von Reaktionen auf politischer, kirchlicher, ärztlicher und medizinethischer Seite hervorgerufen und der bislang vorherrschenden Debatte neuen Auftrieb gegeben. Denn mit dem Wirken des Vereins in Deutschland wird einem Sterbetourismus von Deutschland in die Schweiz Tür und Tor geöffnet. Zudem steigt die Zahl der von DIGNIATAS und DIGNIATAS-Deutschland durchgeführten Suizidbegleitungen von Jahr zu Jahr (Bosshard 2012). Aus alldem ergibt sich die Notwendigkeit einer gesellschaftlichen Diskussion des Themas Suizidhilfe. 


\subsubsection{Gewerbliche Sterbehilfe}

Abzugrenzen von der organisierten Sterbehilfe ist die gewerbliche Sterbehilfe. Ein Gewerbe ist eine planmäßige, auf Dauer angelegte selbständige Tätigkeit, die mit der Absicht auf Gewinnerzielung betrieben wird. Die Tätigkeit der sogenannten freien Berufe, zu denen u. a. auch der ärztliche Beruf zählt, stellt hingegen kein Gewerbe dar. Gewerbliche Sterbehilfe ist eine Form der dauerhaft organisierten gewinnorientierten Sterbehilfe, die sich insofern von der bereits beschriebenen organisierten Suizidhilfe abgrenzt, als dass die Sterbehilfeorganisationen in ihren Satzungen eindeutig darauf hinweisen, nicht gewinnorientiert zu arbeiten. In den letzten Jahren wurden besonders gegen DIGNIATS Vorwürfe dahingehend laut, die Organisation arbeite eigennützig und decke durch die relativ hohen Preise für eine Suizidhilfe nicht nur den tatsächlichen Kostenaufwand des Vereins. Aber besonders der Fall des früheren Hamburger Justizsenators Roger Kusch und das Wirken seines Vereins haben einen breit angelegten innerdeutschen Diskurs um die gewerbliche Suizidhilfe ausgelöst.

Bereits während seiner Zeit als Justizsenator (2001 bis 2006) machte sich Kusch für eine Legalisierung der Tötung auf Verlangen stark und rief damit, nicht nur in seiner damaligen Partei, der CDU, heftige Kritik hervor. Kusch ist zudem Gründungsmitglied des Vereins Dr. Roger Kusch Sterbehilfe e.V. und bot ab August 2008 auf der Homepage seines Vereins Sterbehilfe mittels einer Perfusorpumpe zum Preis von 8.000 Euro an. Dieses Angebot wurde von fünf älteren und eher lebensmüden als termial erkrankten Personen in Anspruch genommen. Einige Monate später bestätigte das Hamburger Verwaltungsgericht in seinem Beschluss vom 6. Februar 2009 das polizeiliche Verbot dieses Angebots und begründete dies damit, dass die „kommerziell betriebene Suizidbegleitung kein erlaubtes Gewerbe sei“, sodass sie wegen Störung der öffentlichen Sicherheit unterbunden werden könne. Diese gewerbliche Suizidunterstützung sei „sozial unwertig“ und gefährde nach Ansicht des Gerichts das Leben von Menschen, die auf sich gestellt vor dem letzten unzumutbaren Schritt zurückscheuen würden (Verwaltungsgericht Hamburg, Beschluss vom 06.02.2009).

Doch damit waren Kuschs umstrittene Suizidhilfepraktiken noch nicht zu Ende. Im Oktober 2009 gründete der ehemalige Justizsenator einen neuen Verein mit dem Namen Sterbehilfe Deutschland e.V. (StHD) in Oststeinbeck in Schleswig-Holstein. Der Verein wirbt in seinem Internetauftritt um Mitglieder, indem er Unterstützung bei der Durchsetzung des Selbstbestimmungsrechtes im Leben und im Sterben verspricht. Hierzu zählt die Hilfe bei der Abfassung und Durchsetzung von Patientenverfügungen ebenso wie die Suizidbegleitung bei 
hoffnungsloser Prognose, unerträglichen Beschwerden oder unzumutbarer Behinderung. Der Verein hat die gleiche Satzung wie der 2012 in Zürich gegründete rechtlich selbständige, aber gleichnamige Verein Sterbehilfe Deutschland und arbeitet mit dem Schweizer Verein eng zusammen. Beide Vereine kooperieren unter dem Logo Sterbehilfe Deutschland/StHD, verfolgen auch bei der Suizidbegleitung die gleichen ethischen Grundsätze und betonen, nicht wirtschaftlich zu arbeiten. Trotzdem mag ein Grund für die Eröffnung des Schweizer Vereins das in Deutschland laufende Gesetzgebungsverfahren gegen die gewerbsmäßige Suizidhilfe sein, welches das Aus für den deutschen Verein bedeuten könnte. Um dem zu entgehen, hat der Verein kürzlich seine Satzung geändert und zahlt derzeit im Falle eines begleiteten Suizids sämtliche Gelder zurück, die er zuvor von dem Mitglied erhalten hat. Zwischen Beitritt und durchgeführter Suizidbegleitung liegen nach Angaben des Vereins zwischen zwei und sechs Monate, Doppelsuizide sind ebenfalls möglich. Auch psychisch Kranken, Dementen im Frühstadium und alten Menschen, die sich nicht mehr selbst versorgen können steht eine Begleitung offen. Grundvoraussetzung ist die unbedingte Einsichts- und Willensfähigkeit, die in einem eingehenden psychiatrischen Gespräch geprüft und in einem Gutachten festgehalten wird. Derzeit gibt es allerdings in ganz Deutschland nur einen Arzt, der zur Erstellung dieser Gutachten bereit ist.

Die Suizidvorbereitungen und ggf. -begleitungen finden in Deutschland statt und sollen nach Möglichkeit vor den Behörden geheim gehalten werden, um ein polizeiliches Einschreiten zu verhindern. Dies ist, wie der Verein anregt, auch beim Einbeziehen von Angehörigen zu bedenken, die einen Suizid sonst aus ,übergroßer Anhänglichkeit oder Verlustangst“ gefährden könnten (StHD 2010). Allerdings können auch Angehörige Suizidhilfe leisten und bekommen dafür vom Verein die notwendigen Medikamente und Instruktionen. Andernfalls wird die Suizidhilfe von ehrenamtlich tätigen Mitarbeitern ausgeführt. Ende 2012 hatte der Verein nach eigenen Angaben etwa 250 Mitglieder und bei 77 Personen Suizidhilfe geleistet. Die stets sehr medienwirksamen Aktivitäten Kuschs sowie seines Vereins, der trotz allem noch immer unter dem Verdacht des gewerbsmäßigen Handelns steht, waren Anlass dafür, einen breiten gesellschaftlichen, politischen, juristischen und medizinethischen Diskurs um die gewerbliche Suizidhilfe hervorzurufen, denn ,[g]eht man von diesem Erscheinungsbild der Sterbehilfe aus, so bedarf es keiner großen Phantasie, um sich vorzustellen, dass sie als Erwerbsquelle genutzt und damit beruflich ausgeübt werden kann.“ (Lorenz 2010, S. 824) 


\subsubsection{Berufsethische und berufsrechtliche Neubewertung der ärztlichen Suizidhilfe}

Einleitend einige allgemeine Informationen über die Bundesärztekammer (BÄK), die ein nicht eingetragener Verein ist, der zudem keine eigene Rechtsfähigkeit innehat. Sie ist die Spitzenorganisation der ärztlichen Selbstverwaltung und stellt eine Arbeitsgemeinschaft der 17 deutschen Ärztekammern dar. Die BÄK wirkt aktiv am gesundheitspolitischen Meinungsbildungsprozess der Gesellschaft mit und entwickelt Perspektiven für eine bürgernahe und verantwortungsvolle Gesundheits- und Sozialpolitik. Die Ärzte in Deutschland sind zu einer Mitgliedschaft in den jeweiligen regionalen Landesärztekammern (LÄK) verpflichtet und gehören demnach über diese Pflichtmitgliedschaft auch der BÄK an. Die LÄKen als Körperschaften des öffentlichen Rechts vertreten die beruflichen Belange ihrer Mitglieder, überwachen die Einhaltung der Berufspflichten der Mitglieder und bieten ihnen Beratung, Information und Hilfe. Einmal jährlich findet der Deutsche Ärztetag als Hauptversammlung der Bundesärztekammer an wechselnden Orten statt. Von 1999 an führte lange Jahre der mittlerweile verstorbene Jörg-Dietrich Hoppe den Vorsitz der BÄK, bis er im Juni 2011 von Frank Ulrich Montgomery übernommen wurde (B ̈̈K 2012). Seit 1979 veröffentlicht die BÄK Grundsätze zur ärztlichen Sterbebegleitung, die entsprechend den Entwicklungen in der Medizin und Rechtsprechung in unregelmäßigen Abständen überarbeitet werden. Die Grundsätze sind ein berufsethisches Dokument, das den Ärzten eine Orientierung in ihrem beruflichen Handeln geben soll. In der Musterberufsordnung (MBO) hingegen sind die normativen Grundlagen des ärztlichen Berufs festgehalten. Sie stellt einen Vorschlag für die berufsrechtlichen Regelungen der einzelnen Landesärztekammern dar. Erst diese sind für den Arzt bindend. Ein Verstoß gegen die Berufsordnung (BO) der LÄK kann mit Verweisen und Geldstrafen geahndet werden. Die Empfehlung an die Aufsichtsbehörde, die Zulassung als Arzt zu widerrufen, ist die weitestgehend mögliche Strafe.

Am 17. Februar 2011 beschloss der Vorstand der BÄK die Überarbeitung der zuletzt 2004 geänderten Grundsätze zur ärztlichen Sterbebegleitung. Die frühere Aussage, wonach die Mithilfe des Arztes bei der Selbsttötung dem ärztlichen Ethos widerspricht und strafbar sein kann (B̈̈K 2004, Präambel der Grundsätze) wurde dahingehend geändert, dass die Mitwirkung des Arztes bei der Selbsttötung keine ärztliche Aufgabe darstellt (BÄK 2011, Präambel der Grundsätze). Mit dieser Formulierung, die von manchen Kommentatoren als „Aufgabe des ärztlichen Ethos“ interpretiert wurde (vgl. Gehring 2011), sollten „die verschie- 
denen und differenzierten individuellen Moralvorstellungen von Ärzten in einer pluralistischen Gesellschaft anerkannt [werden], ohne die grundlegenden Aussagen zur ärztlichen Sterbebegleitung infrage zu stellen“, wie Hoppe im Vorwort zur Veröffentlichung der neuen Grundsätze im Deutschen Ärzteblatt schrieb (Hoppe 2011, S. 346).

Der Aufgabe der berufsethischen Ächtung der ärztlichen Suizidhilfe in den Grundsätzen folgte auf dem 114. Deutschen Ärztetag in Kiel im Juni 2011 nach kontroversen Debatten, aber doch mit klarer Mehrheit, ein berufsrechtliches Verbot der ärztlichen Suizidhilfe. So heißt es in dem mit dem Titel Beihilfe für Sterbende überschriebenen neuen $\S 16 \mathrm{MBO}$ : „Ärztinnen und Ärzte haben Sterbenden unter Wahrung ihrer Würde und unter Achtung ihres Willens beizustehen. Es ist ihnen verboten, Patientinnen und Patienten auf deren Verlangen zu töten. Sie dürfen keine Hilfe zur Selbsttötung leisten.“ ( $(16 \mathrm{MBO})$ Damit ergibt sich in Deutschland die Tatsache, dass das Berufsrecht etwas verbietet, was das Strafrecht grundsätzlich erlaubt. Dieser Beschluss wurde bislang jedoch nur von 10 der insgesamt 17 LÄKen übernommen. Die restlichen Kammern haben versucht, ihren eigenen Weg zu finden. Die LÄKen Bayern und Baden-Württemberg haben den Passus gar nicht in ihre BO übernommen, die LÄK Westfalen-Lippe hat das Dürfen-nicht in ein Sollen-nicht umgewandelt. In der BO der LÄK Berlin wurde das explizite Verbot aus dem $§ 16 \mathrm{MBO}$ herausgenommen und im $\S 1$ in Anlehnung an die Grundsätze zur ärztlichen Sterbebegleitung festgehalten, dass die Suizidhilfe keine ärztliche Aufgabe darstellt. Ferner wurde die Sollen-Nicht-Empfehlung der LÄK Westfalen-Lippe übernommen. Der Berliner Kammerpräsident Günther Jonitz ist in einem Interview mit Rudat überzeugt: „Wir haben damit eine wunderbare Lösung, die jede Menge Bürokratie vermeidet.“ (Rudat 2013) 


\subsection{Reaktionen auf die aktuellen Ereignisse}

\subsubsection{Nationaler/Deutscher Ethikrat}

Der Nationale Ethikrat wurde im Jahr 2001 durch die Bundesregierung unter dem damaligen Bundeskanzler Gerhard Schröder eingesetzt und trat am 8. Juni 2001 zu seiner konstituierenden Sitzung zusammen. Die bis zu 25 Mitglieder wurden vom Bundeskanzler direkt berufen und für die Dauer von vier Jahren eingesetzt. Im Februar 2008 wurde der Nationale Ethikrat aufgelöst und durch den neu gegründeten Deutschen Ethikrat ersetzt. Der Deutsche Ethikrat knüpft in seinem Auftrag und in seiner Publikationstätigkeit an die Arbeit des Nationalen Ethikrates an. Die nunmehr 26 Mitglieder, auch für die Dauer von vier Jahren berufen, werden jeweils zur Hälfte vom Bundesrat und der Bundesregierung vorgeschlagen und anschließend vom Bundespräsidenten eingesetzt. $\mathrm{Zu}$ den Mitgliedern zählen Wissenschaftler aus verschiedenen Fachrichtungen um zu gewährleisten, dass der Rat ein möglichst vielschichtiges Meinungsspektrum mit unterschiedlichen ethischen Ansätzen repräsentiert. Die Aufgaben des Ethikrates umfassen die Information der Öffentlichkeit und die Förderung einer Diskussion um Fragen, die sich im Zusammenhang mit Forschung und Entwicklungung der Lebenswissenschaften ergeben. Hinzu kommt die Erarbeitung von Stellungnahmen und Empfehlungen für das politische und gesetzgeberische Handeln sowie die Zusammenarbeit mit ausländischen Ethikräten, internationalen Organisationen und vergleichbaren Einrichtungen (Deutscher Ethikrat 2013).

Als Ausgangspunkt für die Beschäftigung mit dem Lebensende hat der Nationale Ethikrat bereits 2005 in der Stellungnahme Patientenverfügung. Ein Instrument der Selbstbestimmung das Recht des Patienten zur Selbstbestimmung über den eigenen Körper beschrieben und betont, dass das Selbstbestimmungsrecht für Gesunde wie auch für Kranke gilt und dabei besonders auf die Schwerkranken und Sterbenden verwiesen (Nationaler Ethikrat 2005). An diese Publikation knüpft die Stellungnahme Selbstbestimmung und Fürsorge am Lebensende aus dem Jahr 2006 an, in dessen Vorfeld der Ethikrat die Fragen eines verantwortungsvollen Umgangs mit dem Sterben intensiv diskutiert hat. Im Folgenden werden die wichtigsten Aussagen dieser Stellungnahme aufgezeigt.

Anfänglich betont der Ethikrat, dass bei Entscheidungen, die sehr kranke Menschen am Ende ihres Lebens betreffen, immer grundlegende Werte und Normen maßgeblich seien, die in der 
Menschenwürde und den Menschenrechten verankert sind. Bei allen Überlegungen seien der Schutz des Lebens und der körperlichen Unversehrtheit, der Anspruch auf Selbstbestimmung und das Prinzip der Solidarität und Fürsorge zu berücksichtigen. Zugleich wird festgehalten, dass die Frage, ob Patienten, die an lang andauernden unheilbaren Krankheiten leiden, ärztliche Assistenz bei der Selbsttötung in Anspruch nehmen dürfen, eine wichtige Rolle in der öffentlichen Auseinandersetzung spiele. Darüber hinaus besteht jedoch kein Konsens darüber, wie die Hilfe von Ärzten bei einer Selbsttötung ethisch und berufsrechtlich zu bewerten sei. Zu dieser Problematik haben sich drei Lager im Deutschen Ethikrat gebildet.

Ein Teil der Experten folgt der Ansicht der BÄK und ist der Meinung, dass die Suizidhilfe dem beruflichen Auftrag des Arztes widerspreche und dem ärztlichen Ethos entgegenstehe. Ärzte könnten zudem von Patienten unter Druck gesetzt werden, Sterbehilfe zu leisten und die Schwelle zur Durchführung einer Selbsttötung sinken, wenn diese mit ärztlicher Assistenz stattfinden würde. Hinzu kommt, dass es immer schwierig sein würde, die Freiverantwortlichkeit eines Suizids festzustellen und diejenigen Patienten abzugrenzen (beispielsweise im Hinblick auf das Suizidhilfeersuchen psychisch Erkrankter), denen die Assistenz zugestanden wird. Viele Ratsmitglieder befürchten, dass für die ärztliche Suizidassistenz aufgestellte Regelungen in der Praxis nicht kontrollierbar seien und sehen eine große Gefahr darin, dass sich Missbrauch ausbreitet (Nationaler Ethikrat 2006).

Der andere Teil der Experten führt an, dass eine Suizidbegleitung nicht immer dem ärztlichen Ethos entgegenstehe. Trotz des Heilungsauftrags der Ärzteschaft könne in Krisensituationen unheilbarer Krankheit, Verzweiflung und Wohlerwogenheit auch Suizidassistenz dem Gebot, zum Besten des Patienten zu handeln entsprechen und dem ärztlichen Ethos folgen. Nur die Mediziner könnten durch Medikamente ein würdevolles Sterben ermöglichen und so den Angehörigen und dem Sterbewilligen die Ängste bei diesem letzten Schritt nehmen. Dadurch werde das Vertrauen in den Arzt eher gestärkt als geschwächt, wobei es natürlich jedem Arzt freisteht, ob er die Suizidhilfe mit seinem Gewissen vereinbaren könne oder nicht. Auch die Feststellung einer Freiverantwortlichkeit gehöre eher zu den alltäglichen Aufgaben der Ärzteschaft, sodass hier wenig Missbrauchsgefahr bestehe. Untersuchungen in anderen Ländern zeigen, dass die Hemmschwelle für einen Suizid nicht durch die Möglichkeit einer ärztlichen Hilfe sinkt, sondern vielmehr nur ein Bruchteil der Patienten von dieser Option überhaupt Gebrauch macht. Daher bestehe keine Gefahr eines Dammbruchs, wie er von Gegnern der ärztlichen Suizidassistenz oft befürchtet würde. Von Bedeutung sei eher die Gewissheit für die Patienten, einen letzten Ausweg zu haben. Die Experten meinen, dass allein durch die Möglichkeit der ärztlichen Suizidhilfe den Menschen die notwendige Kraft gegeben werden 
kann, ihr Leid zu ertragen und folglich die Zahl der Suizide verringert werden könnte. Dieser Teil des Ethikrates plädiert für eine berufsrechtliche Zulassung ärztlicher Suizidhilfe in Fällen unerträglichen und unheilbaren Leidens, wenn nach Beratung und Bedenkzeit der Sterbewunsch freiverantwortlich, dauerhaft und endgültig sei (op. cit.).

Ein drittes Lager im Deutschen Ethikrat beschreibt die Frage nach Suizidhilfe als höchstpersönliche Gewissensentscheidung des Arztes, der nach langer Begleitung eines Patienten trotz seiner Lebenserhaltungspflicht einem ernstlich bedachten Sterbewunsch in seiner persönlichen Verantwortung durchaus nachkommen könne. Der Arzt solle allerdings nicht der bislang herrschenden Rechtsunsicherheit unterworfen sein, den bewusstlosen Patienten dann gemäß seiner Garantenstellung zu verlassen, sondern ihn bis zum Tod begleiten können. Derartige Gewissensentscheidungen sollen nach Ansicht der Fachleute als tragische Einzelfallentscheidungen standesethisch gebilligt werden und nicht von einer berufsrechtlichen Verfolgung bedroht sein (op. cit.).

Anschließend geht die Stellungnahme bereits 2006 auch auf das Problem der organisierten bzw. gewinnorientierten Suizidhilfe ein. Hinsichtlich der organisierten Suizidhilfe fand der Ethikrat keine gemeinsame ethische Bewertung. Jedoch hat ein Großteil der Mitglieder ernsthafte Bedenken dagegen, da die Angebote der Organisationen den Anschein erwecken, Suizidhandlungen seien normal und die Gesellschaft könne ihren Schutzauftrag gegenüber lebensmüden Menschen nicht mehr in der gebotenen Weise erfüllen. Einige Mitglieder des Ethikrates vertreten jedoch die Auffassung, dass Patienten in einer existenziellen Grenzsituation die Hilfe von Organisationen in Anspruch nehmen könnten. Zudem könnte bei angemessener Betreuung der Patienten, auch wenn diese Form der Sterbehilfe Unbehagen bei den Experten auslöst, die Kontrollierbarkeit und Transparenz der Suizidhilfe erhöht werden. Zudem sollten Patienten nicht hilflos auf sich selbst gestellt und auf die Hilfe von überforderten Angehörigen und Nahestehenden angewiesen sein. Stattdessen sollte die organisierte Sterbehilfe nicht grundsätzlich verboten und durch staatliche Aufsicht die Einhaltung bestimmter Regeln gesichert werden. Herauszustellen ist, dass die Befürworter diese Form der Sterbehilfe nicht unbedingt unterstützen, sie aber auch nicht grundsätzlich ausschließen, solange Sterbewillige nicht mit professioneller Suizidhilfe durch ihre behandelnden Ärzte rechnen können (op. cit.).

Auch dem Thema der gewerblichen Sterbehilfe nehmen sich die Experten in ihrer Stellungnahme 2006 kurz an. Bei diesem Sachverhalt herrscht Übereinstimmung, dass eine Kommerzialisierung der Suizidhilfe notfalls verboten werden sollte, da eine gewerbsmäßig auf 
Gewinn ausgerichtete Suizidhilfe ethisch keinesfalls akzeptabel sei. Dabei sei es gleich, ob die gewerbliche Sterbehilfe individuell oder in organisierter Form angeboten werde (op.cit.).

Unzweifelhaft hat der Ethikrat den gesellschaftlichen Diskussionsbedarf um die Hilfe zum Suizid erkannt. Hinsichtlich der Mitwirkung des ärztlichen Standes bei der Selbsttötung gibt es jedoch bislang keine klare Haltung des Rates, obgleich bereits der Nationale Ethikrat in seinem Infobrief vom Dezember 2003 auf die Schwierigkeit der individuellen Verantwortung des Arztes beim Thema Sterbehilfe hingewiesen hat (Nationaler Ethikrat 2003). Es fällt zudem auf, dass in der Stellungnahme aus dem Jahr 2006 wiederholt auf das ärztliche Ethos als Begrenzung oder auch als Legitimierung einer ärztlichen Suizidhilfe verwiesen wird. Das zeigt, dass bereits bei der Frage, was genau unter einem ärztlichen Ethos zu verstehen ist, unter den Experten keine Einigkeit besteht.

Im März 2014 lieferte die derzeitige Vorsitzende des Ethikrates, die Kölner Medizinethikerin Christiane Woopen, der Debatte um die Sterbehilfe in Deutschland neuen Gesprächsstoff, indem sie sich in einem Interview mit dem FOCUS Magazin dafür aussprach, ärztlich assistierten Suizid in Ausnahmefällen zuzulassen und zugleich die Haltung der BÄK kritisierte:

„Für die wenigen Menschen, deren Todeswunsch trotz aller Bemühungen beständig bleibt und die auf Grund von schwerem, nicht abwendbarem Leid ihrem Leben ein Ende setzen wollen, sollte der Arzt seinem Gewissen folgen dürfen [...] [und dafür] von der Bundesärztekammer nicht gescholten oder gar nach Landesberufsrecht bestraft werden. [...] Wenn der Arzt auf der Grundlage einer lange dauernden und guten Kenntnis des Patienten zum Schluss kommt, dass er es mit seinem Gewissen vereinbaren kann, ihm ein Mittel für den Suizid zur Verfügung zu stellen, dann sollte dies als existenzieller Ausnahmefall akzeptiert werden." Das Gesetz dürfe, wie sie weiterhin ausführt, in diesen sehr seltenen Fällen schweigen (o. Verf. 2014, S. 42).

Ähnlich äußerte sich einige Monate später der Deutsche Ethikrat in einer ad hoc Empfehlung im Dezember 2014:

„Die Mehrheit des Deutschen Ethikrates empfiehlt, dass die Ärztekammern einheitlich zum Ausdruck bringen sollten, dass ungeachtet des Grundsatzes, dass Beihilfe zum Suizid keine ärztliche Aufgabe ist, im Widerspruch dazu stehende Gewissensentscheidungen in einem vertrauensvollen Arzt-Patient-Verhältnis bei Ausnahmesituationen respektiert werden.“

(Deutscher Ethikrat 2014, S. 4) 


\subsubsection{Juristische und politische Bestrebungen}

Bei einem gesellschaftlich so brisanten Thema wie dem der Suizidhilfe wird in einer Debatte häufig die Forderung nach einem politischen bzw. juristischen Lösungsweg des Konflikts erhoben. Aus diesem Grund stehen nach langwierigen Auseinandersetzungen um die aktive Sterbehilfe in den 1980er und 1990er Jahren und den ausschweifenden Kontroversen um die Patientenverfügung nun seit einigen Jahren die rechtlichen Grundlagen der gewerblichen, organisierten und ärztlichen Suizidhilfe im Zentrum des öffentlichen Interesses.

Bereits seit gut zehn Jahren häufen sich Kommissionsberichte, Stellungnahmen und Gesetzesentwürfe zur Suizidhilfe. Die Arbeitsgruppe des Justizministeriums Patientenautonomie am Lebensende beschäftigte sich 2004 mit ethischen, rechtlichen und medizinischen Aspekten zur Bewertung von Patientenverfügungen. Zwei Jahre später befasste sich der in Stuttgart tagende 66. Deutsche Juristentag (DJT) mit der Erarbeitung eines detaillierten Programms für eine Gesetzgebung zum Thema Strafrecht bei der Sterbebegleitung und Patientenautonomie. Mit dem zum 1. September 2009 in Kraft getretenen 3. Betreuungsrechtsänderungsgesetz hat der Staat erstmals eine juristische Regelung zur Patientenverfügung verabschiedet. Doch obwohl bis vor einigen Jahren eher das Thema Patientenverfügung Kern der Sterbehilfedebatte war (Schreiber 2007), waren sowohl der im Folgenden dargestellte Alternativentwurf Sterbehilfe als auch der 66. DJT in Bezug auf die aktuelle Debatte um die organisierte und gewerbliche Sterbehilfe sehr voraussehend. Zudem beschäftigten sich beide Gremien mit einer Prüfung der Positionierung des ärztlichen Standesrechts zur Suizidhilfe.

Im Herbst 2005 wurde der Alternativentwurf Sterbebegleitung (AE-StB) von einem Arbeitskreis von Juristen aus Deutschland, Österreich und der Schweiz veröffentlicht, der den Alternativentwurf Sterbehilfe von 1986 aufgreift und weiterentwickelt. Er sieht unter anderem einen neu zu schaffenden $\S 215$ a vor, der die Unterstützung einer Selbsttötung aus Gewinnsucht mit einer Freiheitsstrafe bis zu fünf Jahren oder einer Geldstrafe ahnden soll. Anlass für diesen Änderungsvorschlag war der zunehmende Sterbetourismus schwer kranker Menschen in die Schweiz. Die Wissenschaftler des AE-StB von 2005 sahen in Deutschland, da die Ärzte hier fast durchweg aus standesrechtlichen und ethischen Gründen die Suizidhilfe ablehnen, die Gefahr des Missbrauchs durch gewinnorientierte private Unternehmer oder Organisationen in dieser Notlage, da diese ohne den Vorrang therapeutischer Hilfen und des ärztliches Ethos arbeiten würden (Schöch et al. 2005). Der in dem Alternativentwurf 
beinhaltete Entwurf eines Sterbebegleitungsgesetzes fordert die Straflosigkeit und standesrechtliche Tolerierung des ärztlich assistierten Suizids bei terminal kranken Patienten:

„§ 4 Ärztlich assistierte Selbsttötung

(1) Ein Arzt darf auf ausdrückliches und ernstliches Verlangen eines tödlich Kranken nach Ausschöpfung aller therapeutischen Möglichkeiten zur Abwendung eines unerträglichen und unheilbaren Leidens Beihilfe zur Selbsttötung leisten.

(2) Ein Arzt ist zu einer solchen Hilfe nicht verpflichtet, soll jedoch auf ausdrücklichen Wunsch des Patienten nach Möglichkeit an einen anderen Arzt verweisen, der hierzu bereit ist.“(op. cit., S. 38)

Der Deutsche Juristentag e. V. (DJT) ist ein viel beachtetes Forum für Juristen und befasst sich auf regelmäßig stattfindenden Tagungen mit aktuellen rechtspolitischen Problemen. In seinen Beschlüssen hat sich der 66. DJT für eine Änderung der ausnahmslosen Ablehnung der ärztlichen Suizidhilfe eingesetzt und gefordert, dass:

„die ausnahmslose standesrechtliche Missbilligung des ärztlich assistierten Suizids [...] einer differenzierten Beurteilung weichen [sollte], welche die Mitwirkung des Arztes an dem Suizid eines Patienten mit unerträglichen, unheilbaren und mit palliativmedizinischen Mitteln nicht ausreichend zu linderndem Leiden als eine nicht nur strafrechtlich zulässige, sondern auch ethisch vertretbare Form der Sterbehilfe toleriert.“" (DJT 2006, S. 12)

Eine erste niedersächsische Gesetzesinitiative zum Verbot der geschäftsmäßigen Sterbehilfe scheiterte Anfang 2006 am Widerstand der FDP, ebenso eine weitere Gesetzesinitiative der Länder Saarland, Thüringen und Hessen im selben Jahr. Trotz des ebenfalls auf eine Verbotsregelung abzielenden Beschlusses des Bundesrats 2008 (resultierend aus einem Antrag von 13 Bundesländern und intensiver Beratungen dazu im Nachgang) konnten sich die Länder anschließend auf kein verbindliches Regelungskonzept verständigen. Erst Ende 2012 stellte das Bundesjustizministerium unter Leitung von Justizministerin Sabine LeutheusserSchnarrenberger (FDP) nach langwierigen, vorhergehenden Beratungen einen Gesetzesentwurf vor, der die kommerzialisierte Sterbehilfe unter Strafe stellen sollte mittels der Schaffung eines neuen Straftatbestandes der gewerblichen Förderung der Selbsttötung (Bundesregierung 2012, Gesetzesentwurf 17/11126). Nach nur wenigen politischen Debatten über den Gesetzesentwurf wurde dieser von Bundeskanzlerin Angela Merkel gestoppt und liegt seit den Neuwahlen des Bundestages 2013 auf Eis, ist also „erledigt durch Ablauf der Wahlperiode“. (Deutscher Bundestag 2013) Vermutlich ging dieser Entwurf Kritikern aus Kirchen, Verbänden und der Union nicht weit genug, da er lediglich die gewerbsmäßige Hilfe zur Selbsttötung unter Strafe stellen wollte (Klinkhammer 2014). 
Die derzeitige Bundesregierung aus CDU/CSU und SPD hat in ihrem Koalitionsvertrag festgelegt, eine gesetzliche Regelung der organisierten und gewebsmäßigen Suizidhilfe zu finden. Anfang 2014 kündigte Bundesgesundheitsminister Hermann Gröhe (CDU) an, die organisierte Suizidhilfe durch Vereine wie DIGNITAS-Deutschland und StHD verbieten zu wollen. Im April 2014 beschlossen die Fraktionsvorstände der großen Koalition, nach der Sommerpause erste Gespräche zu diesem Thema im Bundestag abzuhalten. Im Rahmen einer Mitte November 2014 im Bundestag stattgefundenden Orientierungsdebatte stellten einige Gruppen von Abgeordneten fraktionsübergreifende Positionspapiere zur Regelung der Suizidhilfe vor. Bei allen herrschte Einigkeit über die dringende Notwendigkeit des Ausbaus der Hospizarbeit und der Palliativversorgung in Deutschland. Hinsichtlich einer Regelung der ärztlichen Suizidassistenz und der gewebsmäßigen bzw. organisierten Sterbehilfe gehen die Meinungen jedoch weit auseinander.

Die Bundestagsabgeordneten Claudia Lücking-Michel, Michael Brand (beide CDU) und Michael Frieser (CSU) sprechen sich in ihrem Positionspapier für das grundsätzliche Aufrechterhalten der geltenden Regelungen zur Straflosigkeit von Suizid und Suizidbeihilfe aus. Sie plädieren aber gleichzeitig für ein Verbot der Sterbehilfevereine und anderer organisierter Formen der Förderung der Selbsttötung bzw. Suizidhilfe einhergehend mit dem Verbot der Werbung hierfür. Für die Abgeordneten soll auch die ärztliche Suizidassistenz unter dieses Verbot fallen mit der Begründung, dass ein organisiertes Angebot ärztlicher Suizidhilfe die Entscheidung zum Suizid geschwächter oder verzweifelter Menschen sogar fördern könnte, indem sie sich zu diesem Entschluss gedrängt fühlten. Sogar das ärztliche Standesrecht stellt nach Ansicht der Abgeordneten keinen ausreichenden Schutz für Sterbewillige dar, da es nur Ärzte, nicht aber andere Personen betrifft, die an der Beschaffung von tödlichen Mitteln beteiligt sein könnten. Sie befürchten, dass die Suizidhilfe durch Ärzte oder Organisationen zu einer normalen Option unter vielen werden könnte und eine Werteverschiebung zur Folge hätte (Lücking-Michel et al. 2014).

Im Gegensatz dazu sprechen sich die Abgeordneten Renate Künast, Kai Gehring (beide Bündnis 90/Die Grünen) und Petra Sitte (DIE LINKE) in ihrem Positionspapier gegen eine Strafbarkeit der Suizidassistenz von Angehörigen, Ärzten oder Sterbehilfevereinen aus, da der Mensch Souverän seines eigenen Lebens ist und seine Selbstbestimmung und Würde auch am Lebensende im Vordergrund stehen müssen. In einem Verbot der Suizidhilfe sehen die Abgeordneten die große Gefahr, dass sterbewilligen Patienten die Möglichkeit eines ergebnisoffenen Gesprächs über ihren Suizidwunsch genommen würde. Vielmehr wollen sie die Patienten ermutigen, sich mit einem ihnen vertrauten Arzt darüber offen auszutauschen, 
sodass dieser dann die eigenverantwortliche Entscheidung des Patienten ggf. unterstützen könne. Lediglich in Hinblick auf das Beratungsverfahren bei Sterbehilfevereinen sehen Künast et al. den Bedarf einer klaren Regelung (Künast et al. 2014).

Eine Art Kompromiss im Sinne einer moderaten strafrechtlichen Regelung der Suizidhilfe schlagen die Abgeordneten Elisabeth Scharfenberg und Harald Terpe (beide Bündnis 90/Die Grünen) vor. So plädieren sie einerseits für ein klares Verbot professioneller Sterbehilfeorganisationen, um eine Etablierung des assistierten Suizids als normales Dienstleistungsangebot oder gar als gängige Form der gesundheitlichen Versorgung in Deutschland zu verhindern. Unter dieses Verbot würde auch eine (wiederholt geleistete) ärztliche Suizidhilfe fallen, wie sie derzeit von einzelnen Ärzten betrieben wird. Anderseits möchten die Abgeordneten der individuellen Notsituation von Angehörigen Rechnung tragen, die um Suizidhilfe gebeten werden. Vorgeschlagen wird deshalb eine Strafbarkeit der regelmäßigen, auf Wiederholung angelegten Suizidhilfe (und der Werbung hierfür), die nicht aus einer Nähebeziehung zwischen Sterbewilligem und Anbieter entspringt. Für alle anderen, also auch für im Rahmen einer Einzelfallentscheidung tätig werdende Ärzte, zu denen der suizidwillige Patient in einer langjährigen Vertrauensbeziehung steht, soll Suizidhilfe nicht strafbar sein (Scharfenberg u. Terpe 2014).

Ähnlich ist auch die Haltung der Abgeordneten Kerstin Griese und Eva Högl (beide SPD), die sich in ihrem Positionspapier für ein Verbot der vereinsmäßigen Suizidhilfe aussprechen. Gleichzeitig plädieren sie für einen Erhalt und die Sicherung des Freiraums, der Ärzten in ethischen Grenzsituationen am Ende eines Lebens zustehe (nach Ansicht der Autoren). Griese und Högl weisen als einzige Autoren auf das Dilemma der unterschiedlichen Formulierungen bezüglich der ärztlichen Suizidhilfe in den BOen der LÄKen hin und fordern die Ärzteschaft zu einer klaren Regelung im Standesrecht auf. Sie verweisen weiterhin auf die Notwendigkeit, in der Bundestagsdebatte in den nächsten Monaten zu klären, ob dieses berufsrechtliche Verbot den ärztlichen Freiraum bezüglich der legalen Möglichkeiten zur Hilfe am Ende eines Lebens einschränkt oder nicht (Griese u. Högl 2014).

Die Abgeordneten Peter Hintze, Katharina Reiche (beide CDU), Dagmar Wöhrl (CSU) und die SPD-Abgeordneten Karl Lauterbach, Burkhard Lischka und Carola Reimann sprechen sich in ihrem Positionspapier dezidiert für eine Rechtssicherheit für Suizidhilfe leistende Ärzte aus, lehnen aber eine weitergehende Regulierung ärztlichen Handelns mit den Mitteln des Strafrechts ab. Die Abgeordneten verweisen diesbezüglich auf das besondere Vertrauensverhältnis zwischen Arzt und Patient, in dessen Rahmen Ärzte einen dauerhaften 
und selbstbestimmten Suizidwunsch fachgerecht überprüfen können und die behandelnden Ärzte aufgrund ihrer langen und intensiven Begleitung des Patienten am besten wissen, was im konkreten Einzelfall medizinisch angezeigt und in Würdigung der Gesamtsituation des Patienten $\mathrm{zu}$ vertreten sei. Allerdings solle die Regelung der Straffreiheit der ärztlichen Suizidhilfe an die Voraussetzungen gebunden sein, dass es sich um volljährige und einsichtsfähige Patienten mit einer unumkehrbar zum Tode führenden Krankheit handelt, der Patient objektiv leidet und er umfassend bezüglich anderer, insbesondere palliativmedizinischer Behandlungsmöglichkeiten beraten wurde. Zudem müsse im Sinne eines VierAugen-Prinzips die ärztliche Diagnose von einem anderen unabhängigen Arzt bestätigt worden sein. Die Abgeordneten halten eine solche Regelung, die eine freiwillige ärztliche Hilfestellung zwar ermöglicht, sie jedoch an klar definierte Voraussetzungen knüpft, für am besten geeignet, auf eine breite gesellschaftliche Akzeptanz zu stoßen und für Rechtsfrieden zu sorgen (Hintze et al. 2014).

Angesichts der sehr unterschiedlichen Standpunkte in den vorgestellten Positionspapieren kann die kommende Debatte sicher mit Spannung erwartet werden. 2015 soll mit der Erarbeitung der einzelnen Gesetzesentwürfe begonnen werden. Ein im August 2014 von Gian Domenico Borasio, Ralf Jox, Jochen Taupitz und Urban Wiesing vorgestellter Gesetzesentwurf fand im Bundestag bislang keine Beachtung. Dieser Gesetzesentwurf sieht vor, in einem neu zu schaffenden $\S 217$ StGB die Beihilfe zur Selbsttötung unter Strafe zu stellen, allerdings mit Ausnahme einer Suizidhilfe, die von Angehörigen oder Ärzten unter Einhaltung strenger Sorgfaltspflichten und ausschließlich bei unheilbarer Erkrankung mit begrenzter Lebenserwartung geleistet wird. Der Arzt muss zuvor die Freiwilligkeit des Suizidwunsches geprüft, ausführlich über palliativmedizinische Möglichkeiten informiert und einen zweiten Arzt hinzugezogen haben. Zudem soll jede Werbung für Suizidhilfe verboten werden und eine Klarstellung für das Betäubungsmittelgesetz erfolgen (Borasio et al. 2014).

\subsubsection{Haltung der deutschen Ärzte}

In der deutschen Ärzteschaft herrscht bezüglich der Haltung zur organisierten und gewerblichen Sterbehilfe weitgehend Einigkeit. Erst im Mai 2014 wurde gemeldet, dass die BÄK die Große Koalition auffordert, möglichst rasch ein Gesetz gegen die kommerzielle Sterbehilfe umzusetzen. Allerdings wird in der Ärzteschaft das Thema der ärztlichen Hilfe zur 
Selbsttötung umso kontroverser diskutiert. In diesem Zusammenhang konstatierte der Präsident der Berliner Ärztekammer, Günther Jonitz, auf einem 2013 in der Bundeshauptstadt tagenden Symposium zum Thema Sterbehilfe aus ärztlicher Sicht, dass die gesellschaftspolitische Debatte das Thema Sterbehilfe unzulässigerweise auf die Rolle des Arztes fokussiere und stellte im Anschluss die Frage, was eigentlich die Rolle des Arztes sei (Jonitz 2013). Dies ist sicher eine Kernfrage in der aktuellen Debatte um den assistierten Suizid, denn das 2011 in der MBO festgeschriebene berufsrechtliche Verbot der ärztlichen Suizidhilfe geht nicht auf die verschiedenen Überzeugungen innerhalb der Ärzteschaft zur Suizidhilfe ein. Dies zeigt eine (im Auftrag der BÄK durchgeführte) repräsentative Mitgliederumfrage zum Thema Ärztlich begleiteter Suizid und aktive Sterbehilfe aus Sicht der deutschen Ärzteschaft des Instituts für Demoskopie Allensbach aus dem Jahr 2010 (Institut für Demoskopie Allensbach 2010). Das Ergebnis zeigt, dass zwar eine deutliche Mehrheit von $67 \%$ der Befragten die Legalisierung einer ärztlichen Suizidhilfe ablehnt, immer können sich aber fast ein Drittel (30 \%) vorstellen, diese Hilfe zu leisten. Wichtige Argumente für die Befürworter einer Legalisierung waren erstens, dass es zum Selbstbestimmungsrecht eines Patienten gehöre, den Zeitpunkt seines Todes selbst zu bestimmen. Zweitens hielten sie den Arzt für besonders gut geeignet, durch sein Wissen um die richtige Dosierung von Medikamenten den Patienten beim Suizid zu unterstützen und drittens sahen sie durch die ärztliche Begleitung beim Suizid die Möglichkeit zu verhindern, dass ein Patient unnötig lange Schmerzen erleiden muss. Sowohl Gegner als auch Befürworter fürchten bei einer Legalisierung des ärztlich begleiteten Suizids die Gefahr, dass sich Menschen um Suizidhilfe bemühen, weil sie sich als Belastung für Familie oder Gesellschaft fühlen. Gegner der ärztlichen Suizidhilfe führten an, dass es fast unmöglich sei einzuschätzen, ob der Sterbewunsch des Patienten wirklich endgültig sei und dass niemand sagen könne, wann der Gesundheitszustand eines Patienten einen begleiteten Suizid rechtfertige. $83 \%$ unterstützten die Aussage, dass es gegen den hippokratischen Eid verstoße, wenn Ärzte Patienten beim Suizid unterstützen. Nur $30 \%$ der Befürworter der Legalisierung konnten sich dem anschließen. Und obwohl auch die Befürworter bei einer Legalisierung des ärztlich assistierten Suizids die Gefahr negativer Auswirklungen auf das Ansehen der Ärzte sahen, käme doch für mehr als jeden dritten Arzt (37\%) ein begleiteter Suizid unter bestimmten Bedingungen in Frage (op. cit.).

Anhand der Allensbach-Umfrage zeigt sich, wie unterschiedlich die persönlichen ethischen Überzeugungen der Ärzte in Deutschland bezüglich der Suizidhilfe sind. Dennoch äußerte sich Hoppe in einem seiner letzten Interviews 2011 wie folgt. Die Interviewer Klinkhammer 
und Stüwe konfrontierten Hoppe mit der Feststellung, dass in der Diskussion um die Suizidhilfe oft auf unterschiedliche Vorstellungen von Moral und Ethik in der Gesellschaft und Ärzteschaft verwiesen werde und stellten ihm die Frage, ob es gar kein einheitliches ärztliches Ethos mehr gebe, sondern nur noch verschiedene Ethiken von relativem Gewicht. Darauf antwortete Hoppe:

„Die ärztliche Ethik, die ich beschrieben habe [Menschen gesund zu erhalten, Krankheiten zu erkennen und zu bekämpfen, Leiden zu lindern und Sterbenden bis zum Tod beizustehen], ist allgemeiner Konsens. Sie wird auch von Ärztinnen und Ärzten ernst genommen und in ihrer täglichen Arbeit beachtet. Dass die ärztliche Assistenz beim Suizid nicht zu den ärztlichen Aufgaben gehört, ist auch Allgemeingut. Ich glaube nicht, dass wir in diesen Fragen verschiedene Ethiken haben." (Klinkhammer u. Stüwe 2011)

Das Berliner Verwaltungsgericht beschäftigte sich Anfang 2012 mit der Frage, wie weit die Befugnisse der Ärztekammern mit Blick auf das berufsrechtliche Verbot der ärztlichen Suizidhilfe und in Bezug auf die Überzeugungen ihrer einzelnen Mitglieder gehen dürfen. In dem darauf folgenden Urteil vom 30. März 2012 wurde festgestellt, dass die zuständige Ärztekammer kein uneingeschränktes Verbot der Überlassung todbringender Medikamente an Sterbewillige gegenüber einem Arzt aussprechen dürfe (Verwaltungsgericht Berlin 2012 b). Hintergrund dieses Urteils war die Klage des Berliner Urologen Uwe Christian Arnold, der zum damaligen Zeitpunkt zweiter Vorsitzender des Vereins DIGNITAS-Deutschland war. Ihm untersagte seine LÄK im Jahr 2007, anderen Personen todbringende Substanzen für einen beabsichtigten Suizid zum Gebrauch zu überlassen. In einer Presseerklärung erläuterte das Gericht das Urteil folgendermaßen:

„Zu den Berufspflichten der Ärzte gehöre die gewissenhafte Ausübung ihres Berufs u. a. nach den Geboten der ärztlichen Ethik. Die ärztliche Ethik umfasse die durch den Ärztestand anerkannten, den einzelnen Standesgenossen bindenden Grundregeln des Berufs. Diesen Grundregeln sei ein allgemeines Verbot des ärztlich assistierten Suizids zu entnehmen. Hiergegen verstoße die Überlassung todbringender Medikamente an sterbewillige Personen.

Gemessen am verfassungsrechtlichen Maßstab der Freiheit der Berufsausübung (Art. 12 GG) und der Gewissensfreiheit des Arztes (Art. 2 Abs. 1 GG) habe aber kein uneingeschränktes Verbot des ärztlich assistierten Suizids ausgesprochen werden dürfen. Mit den genannten Grundrechten unvereinbar sei es nämlich, die ärztliche Beilhilfe zum Suizid auch in Ausnahmefällen [...] zu verbieten, in denen ein Arzt aufgrund einer lang andauernden, engen persönlichen Beziehung in einen Gewissenkonflikt geraten würde, weil die Person, die freiverantwortlich die Selbsttötung wünsche, unerträglich und irreversibel an einer Krankheit leide und alternative Mittel der Leidensbegrenzung nicht ausreichend zur Verfügung stünden.“

(Verwaltungsgericht Berlin 2012 a, Pressemitteilung Nr. 17) 
Abschließend stellte das Gericht in seiner Erklärung ausdrücklich klar, „dass ein Verbot der Überlassung todbringender Medikamente an Sterbewillige verfassungsrechtlich unbedenklich sei, soweit diese Gesunden oder in ihrer Entscheidungsfähigkeit beeinträchtigten psychisch Kranken überlassen werden sollen.“ (op. cit.) Nach Ansicht des Gerichts sei auch ein Verbot beruflicher oder organisierter Sterbehilfe, wie sie der Verein DIGNITAS-Deutschland anbietet, zulässig. Zusammenfassend wird in diesem Urteil die Rolle der Ärztekammern gewürdigt, allerdings wird aber auch deutlich die Freiheit der Berufsausübung und das Gewissen des Arztes in berechtigten Einzelfallentscheidungen unterstrichen.

\subsubsection{Medizinethische und medizinrechtliche Kommentare}

Die berufsrechtliche und -ethische Neubewertung der ärztlich begleiteten Selbsttötung hat eine Vielzahl von Publikationen nach sich gezogen, die sich kritisch mit dem ärztlichen Standesrecht befassen. Die nachfolgende Auswahl der Literaturbeiträge zeigt, wie unterschiedlich das Verhalten der BÄK und die Grundsätze bzw. die MBO bewertet werden.

Die Deutsche Gesellschaft für Palliativmedizin (DGP) begrüßte die Überarbeitung der Grundsätze zur ärztlichen Sterbebegleitung und nahm wie folgt Stellung dazu:

„[...] Die DGP vertritt ebenfalls die Auffassung, dass der ärztlich assistierte Suizid nicht zu den Aufgaben des Arztes gehört. Dennoch ist sie sich dessen bewusst, dass die Beihilfe zum Suizid von ihren Mitgliedern ethisch unterschiedlich bewertet wird und Ärzte im Einzelfall vor einer ethischen Herausforderung stehen, wenn Patienten sie um Beihilfe zum Suizid bitten." (DGP 2011, S.1)

In ihrer Stellungnahme sprach sich die DGP abschließend dafür aus, dass von einer berufsrechtlichen Ächtung der ärztlichen Hilfe beim freiverantwortlichen Suizid im begründeten Fall Abstand genommen werden sollte (op. cit.). Zudem forderte der Vorstand der DGP nach seiner Klausurtagung im März 2013 die LÄKen zu einer Vereinheitlichung ihrer Berufsordnungen hinsichtlich eines Verbots der ärztlichen Suizidassistenz auf. Allerdings betonte die DGP weiterhin, dass das Verbot nicht zwingend an eine Sanktion gebunden sein sollte, sodass die LÄKen im begründeten Einzelfall von einer berufsrechtlichen Sanktionierung der ärztlichen Hilfe zum Suizid absehen könnten (Nauck et al. 2014). In den Anfang des Jahres 2014 erschienenen Reflexionen zum ärztlich assistierten Suizid stellt die DGP schließlich fest, dass ,,jenseits der Erfordernisse, eine berufsrechtliche Klärung herbeizuführen, [...] derzeit 
von Seiten der DGP kein Neuregelungsbedarf gesehen [wird], insbesondere nicht im Strafrecht.“(DGP 2014, S. 5)

Die Darmstädter Philosophin Petra Gehring sah in der Neufassung der Grundsätze und dem damit verbundenen Verzicht auf die ihrer Meinung nach anklagende Formulierung, „die Mitwirkung des Arztes bei der Selbsttötung widerspricht dem ärztlichen Ethos“ (BÄK 2004, Präambel der Grundsätze, S. 1298), eine einschneidende Veränderung des Berufsbildes des Arztes, indem sich die Ärzteschaft nun die Mitwirkung bei der Selbsttötung freistellt. In diesem Zusammenhang warf sie die Frage auf, ob es überhaupt noch ein ärztliches Ethos geben solle, da die neue Formulierung als Freigabe der Option einer Selbsttötungsbeteiligung im Stile einer nichtärztlichen Nebentätigkeit von Medizinern als Privatmenschen anzusehen sei (Gehring 2011).

Unter dem prägnanten Titel Das ärztliche Ethos bleibt intakt betonten dahingegen die Autoren Jörg-Dietrich Hoppe, Volker Lipp, und Alfred Simon, dass die neugefassten Grundsätze zur ärztlichen Sterbebegleitung zwar insofern weiterentwickelt wurden, als dass sie an die neue Rechtslage angepasst und einzelne Punkte präzisiert wurden. Allerdings bleibt es ihrer Meinung nach bei der eindeutigen Ablehnung der ärztlichen Hilfe zum Suizid, sodass ein Positionswandel der deutschen Ärzteschaft oder gar eine Revolution des ärztlichen Selbstverständnisses nicht zu verzeichnen sei. Dem Vorwurf Gehrings, dass es sich bei der Freigabe einer Suizidassistenz um eine nichtärztliche Nebentätigkeit von Medizinern als Privatmenschen handele, halten Hoppe et. al. entgegen, dass die beruflichen Pflichten des Arztes unteilbar sind, ein Arzt sich also nicht in eine Privatperson und einen Berufsträger aufspalten könne (Hoppe et al. 2011).

Ende 2011 kritisierte der Medizinethiker Jochen Vollmann aus Bochum die Handlungsweise der В $\mathrm{ÄK}$ und wies deren Vorgehen mit dem Argument zurück, dass berufsrechtlich nicht verboten werden könne, was strafrechtlich erlaubt sei. Diese Vorgehensweise, so Vollmann, stehe im Widerspruch zu ethisch wohl begründeten Wünschen von Patienten und spiegele nicht den Wertepluralismus der Ärzteschaft wider. Seiner Meinung nach soll ein modernes ärztliches Berufsethos die unterschiedlichen ethischen Einstellungen innerhalb der Ärzteschaft konstruktiv integrieren, ,anstatt durch Mehrheitsentscheidungen ein angeblich einheitliches ärztliches Ethos berufsrechtlich vorzuschreiben, was es in Wirklichkeit nicht gibt.“ (Vollmann 2011, S. 2)

Der Bonner Rechtswissenschaftler Torsten Verrel war selbst an der Neufassung der Grundsätze beteiligt. Er beschreibt die seiner Meinung nach ethisch abgerüsteten Grundsätze (da der 
Verweis auf das ärztliche Ethos herausgenommen wurde) als Zurücknahme der bislang vorherrschenden ausdrücklichen Missbilligung der ärztlichen Suizidhilfe und sieht in ihnen weder eine Unzuständigkeitserklärung der BÄK noch den Einstieg in eine ärztliche Routine der Selbsttötungshilfe. Die Änderung der MBO zu diesem Thema beschreibt er hingegen als bedauerlichen Rückfall in das überkommene Schwarz-Weiß-Schema, denn „ein offener, vom Stigma der Unärztlichkeit befreiter Umgang von Ärzten mit Suizidwünschen unheilbar Kranker rettet mehr Leben als die Beschwörung der Ethik des Hippokrates“ (Verrel 2011, S. 340), wie er abschließend bekräftigt.

Der Göttinger Medizinethiker Alfred Simon wies bereits nach Veröffentlichung der Allensbach-Umfrage 2010 darauf hin, dass nach den Ergebnissen der Befragung zwar ein Großteil der Ärzte die berufspolitischen Aussagen der BÄK hinsichtlich der Suizidbegleitung teilt, aber die Mehrheiten nicht so eindeutig seien, dass man von einer geschlossenen Haltung der Ärzteschaft sprechen könne. Er sieht die BÄK zu verstärkten Anstrengungen verpflichtet, nicht nur gegenüber der Gesellschaft, sondern auch gegenüber der Ärzteschaft ihre Position zur ärztlichen Suizidbegleitung zu verdeutlichen. Dies lediglich mit dem Verweis auf das ärztliche Ethos zu tun reiche dabei sicher nicht aus, vielmehr sei eine offene Auseinandersetzung über das ärztliche Berufsverständnis erforderlich (Simon 2010).

Der Bonner Medizinethiker Hartmut Kreß sieht in der Neufassung der MBO zur ärztlichen Suizidhilfe zudem eine außerordentliche rechtsethische Problematik, denn durch das berufsrechtliche Verbot einer strafrechtlich erlaubten Suizidhilfe schaffe die Ärzteschaft für sich selbst geradezu ein Sonder- und Nebenrecht, wodurch die Einheit der deutschen Rechtsordnung relativiert werde. Denn der Beschluss des Ärztetages habe das geltende staatliche Recht nicht präzisiert und arztbezogen konkretisiert, sondern vielmehr eingeengt. Folglich werde auf diese Weise sogar das Grundrecht von Patienten auf Selbstbestimmung beiseitegeschoben und konterkariert. Der Ärztetag habe außer Acht gelassen, dass das individuelle Grundrecht des Arztes auf Gewissensfreiheit vor korporativen und kollektiven Wertvorstellungen Vorrang besitze, denn die Freiheit der Gewissensentscheidung sei, wie er hervorhebt, ein Kernstück der ärztlichen Ethik (Kreß 2012).

Die Medizinethiker Gerrit Hohendorf und Fuat Oduncu begrüßen die Neufassung der MBO mit ihrer klaren Ablehnung der ärztlichen Suizidhilfe. Allerdings fordern sie, dass diese Haltung auch einer entsprechend guten ethischen Begründung bedürfe, denn „nur so können Ärzte, die in einer Ausnahmesituation keine andere Hilfe für das Leiden ihres Patienten sehen als die Suizidassistenz, ihre Handlungen an einem klar formulierten ärztlichen Auftrag und 
Ethos überprüfen.“ (Oduncu u. Hohendorf 2011, S. 238) Die Autoren betonen, dass es nicht darum gehe, den standesrechtlichen moralischen Stab über den Einzelnen zu brechen, sondern vielmehr seien die Gremien aufgefordert, die besonderen Gründe einer Normüberschreitung im Einzelfall zu berücksichtigen. Allerdings stehen die Autoren einer ärztlichen Hilfe zur Selbsttötung klar ablehnend gegenüber, da für sie die Rolle des Arztes, der anhand medizinischer Kriterien über den Wert und Unwert eines menschlichen Lebens entscheidet, eindeutig nicht mit dem ärztlichen Ethos vereinbar sei (op. cit.).

Der Arzt und Medizinethiker Meinolfus Strätling begrüßt, dass die BÄK in ihren überarbeiteten Grundsätzen von 2011 ihre frühere und schon damals oft kritisierte Auffassung, dass die ärztliche Suizidassistenz mit dem Ethos unvereinbar sei, aufgegeben habe und mit der Neuformulierung versuche, einen Kompromiss zwischen den zutiefst unterschiedlichen individuellen Auffassungen eines ärztlichen Ethos zu finden. Allerdings sieht er die Aussage, wonach die Suizidhilfe keine ärztliche Aufgabe darstelle als ethisch unbegründet an, denn eine Ärzteschaft dürfe sich seiner Meinung nach nicht einfach für nicht zuständig erklären. Somit sind auch die Grundsätze keine wirkliche Verbesserung zur Klärung der ärztlichen Suizidhilfe, sondern könnten vielmehr eine gewaltige und höchst bedenkliche Grauzone zementieren, in der sich wohlmeinende Helfer und Organisationen oft auch unter Anwendung fraglicher Techniken diesem Problem annehmen würden. Er betont, dass die BÄK nicht einerseits differenzierten Pluralismus als ethisch-moralische Grundlage der Einzelfallentscheidung anerkennen könne, aber andererseits als Dachorganisation der Ärzte die Entscheidungsgrundlage ihrer Mitglieder relativieren, diffamieren oder gar standesrechtlich unmöglich machen dürfe, da jeder Arzt in einer ethisch kontroversen Frage, wie der Suizidhilfe, respektierungswürdige persönliche Wertvorstellungen habe. Er hebt abschließend hervor, dass:

„ein vermehrtes, offenes Eintreten gerade auch der Ärzteschaft in die gesamtgesellschaftlich ohnehin bereits bestehende Diskussion [...] daher sicher ermutigen [kann und sollte]. Im Sinne der Wahrnehmung eines solchen ,Ethos der Verantwortung und bejahenden Verantwortungsbereitschaft" wird der erste Schritt sein müssen, sich deutlich aufgeschlossener als bisher den [...] Realitäten zu stellen.“ (Strätling 2012, S. 102)

Der Tübinger Medizinethiker Urban Wiesing befürchtet angesichts der unterschiedlichen berufsrechtlichen Regelungen einen innerdeutschen Suizidtourismus. In Bezugnahme auf die neue MBO stellt er fest, dass ein Ärztetag nicht zu entscheiden habe, welche Formen des Sterbens ethisch akzeptabel seien und der BÄK nicht die Aufgabe obliege, gesellschaftliche Entwicklungen, welche die Delegierten als nicht wünschenswert erachten, durch berufs- 
rechtliche Verbote zu verhindern, die zudem, wenn sie schon die Freiheit der Mitglieder einschränken würden, dann wenigstens guter Gründe bedürfen. Die zwei Drittel der Ärzteschaft, welche die Suizidhilfe aus ethischen Gründen ablehnen, dürften dennoch dem restlichen Drittel selbige nicht verbieten. In diesem Sinne hält er bereits in der Überschrift seines Aufsatzes fest: „Durfte der Kieler Ärztetag den ärztlich assistierten Suizid verbieten? Nein!“‘. (Wiesing 2012 b, S. 1)

Diese Frage beantwortete Martina Wenker, Präsidentin der LÄK Niedersachsen und Vizepräsidentin der B ̈̈K, wiederum mit einem klaren Ja. Dabei grenzt sie die Fragen: „Durfte sich der Deutsche Ärztetag mit der Frage nach dem Verbot des ärztlich-assistierten Suizids beschäftigen und diese Frage in der MBO regeln?“ und „Dürfen oder durften die Landesärztekammern den in der MBO enthaltenen Vorschlag in ihre Berufordnungen übernehmen?“ (Wenker 2013, S. 75) voneinander ab. Bezüglich der ersten Frage stellt sie fest, dass mit Hilfe der MBO das Ansehen des Arztberufs gewahrt, berufswürdiges Verhalten gefördert und berufswidriges Verhalten verhindert werden solle und daher den Regelungen, die sich im Rahmen dieser Zielverwirklichungen bewegen, nicht vorgeworfen werden könne, dass die BÄK damit ihre Zuständigkeiten überschreite. In diesem Sinne stellt der $§ 16$ MBO fest, dass es sich bei dem ärztlich assistierten Suizid um ein berufswidriges Verhalten handelt, das dem Ansehen der Ärzteschaft schadet und folglich berufsrechtlich sehr wohl verboten werden kann, auch wenn dies im Rahmen einer Mehrheitsentscheidung entschieden wurde, die den pluralistischen Ausrichtungen der Ärzteschaft oder einer, wie sie sagt, Einstellung der Minderheit widerspreche. Hinsichtlich der zweiten von ihr aufgeworfenen Frage führt sie aus, dass Ärzte die Pflicht haben, ihren Beruf gewissenhaft auszuüben gemäß der Heilberufe- und Kammergesetze der einzelnen Länder und genau diese Gesetze wiederum die LÄKen ermächtigen, die Umstände einer gewissenhaften Berufsausübung zu regeln und damit Vorschriften über Berufspflichten zu schaffen. Demnach seien die LÄKen insbesondere dazu berechtigt, Berufspflichten für die Berufsausübung zu treffen. Der Feststellung Wiesings, dass die MBO erstmals den ärztlich assistierten Suizid untersage und damit über das Strafrecht hinausgehe hält sie entgegen, dass diese Feststellung verkenne, dass allein ein berufsrechtliches Verfahren noch keine berufsrechtlichen Maßnahmen auslöse, sondern zunächst die tatbestandsmäßige, rechtswidrige und schuldhafte Verwirklichung genau zu prüfen und festzustellen sei. Erst beim Vorliegen der Voraussetzungen dafür, sei über die Art und ggf. den Umfang der Sanktionen im Rahmen der berufsrechtlichen Möglichkeiten zu entscheiden (Wenker 2013). 


\subsection{Zusammenfassung und Zwischenergebnis}

Die organisierte und gewerbliche Sterbehilfe sowie die ärztliche Hilfe zum Suizid waren in den letzten Jahren in Deutschland die zentralen Themen der Debatte um die Sterbehilfe, wie eine grundlegende Sichtung der Literatur der letzten Jahre gezeigt hat. Ausgelöst wurde diese Entwicklung durch die Tätigkeit der Schweizer Sterbehilfeorganisationen hierzulande und den damit verbundenen Sterbetourismus in die Schweiz, wobei die Zahl der von DIGNITASDeutschland durchgeführten Suizidbegleitungen von Jahr zu Jahr steigt (Bosshard 2012) und somit die dringende Notwendigkeit des gesellschaftlichen Diskurses unterstreicht. Hinzu kommen die Kontroversen um den Verein Sterbehilfe Deutschland und die damit verbundene Frage nach einer gewerblich organisierten Suizidhilfe, die trotz einer Satzungsänderung des Vereins weiterhin im Raum steht. Auch die im Jahr 2011 durch die BÄK vorgenommene berufsethische Neubewertung der ärztlichen Suizidhilfe in den Grundsätzen zur ärztlichen Sterbebegleitung, der im selben Jahr ein berufsrechtliches Verbot der ärztlichen Suizidhilfe im $\S 16$ MBO folgte, hat einen umfangreichen öffentlichen Diskurs nach sich gezogen. Dieser wurde noch intensiviert durch die Tatsache, dass im Nachhinein nur ein Teil der LÄKen das in der MBO festgeschriebene Verbot gleichlautend in ihre BOen übernommen haben und andere LÄKen eine offenere Formulierung gewählt haben, was einen innerdeutschen Suizidtourismus zur Folge haben könnte. Grundsätzlich ist es allerdings sehr zu befürworten, dass nach den Kontroversen um den Behandlungsabbruch oder die Patientenverfügung, die sicher für viele Bürger große Relevanz hatten, nun auch diese Form der Sterbehilfe im Fokus des öffentlichen Interesses steht. Auch wenn der Wunsch nach Hilfe zum Suizid nur von einem geringen Prozentsatz der Patienten geäußert wird, bedeutet er für die meist schwer kranken und leidenden Menschen die elementare Forderung nach Selbstbestimmung im Sterben.

Der organisierten und gewerblichen Sterbehilfe stehen Expertenrunden wie der Deutsche Ethikrat, juristische Gremien wie der Deutsche Juristentag und die Mehrheit der politischen Vereinigungen nicht nur ablehnend gegenüber, sondern sie verfolgen auch das Ziel, beides in naher Zukunft durch einen Gesetzesentwurf zu regeln bzw. zu verbieten. Im Bundestag wurden darüber bereits erste Debatten geführt und Positionsentwürfe von einzelnen Abgeordneten sowie ein Gesetzesentwurf von einer Gruppe angesehener Medizinethiker und 
Juristen vorgelegt. Ob sich das geplante Gesetzgebungsverfahren in Deutschland jedoch durchsetzt und was dieses dann konkret beinhaltet, wird sich in den nächsten Monaten zeigen.

Trotz der vehementen Forderung verschiedener Experten und Gremien ist eine Auflösung des durch die BÄK geschaffenen Paradoxon des berufsrechtlichen Verbots einer strafrechtlich zulässigen Handlung (wie auch des berufsrechtlichen Flickenteppichs diesbezüglich) hingegen noch nicht in Sicht. Hinzu kommt, dass die derzeitige Form der Grundsätze zur ärztlichen Sterbebegleitung wie auch die MBO für um Suizidassistenz gebetene Ärzte keine Hilfestellung in der diffizilen Einzelfallentscheidung ist, denn immerhin kann sich ein Drittel der Ärzteschaft grundsätzlich vorstellen, diese Hilfe zu leisten.

Auf der Suche nach einer Grundlage für das ärztliche Handeln wird an dieser Stelle in der Vielzahl der juristischen, politischen und medizinethischen Kommentare immer wieder auf das ärztliche Ethos als Basis ärztlicher Entscheidungen verwiesen. Wo sich die Gegner der Suizidhilfe jedoch darauf berufen, dass die Suizidhilfe dem ärztlichen Ethos per se widerspricht und negative Auswirkungen auf das berufliche Ansehen der Ärzteschaft und die Arzt-Patient-Beziehung hätte, beziehen sich die Befürworter dieser Praxis darauf, dass es dem ärztlichen Ethos ebenso entgegensteht, einem begründeten, wohlerwogenen Suizidwunsch eines schwer leidenden terminal erkrankten Patienten gemäß seiner Selbstbestimmung nicht nachzukommen. Sie verweisen außerdem darauf, dass das Eingehen auf den Suizidwunsch die Vertrauensbeziehung zwischen Arzt und Patienten sogar stärken würde.

Durch die Vielzahl der aufgezeigten Reaktionen zum Thema Suizidhilfe konnte deutlich gemacht werden, dass die Frage nach der Zulässigkeit des ärztlich assistierten Suizids derzeit vielfach mit Bezugnahme auf das ärztliche Standesethos diskutiert wird, wobei jedoch unklar bleibt, was genau darunter zu verstehen ist und welche Bedeutung dem ärztlichen Berufsethos im Rahmen konkreter medizinethischer Debatten zukommen soll (Salloch u. Vollmann 2011). Um zu einem genaueren Verständnis zu gelangen, wird der Kernpunkt dieser Debatte im Zentrum der Überlegungen des folgenden Kapitels stehen. Nach grundlegenden Ausführungen zum Verhältnis von Ethos und Ethik in der Medizin sowie zum Standesethos und dessen Funktion in der Arzt-Patient-Beziehung wird abschließend die Frage zu klären sein, ob ärztliche Suizidassistenz einen Vertrauensverlust der Gesellschaft in die Ärzteschaft nach sich zieht und so ggf. dem ärztlichen Ethos entgegensteht. 


\section{4 ÄRZTLICH ASSISTIERTER SUIZID UND ÄRZTLICHES ETHOS}

\subsection{Grundlegendes zum ärztlichen Ethos}

\subsubsection{Zum Verhältnis von Ethos und Ethik in der Medizin}

Der Begriff Ethos entstammt dem Griechischen, in welchem mit êthos eine Gewohnheit, eine Gesinnung oder ein Charakter bezeichnet wird. Dabei wird die Grenzziehung zum Begriff Moral nicht deutlich vollzogen, vielmehr werden beide Begriffe im Wesentlichen heutzutage synonym verwendet, da sie auch wortgeschichtlich praktisch gleichbedeutend sind (SchöneSeifert 2013). Unter Moral versteht man sozial geteilte, für bestimmte Gruppen verbindliche und oft verinnerlichte Wertmaßstäbe, Regeln und Normen, die Menschen bei ihrem Handeln leiten. Die Ethik hingegen wird als Theorie der Moral definiert und dient dem Erkennen, Analysieren und Begründen von moralischen Normen und Werten. Diese Reflexion auf die Moral bezweckt ein Hinterfragen des (aktuell nicht mehr) Selbstverständlichen und lässt mitunter durch eine Beschäftigung mit der Frage, was sich für Schwierigkeiten aus den Traditionen und Wertvorstellungen ergeben, Konflikte entstehen, aber zugleich auch neue Denkweisen (Schicktanz 2013). An dieser Stelle ist anzumerken, dass die Begriffe Moral und Ethik bzw. moralisch und ethisch in vielen Publikationen und der Umgangssprache häufig bedeutungsgleich verwendet werden.

Im Kontext der Medizin kommen Ethos und Ethik eine besondere Bedeutung zu, denn angesichts der zunehmend komplexeren Herausforderungen der Medizin werden sich immer neue ethische Überlegungen und Begründungsversuche als notwendig erweisen. Die medizinische Ethik versucht, diesen Herausforderungen zu begegnen und kann als eine Art Gewaltenteilung zwischen den drei wesentlichen Größen in diesem Bereich angesehen werden, nämlich der Autonomie des Patienten, der Autonomie des Arztes und den Ansprüchen der Gesellschaft (von Engelhardt 1997). Das ärztliche Ethos deutet zudem auf eine Verantwortlichkeit hin, die über das normale $\mathrm{Maß}$ an Wohlverhalten hinausgeht, da einerseits an den Arzt als Menschen beträchtliche Anforderungen an Persönlichkeit, Einstellung und Verhalten generell gestellt werden und andererseits an den Arzt als Repräsentanten seines Berufs einzigartige Anforderungen gelten in Bezug und Rücksicht darauf, dass sie in Hinblick auf die 
Gesundheit Einfluss auf ein hohes existenzielles Gut des Patienten nehmen und oft mit Personen in besonders verletzlichen und vertraulichen Umständen zu tun haben. In diesem Sinne deuten ärztliches Ethos und ärztliche Ethik als Standesethik vor allem auf die außerordentliche Verantwortung des Arztes hin, die über die eigentlichen moralischen Verpflichtungen jedes Menschen hinausgehen (Gelhaus 2013).

\subsection{2 Ärztliches Ethos als Standesethos (Hippokratischer Eid und Genfer Ärztegelöbnis)}

Bereits in der Antike wurde mit dem Arztberuf die Vorstellung besonderer moralischer Ansprüche und Verantwortung verbunden. Daher wurde vielerorts und über viele Epochen hinweg in der Heilkunde das Verhalten der Ausübenden in moralischer Hinsicht beispielsweise mittels Eiden oder Gelöbnissen normiert (Wiesing u. Marckmann 2006). Damit wurde versucht, die Werte und Normen zu verankern, die das besondere ärztliche Standesethos ausmachen und ärztliches Handeln in moralischer Hinsicht festzuschreiben. Im Folgenden wird mit dem Eid des Hippokrates und dem Genfer Ärztegelöbnis eine Auswahl der für das Standesethos bedeutsamen Verhaltenskodizes vorgestellt und herausgearbeitet, welche Grundwerte diese Dokumente enthalten.

Der sicher bekannteste und in Bezug auf das ärztliche Ethos meist zitierte Kodex ist der Eid des Hippokrates, der als Abbild des ärztlichen Ethos durch die Jahrhunderte gelten kann, obgleich er keineswegs für alle Ärzte der Antike gültig war. Er stammt aus dem 5./4. Jh. v. Chr. und wird Hippokrates von Kos (ca. 460-375 v. Chr.) zugeschrieben, dem wohl berühmtesten Arzt der Antike. Ungewiss ist allerdings, ob Hippokrates wirklich der Verfasser dieses Eides war. Der Eid steht zu Beginn des Corpus Hippocraticum, einer vom 4. Jh. v. Chr. bis zum 1. Jh. n. Chr. entstandenen Sammlung von über 60 Schriften verschiedener Autoren zu medizinischen Themen (von Engelhardt 1997) und lautet in einer deutschen Übersetzung wie folgt: 
„Ich schwöre bei Apollon dem Arzt und bei Asklepios, Hygieia und Panakeia sowie unter Anrufung aller Götter und Göttinnen als Zeugen, dass ich nach Kräften und gemäß meinem Urteil diesen Eid und diesen Vertrag erfüllen werde:

Denjenigen, der mich diese Kunst gelehrt hat, werde ich meinen Eltern gleichstellen und das Leben mit ihm teilen; falls es nötig ist, werde ich ihn mitversorgen. Seine männlichen Nachkommen werde ich wie meine Brüder achten und sie ohne Honorar und ohne Vertrag diese Kunst lehren, wenn sie sie erlernen wollen. Mit Unterricht, Vorlesungen und allen übrigen Aspekten der Ausbildung werde ich meine eigenen Söhne, die Söhne meines Lehrers und diejenigen Schüler versorgen, die nach ärztlichem Brauch den Vertrag unterschrieben und den Eid abgelegt haben, sonst aber niemanden.

Die diätetischen Maßnahmen werde ich nach Kräften und gemäß meinem Urteil zum Nutzen der Kranken einsetzen, Schädigung und Unrecht aber ausschließen.

Ich werde niemandem, nicht einmal auf ausdrückliches Verlangen, ein tödliches Medikament geben, und ich werde auch keinen entsprechenden Rat erteilen; ebenso werde ich keiner Frau ein Abtreibungsmittel aushändigen.

Lauter und gewissenhaft werde ich mein Leben und meine Kunst bewahren. Auf keinen Fall werde ich Blasensteinkranke operieren, sondern ich werde hier den Handwerkschirurgen Platz machen, die darin erfahren sind.

In wie viele Häuser ich auch kommen werde, zum Nutzen der Kranken will ich eintreten und mich von jedem vorsätzlichen Unrecht und jeder anderen Sittenlosigkeit fernhalten, auch von sexuellen Handlungen mit Frauen und Männern, sowohl Freien als auch Sklaven.

Über alles, was ich während oder außerhalb der Behandlung im Leben der Menschen sehe oder höre und das man nicht nach draußen tragen darf, werde ich schweigen und es geheim halten.

Wenn ich diesen meinen Eid erfülle und ihn nicht antaste, so möge ich mein Leben und meine Kunst genießen, gerühmt bei allen Menschen für alle Zeiten; wenn ich ihn aber übertrete und meineidig werde, dann soll das Gegenteil davon geschehen.“

(Übersetzung aus dem Griechischen von Axel Bauer 1993)

Der Hippokratische Eid wird umrahmt von einer Eingangs- bzw. Schwurformel mit Anrufung der Götter und einer Schlussformel. Der Mittelteil beinhaltet die Verpflichtung gegenüber der ärztlichen Schule und den ärztlichen Kollegen in Form eines Lehrvertrags, der das LehrerSchüler-Verhältnis, die Ausbildung und einige versorgungsrelevante Aspekte regelt. Nachfolgend werden wichtige Verpflichtungen und Verhaltensnormen gegenüber den Patienten angesprochen. Ganz zentrale Bestandteile des Textes sind die Werte Fürsorge bzw. Wohltun (diätetische Maßnahmen zum Nutzen der Kranken) und das Nicht-Schaden (Schädigung/ Unrecht ausschließen) sowie der Wert Gleichheit und Gerechtigkeit (Nutzen des Kranken vorrangig, Wohnsituation/Stand ist nebensächlich). Des Weiteren wird bekräftigt, dass der 
Arzt nicht nur in seinem Beruf (seiner „Kunst“), sondern auch in seinem ganzen Leben an eine besondere moralische Haltung gebunden ist. Um einen Missbrauch ärztlicher Macht zu verhindern werden zudem verschiedene handlungsrelevante Regelungen aufgestellt, wie die Schweigepflicht und der Hinweis, sich von vorsätzlichem Unrecht und Sittenlosigkeit fernzuhalten. Die Regelungen werden durch konkrete Verbote bestimmter Praktiken, wie der Tötung auf Verlangen, der Suizidhilfe, der Abtreibung und des Steinschnitts ergänzt. Hierbei muss angemerkt werden, dass der Text an sich im Original durchaus Spielraum für Interpretationen bietet. Zum Beispiel stellt sich die Frage, ob das Verbot des Steinschnitts auch als Hinweis gilt, sich als Arzt von als dubios angesehenen Praktiken fernzuhalten oder ob es sich lediglich auf die in der Antike sehr riskante operative Entfernung von Blasensteinen bezieht. In den vielfältigen Übersetzungen finden sich erst recht Divergenzen, die unter anderem bei der Frage uneins sind, ob ein generelles Abtreibungsverbot oder nur verschiedene Formen der Abtreibung gemeint sind (Wiesing 2012 a).

Der hippokratische Eid mit seinen Werten und Verhaltensvorschriften ist folglich zum einen als Dokument zu verstehen, das ein Licht auf das Ethos einer bestimmten Gruppe antiker Ärzte wirft, zum anderen enthält er generationsübergreifende, ethische Erkenntnisse und Errungenschaften, die auch von der modernen Medizinethik übernommen wurden. Allerdings bedarf der Eid (berücksichtigt man die Entstehungszeit) der stetigen Aktualisierung, Neuinterpretation und Ergänzung, so beispielsweise in Hinblick auf die Selbstbestimmung des Patienten. Hinzu kommt, dass dieser Verhaltenskodex eine für antike Verhältnisse sehr strenge Haltung zu Abtreibung und ärztlicher Suizidhilfe einnimmt, die keineswegs von allen Ärzten der damaligen Zeit geteilt wurde (op.cit.).

Im September 1948 wurde auf der 2. Generalversammlung des Weltärztebundes in Genf die Genfer Deklaration, häufiger auch als Genfer Ärztegelöbnis bezeichnet, verabschiedet. Sie wurde von der BÄK übernommen und der MBO vorangestellt, womit sie für alle Ärzte in Deutschland eine gewisse Verbindlichkeit hat. Darauf weist auch der (nur in der MBO, aber nicht in der Originalfassung des Weltärztebundes vorkommende) Zusatz hin, dass für jede Ärztin und jeden Arzt das Gelöbnis gelten möge. Das Gelöbnis lautet wie folgt: 


\section{„GELÖBNIS}

Bei meiner Aufnahme in den ärztlichen Berufsstand gelobe ich feierlich:

mein Leben in den Dienst der Menschlichkeit zu stellen.

Ich werde meinen Lehrern die schuldige Achtung und Dankbarkeit erweisen.

Ich werde meinen Beruf mit Gewissenhaftigkeit und Würde ausüben.

Die Gesundheit meines Patienten soll oberstes Gebot meines Handelns sein.

Ich werde alle mir anvertrauten Geheimnisse auch über den Tod des Patienten hinaus wahren.

Ich werde mit allen meinen Kräften die Ehre und die edle Überlieferung des ärztlichen Berufes aufrechterhalten.

Meine Kolleginnen und Kollegen sollen meine Schwestern und Brüder sein.

Ich werde mich in meinen ärztlichen Pflichten meinem Patienten gegenüber nicht beeinflussen lassen durch Alter, Krankheit oder Behinderung, Konfession, ethnische Herkunft, Geschlecht, Staatsangehörigkeit, politische Zugehörigkeit, Rasse, sexuelle Orientierung oder soziale Stellung.

Ich werde jedem Menschenleben von seinem Beginn an Ehrfurcht entgegenbringen und selbst unter Bedrohung meine ärztliche Kunst nicht in Widerspruch zu den Geboten der Menschlichkeit anwenden.

Dies alles verspreche ich feierlich und frei auf meine Ehre.

(Weltärztebund 1948, Deklaration von Genf, Fassung von 1994)

Wie im Hippokratischen Eid sind auch in diesem Gelöbnis die Werte der Fürsorge bzw. des Wohltuns (Gesundheit des Patienten als oberstes Gebot) sowie der Gleichheit und Gerechtigkeit verankert, wenn auch in modernerer Wortwahl. Das Gebot des Nicht-Schadens wurde nicht explizit erwähnt, mag aber im Absatz des Wohltuns impliziert sein. Die Schweigepflicht sowie Passagen des Lehrvertrags sind in beiden Dokumenten enthalten, ebenso der Hinweis auf eine besondere moralische Verpflichtung in der Lebensführung („Bei meiner Aufnahme in den ärztlichen Berufsstand gelobe ich feierlich, mein Leben in den Dienst der Menschlichkeit zu stellen“). Sicher haben dazu die Erfahrungen des Dritten Reiches beigetragen, die Ärzte in ihrem Gelöbnis noch einmal ausdrücklich auf die Werte Gleichheit und Gerechtigkeit hinzuweisen (vgl. Absatz: „Ich werde mich in meinen ärztlichen Pflichten meinen Patienten gegenüber nicht beeinflussen lassen...") wie auch darauf, die ärztliche Kunst auch unter Bedrohung nicht zu missbrauchen und in Widerspruch zu den Geboten der Menschlichkeit anzuwenden. Des Weiteren wurden die Verbote der Tötung auf Verlangen, der Suizidhilfe und der Abtreibung in den deutlichen Hinweis umgewandelt, dass jedem Menschenleben von Beginn an Ehrfurcht entgegengebracht werden soll. 
Folglich betont das Genfer Ärztegelöbnis die grundlegenden Werte des Hippokratischen Eides und vereint diese mit modernen Auffassungen der ärztlichen Gesinnung in Lebensführung und Berufsausübung. In beiden Dokumenten sind mit der Fürsorge, dem NichtSchaden und der Gleichheit und Gerechtigkeit drei der vier ethisch moralischen Prinzipien enthalten, welche die Autoren Beauchamp und Childress bereits Ende der 1970er Jahre in ihrem (mittlerweile mehrfach überarbeiteten) Buch Principles of Biomedical Ethics als orientierungsgebenden Ausgangspunkt für ethische Fragen im Bereich der Medizin herausgearbeitet haben (Beauchamp u. Childress 2009). Heute werden diese Werte weithin anerkannt und gelten als die Prinzipien der Medizinethik. Zunächst stehen diese Prinzipien gleichwertig nebeneinander, können aber im Konfliktfall miteinander konkurrieren. Weiterhin ist es bei der ethischen Entscheidungsfindung wichtig, ,dass keines der Prinzipien allein zur Begründung moralischen Handelns im klinischen Alltag herangezogen werden kann. Vielmehr müssen die verschiedenen Prinzipien und die daraus resultierenden Pflichten im Verhältnis zueinander betrachtet und gegeneinander abgewogen werden.“ (Simon 2013, S. 138)

Anzumerken ist, dass weder der Hippokratische Eid noch das Genfer Gelöbnis auf einen weiteren, in der heutigen Zeit wesentlichen Wert in der Medizin eingehen, nämlich den Respekt vor der Autonomie des Patienten, welcher das vierte medizinethische Prinzip nach Beauchamp und Childress darstellt, denn zu den Herausforderungen, vor die uns die moderne Medizin stellt, gehört u.a. ein gewandeltes Modell der Arzt-Patient-Beziehung. Dieses Modell orientiert sich weg von der klassisch paternalistischen Ausrichtung hin zu Konzepten, welche die Selbstbestimmung des informierten und mündigen Patienten in den Fokus stellen, da der Wille des Patienten seit der Nachkriegszeit in Hinblick auf seine Selbstbestimmung einen immer höheren Rang einnimmt. Dieser Wille steht heute über dem, was Ärzte als das Wohl des Patienten einschätzen (Wiesing u. Marckmann 2006). In der MBO wird die Selbstbestimmung des Patienten in einem eigenen Abschnitt, der den ärztlichen Pflichten gegenüber Patienten gewidmet ist, klar betont. Hier heißt es unter anderem, dass jede medizinische Behandlung, ,unter Wahrung der Menschenwürde und unter Achtung der Persönlichkeit, des Willens und der Rechte der Patientinnen und Patienten, insbesondere des Selbstbestimmungsrechts, zu erfolgen [hat].“ (§7 MBO) 


\subsubsection{Funktion des ärztlichen Standesethos}

Der Begriff des Berufsethos lässt sich sicher für viele Professionen verwenden, ist aber in Bezug auf die Ärzteschaft ein vielfach gebrauchtes Schlagwort. Nicht umsonst liegt seit Jahren diese Berufsgruppe unangefochten an der Spitze der Berufsprestige-Skala in repräsentativen Umfragen - und das seit über 20 Jahren. So zählen 76 \% der Deutschen den Arztberuf zu den fünf Berufen, die sie am meisten schätzen (Institut für Demoskopie Allensbach 2013). Auch international gehört der Arztberuf zu den Berufsgruppen, denen die Bevölkerung am meisten Vertrauen schenkt (GfK Verein 2014). Dies mag mit dem der Ärzteschaft zugesprochenen Berufsethos zu tun haben, welches die hohe sittliche Vorstellung vom Wert und den Pflichten eines Berufes beschreibt. Auf die Frage, welche Funktion ein Sittenkodex wie der Hippokratische Eid oder das Genfer Gelöbnis haben könnte, lässt sich folgende Antwort geben:

„Die strengen Normen ärztlichen Verhaltens wie auch die Ausrichtung auf den individuellen Nutzen des Patienten und die Schadensvermeidung sollen das Vertrauen des Patienten ermöglichen, da sich der Arzt als Mitglied dieser Ärztegruppe nur ihm und seinem Wohl verpflichtet fühlt, schädigende Maßnahmen unterlassen und bestimmte Verhaltensweisen einhalten wird. Insofern versucht der Eid, über die moralische Integrität der Berufszugehörigen für die Patienten eine Vertrauensbasis herzustellen.“ (Wiesing 2012 a, S. 39/40)

Folglich gewährleistet das ärztliche Ethos ein rollengebundenes antizipatorisches Systemvertrauen in die Ärzteschaft, das streng genommen nicht auf dem Erfolg der ärztlichen Maßnahmen basiert, denn dieser kann nicht immer garantiert werden, sondern auf Basis der moralischen Integrität, die durch die Zugehörigkeit zum ärztlichen Berufsstand erwartet werden darf. Die Beachtung der für das ärztliche Ethos maßgeblichen Grundwerte muss für den ganzen Berufsstand allerdings verpflichtend sein und von Patienten erwartet werden können, denn der Patient steht, bei aller Mit- und Selbstbestimmung, meist in einer gewissen Abhängigkeit vom Arzt. Man bedenke beispielsweise die Situation eines Eingriffs unter Narkose oder eine Operation, bei der ein Patient oft gar nicht weiß, welcher Arzt nun den konkreten Eingriff vornimmt. In dieses Vertrauens- und Abhängigkeitsverhältnis kann und will sich der Patient folglich nur begeben, wenn er sicher sein kann, dass der ihn betreuende Arzt ausreichend qualifiziert ist und stets zum Wohl und dem Willen des Patienten entsprechend behandelt (Wiesing u. Marckmann 2009). 


\subsection{Das ärztliche Ethos im Kontext der ärztlichen Suizidhilfe}

4.2.1 Der Wunsch nach Suizidhilfe - Eine Überforderung des traditionellen ärztlichen Ethos?

Um das antizipatorische Systemvertrauen zu gewährleisten, muss sich das ärztliche Ethos im Spannungsfeld zwischen Tradition und Fortschritt behaupten. Wo früher nun versucht wurde, in Kodizes wie dem Hippokratischen Eid, dem Genfer Gelöbnis oder auch in der MBO ein Bild des ärztlichen Ethos festzuschreiben und damit Problemfelder in der Medizin und dem Arzt-Patient-Verhältnis zu normieren, wird am Beispiel der ärztlichen Suizidhilfe klar, dass die Fragen, vor die uns die Medizin der Moderne stellt, zu komplex sind, als dass sie mittels eines traditionellen Regelkatalogs (und eines darin festgeschrieben ärztlichen Ethos) allein beantwortet werden könnten. Sie umfassen sowohl die Forderungen mündiger, aufgeklärter Patienten, die auf ihre Selbstbestimmung bedacht sind, als auch die gesamte Problematik konkurrierender oder zumindest gleichberechtigt nebeneinander stehender Weltanschauungen innerhalb der Ärzteschaft. Folglich würde die berufsethische Regelung anspruchsvoller und höchst komplexer medizinethischer Probleme wie der Suizidhilfe mit Hilfe eines einfachen Verhaltenskodex schlichtweg eine Überforderung des ärztlichen Ethos bedeuten. Deshalb sollte sich das ärztliche Ethos der Moderne nicht aus Regelkatalogen ableiten, sondern sich grundlegenden Werten wie zum Beispiel Fürsorge, Gleichheit/Gerechtigkeit, Nicht-Schaden sowie Respekt vor der Patientenautonomie verpflichten. Die Beachtung dieser Grundwerte muss ein Patient vom Arzt unbedingt verlangen können, denn dies gewährleistet letztendlich das Vertrauen im Arzt-Patient-Kontakt. Allerdings lassen sich aus diesen Grundwerten keine allgemeinen Handlungsanweisungen ableiten. Vielmehr bedeutet dieser moderne Umgang mit dem ärztlichen Ethos, dass bei medizinethischen Problemen im Einzelfall die Beachtung dieser Grundwerte sichergestellt und schlussendlich die Gewichtung der verschiedenen Werte im konkreten Fall geprüft werden muss, um eine situationsangemesse Entscheidung im Sinne des Patienten treffen zu können. Somit muss sich im 21. Jahrhundert jede Norm ärztlichen Handelns einzeln prüfen lassen im Namen des ärztlichen Ethos (Wiesing 1999).

Die SAMW hat in ihren medizinisch-ethischen Richtlinien zur Betreuung von Patienten am Lebensende bereits anerkannt, dass auch die individuelle Gewissensentscheidung als Komponente des ärztlichen Ethos von großer Bedeutung ist: 
„In dieser Grenzsituation [Wunsch des Patienten nach Suizidhilfe] kann für den Arzt ein schwer lösbarer Konflikt entstehen. Auf der einen Seite ist die Beihilfe zum Suizid nicht Teil der ärztlichen Tätigkeit, weil sie den Zielen der Medizin widerspricht. Auf der anderen Seite ist die Achtung des Patientenwillens grundlegend für die Arzt-Patienten-Beziehung. Diese Dilemmasituation erfordert eine persönliche Gewissensentscheidung des Arztes. Die Entscheidung, im Einzelfall Beihilfe zum Suizid zu leisten, ist als solche zu respektieren.“ (SAMW 2004, S. 6)

In Deutschland wird Ärzten dieses eigenverantwortliche Abwägungsermessen bei der Suizidassistenz berufsrechtlich nicht zugestanden. Obgleich sich die B ̈̈K meist an innerärztlicher und gesellschaftlicher Diskussion interessiert zeigt und bemüht ist Positionen zu finden, welche die gesamte deutsche Ärzteschaft repräsentieren, wurde gerade im Hinblick auf die Suizidhilfe die Meinungsvielfalt der Ärzteschaft nicht in die Verlautbarungen einbezogen oder transparent gemacht. In der MBO wurde 2011 schlichtweg ein Verbot der ärztlichen Hilfe zur Selbsttötung ausgesprochen und damit versucht, diesbezüglich das ärztliche Ethos der Ärzteschaft vorzuschreiben und das Gewissen des Arztes in der Einzelfallentscheidung zu normieren. Laut Jox hat die BÄK im Nachgang zu den Kontroversen um das Suizidhilfeverbot durch Öffentlichkeitsarbeit vergeblich versucht, „,en Eindruck eines stabilen und seit uralten Zeiten unveränderten Berufsethos zu vermitteln. [...] Der Eindruck ethischer Positionskämpfe, Verwirrungen und Ambivalenzen blieb [allerdings] hängen.“ (Jox 2011, S. 190) Das ärztliche Standesethos ist heute aber nicht mehr nur Ausdruck einer gemeinsamen Vorstellung sittlicher Werte und Pflichten des Berufs. Es betont ebenso die Gültigkeit des individuellen ärztlichen Gewissens als oberste und letzte Instanz aller ärztlichen Behandlungsentscheidungen (de Ridder 2012). Deshalb wäre es wünschenswert, wenn die Ärzteschaft um einen Kompromiss zwischen den zutiefst unterschiedlichen individuellen, auf Basis allgemeiner ethischer Grundsätze abgeleiteten Auffassungen des ärztlichen Ethos einerseits und dem durch die $\mathrm{B} \ddot{\mathrm{AK}}$ vertretenen und publizierten ärztlichen Ethos andererseits bemüht wäre. Die Ärzteschaft sollte sich im Sinne eines solchen Ethos vermehrt in den ohnehin bereits bestehenden öffentlichen Diskurs um die ärztliche Suizidhilfe einbringen und sich deutlich aufgeschlossener den Realitäten und der Meinungsvielfalt in der Ärzteschaft stellen. Allerdings darf kein Arzt zu einer Hilfe zur Selbsttötung verpflichtet zu werden. 
4.2.2 Die Bitte um Suizidhilfe und der „Schwarze Peter“ - Suizidhilfe als ärztliche Aufgabe?

In einer im Dezember 2014 veröffentlichen Mitteilung des Vorstands der BÄK begrüßt dieser ausdrücklich die in Politik und Öffentlichkeit geführte Diskussion über die Sterbebegleitung, betont dabei aber noch einmal ihre Ablehnung der ärztlichen Suizidhilfe:

„Die Berufsordnungen der Ärztekammern formulieren einheitlich und bundesweit, dass es die Aufgabe von Ärzten ist, das Leben zu erhalten, die Gesundheit zu schützen und wiederherzustellen, Leiden zu lindern und Sterbenden Beistand zu leisten (§ 1(2) MBO). Vor diesem Hintergrund und mit Blick auf die gegenwärtige Debatte über eine mögliche gesetzliche Regelung der Sterbehilfe in Deutschland bekräftigen die Ärztekammern, dass die Tötung des Patienten, auch wenn sie auf dessen Verlangen erfolgt, sowie die Beihilfe zum Suizid nicht zu den Aufgaben des Arztes gehören. [...]

Der 114. Deutsche Ärztetag in Kiel hat die Novelle [Überarbeitung des §16 MBO] mit überwältigender Mehrheit beschlossen. Danach ist es Ärzten verboten, Patientinnen und Patienten auf deren Verlangen zu töten. Sie dürfen keine Hilfe zur Selbsttötung leisten. [...] Diese Grundaussage wird durch zum Teil länderspezifische Formulierungen des $\$ 16 \mathrm{MBO}$ nicht in Frage gestellt.“(BÄK 2014, S. 1/2)

Dennoch wird nach wie vor in Publikationen und Debatten bei der Frage, wer denn im Falle der Freigabe einer Suizidhilfe sich dieser sicher eher unliebsamen Aufgabe annehmen sollte, wiederholt der Ärzteschaft die Verantwortung und Sorge hierfür zugeschrieben. Der Grund, warum immer wieder Ärzte als bevorzugte Helfer ins Gespräch kommen, liegt vor allem darin, dass sie der einzige Berufsstand in Deutschland sind, der mittels Rezeptierung legal Zugang zu den entsprechenden Medikamenten hat. Aber nicht nur deshalb spielen die Mediziner eine zentrale Rolle in der Debatte um die Suizidassistenz, obgleich der Gesellschaft wohl größtenteils bewusst sein muss, dass der Wunsch nach Suizidhilfe den Arzt als Helfer der Wahl vor die schwierige Situation stellt, Wille und Wohl des Patienten mit dem eigenen Berufsethos in Übereinstimmung zu bringen (Simon 2010). Genau an der Stelle des Standesethos knüpfen weitere Überlegungen an, die das ärztliche Ethos zur Grundlage machen, auf der der Arzt Hilfe zur Selbsttötung erwägen bzw. leisten darf. Schließlich ist der Berufsstand der Ärzteschaft dazu aufgerufen, Menschen in schwierigen Situationen beizustehen, eben auch dann, wenn sie aus dem Leben scheiden wollen. Zugleich kann nur von diesem Berufsstand die Freiverantwortlichkeit des Handelns fachgerecht überprüft werden. Demzufolge kann genau dieses Standesethos den besten Schutz des Lebens vor nicht indizierter Sterbehilfe erwarten lassen (vgl. Lorenz 2010 u. Verrel 2006). Befürworter des Konzeptes des Arztes als Suizidhelfer weisen in diesem Zusammenhang auf die besondere ärztliche Kompetenz bei der Betreuung Sterbender hin und heben dabei das einmalige 
Vertrauensverhältnis (auf Basis des ärztlichen Ethos) zwischen Arzt und Patient hervor, innerhalb dessen eine derart schwierige Entscheidung getroffen werden sollte (Schildmann u. Vollmann 2006).

Interessant ist, dass auch in den europäischen Ländern vor dem Hintergrund einer zunehmenden Befürwortung von Sterbehilfe in der Öffentlichkeit die entscheidende Frage nach der adäquaten Rolle des Arztes in der Sterbehilfe umstritten bleibt. Eine internationale Studie zu diesem Thema kam zu dem Ergebnis, dass „selbst innerhalb westeuropäischer Länder die länderspezifischen Ansichten darüber, ob der assistierte Suizid [...] nur von Ärzten und Ärztinnen geleistet werden sollte, sehr unterschiedlich sind.“ (Bosshard et al. 2009, S. 8) Dies mag vielleicht auf gewisse nationale Unterschiede in der Auffassung eines ärztlichen Ethos verweisen, was jedoch im Rahmen dieser Arbeit nicht weiter geprüft werden kann.

\subsubsection{Vertrauensverlust durch ärztlich assistierten Suizid?}

Sicher gibt es auch Gemeinsamkeiten in der internationalen Debatte um die Suizidhilfe. So wird nicht nur in Deutschland, sondern auch im angelsächsischen Raum (Wiesing 1999) von Gegnern einer ärztlichen Hilfe zur Selbsttötung häufig dahingehend argumentiert, dass dies eine Gefährdung der ärztlichen Rolle, eine Schwächung des ärztlichen Ethos und demzufolge einen Vertrauensverlust in die Ärzteschaft zur Folge haben würde (vgl. Hoppe u. Hübner 2009, Zimmermann-Acklin 2009 u. Ryser-Düblin et al. 2008). Diese Befürchtung gilt es sehr ernst zu nehmen, denn die ärztliche Tätigkeit und Funktionalität des gesamten Berufsstandes wären erheblich gefährdet, wenn es auf Seiten der Patienten kein Vertrauen mehr in die Ärzte gäbe. Schließlich ist das Vertrauen und demnach das berufliche Ethos die unumstößliche Basis dieses einzigartigen Verhältnisses zweier Menschen.

Auf den ersten Blick ist der drohende Vertrauensverlust sicher ein schwerwiegendes Argument gegen eine ärztliche Hilfe zum Suizid, deshalb soll es im Folgenden einer genauen Prüfung unterzogen werden. Nachdem sich bislang Befürchtungen über einen möglichen Dammbruch, Missbrauchsgefahren oder Auswirkungen auf Dritte (z.B. soziale Randgruppen oder Angehörige) durch die Erfahrungen mit der ärztlichen Suizidhilfe im Ausland nicht bewahrheitet haben (vgl. Marckmann 2013), ist dieses Argument derzeit die einzig legitime 
Begründung dafür, das Ethos und Gewissen des Arztes in der Einzelfallentscheidung einzuschränken und das berufliche Verbot der ärztlichen Suizidhilfe weiter aufrechtzuhalten. Denn das berufsrechtliche Verbot der ärztlichen Suizidhilfe ist letztendlich nicht nur eine normative Handlungsempfehlung, sondern steht zugleich dem Selbstbestimmungsrecht des informierten und einwilligungsfähigen Patienten eindeutig entgegen.

Mehrere Autoren sind sich einig, dass das Vertrauensargument in der Debatte um die Suizidhilfe nicht haltbar ist (vgl. Schöne-Seifert 1999, Jox 2011, Wiesing 2012 b, Marckmann 2013), da es für einen Vertrauensverlust in die Ärzteschaft bislang keinen gesicherten Hinweis gibt. Diese These deckt sich mit einer von der Deutschen Gesellschaft für Humanes Sterben (DGHS) in Auftrag gegebenen Studie des renommierten Meinungsforschungsinstituts forsa aus dem Jahr 2003, im Rahmen derer folgende wichtige Ergebnisse veröffentlicht wurden:

„Lediglich 12 Prozent der Bundesbürger meinen, dass sie das Vertrauen zu ihren Hausarzt verlieren würden, wenn sie wüssten, dass dieser schon einmal bei einem unheilbar kranken Patienten Beihilfe zum Suizid geleistet hat. Die große Mehrheit der Bevölkerung (84 Prozent) sagt: Wenn mein Hausarzt einem unheilbar kranken Patienten bei der Selbsttötung hilft, würde ich das Vertrauen zu ihm nicht verlieren." (DGHS 2003, S. 1)

Selbst bei der sog. aktiven Sterbehilfe sieht nur eine Minderheit von $20 \%$ der Befragten das Vertrauen zu ihrem Hausarzt erschüttert. $74 \%$ der Befragten gaben sogar an, das Vertrauen zu ihrem Hausarzt nicht zu verlieren, wenn sie wüssten, dass er bei einem unheilbar kranken Patienten verbotene, aktive Sterbehilfe geleistet hat (op. cit.). Dieses Ergebnis deckt sich mit internationalen Studien. Eine amerikanische, randomisierte Studie von Hall aus dem Jahr 2005 stellte fest: „Despite the widespread concern, that legalising physician aid in dying would seriously threaten or undermine trust in physicians, the weight of the evidence in the USA is on the contrary, although views vary significantly." (Hall 2005, S. 693) Gleiche Resultate brachten auch zwei frühere Studien aus den USA zu diesem Thema (vgl. Emanuel et al. 1996 u. Graber 1996), sowie eine Studie aus Schweden, die zu folgendem Ergebnis kam: „We found no evidence for the assumption that trust in the medical services would be unambiguously jeopardize if physician-assisted suicide were to be legalized." (Lindblad et al. 2009, S. 260)

Das Vertrauensargument in der Debatte um den ärztlich assistieren Suizid hat jedoch auch Einschränkungen. Zwar kann man sich auf die im vorhergehenden aufgeführten hypothetischen Erfahrungen der Bevölkerung stützen, allerdings gibt es derzeit keine empirischen Studien über tatsächliche Erfahrungen aus Ländern wie den Niederlanden, Belgien, Luxem- 
burg oder US-Staaten wie Oregon, wo die ärztliche Suizidhilfe seit Jahren gesetzlich geregelt ist und praktiziert wird. Dies stellte eine im Rahmen der vorliegenden Arbeit durchgeführte umfangreiche Literaturrecherche heraus, die das Ziel hatte, qualifizierte empirische Studien zu finden, die einen möglichen Vertrauensverlust der Patienten in die Ärzteschaft in Ländern, in denen der ärztlich assistierte Suizid tatsächlich praktiziert wird, belegen oder widerlegen.*

Das Ergebnis der Recherche zeigt, dass die Studienlage in Bezug auf einen möglichen Vertrauensverlust, den die Freigabe einer ärztlichen Suizidhilfe nach sich ziehen würde, eher dürftig ist. Derzeit liegen lediglich Studien über die hypothetischen Erfahrungen deutscher, schwedischer und amerikanischer Patienten vor. Alle vorliegenden Studien kommen zu dem Ergebnis, dass es im Falle einer Zulassung der ärztlichen Suizidhilfe keinen signifikanten empirischen Beleg für einen möglichen Vertrauensverlust gibt. Kritiker einer ärztlichen Suizidhilfe mögen nun sicher auf die geringe Zahl der derzeit vorliegenden Untersuchungen verweisen (in der Tat ist es bedauerlich, dass dieses nicht nur in der deutschen Debatte so zentrale Thema bislang nicht weiter untersucht wurde). Andererseits stehen sie in der Pflicht, die von ihnen befürchteten negativen Auswirkungen auf das Vertrauensverhältnis zwischen Patienten und Ärzten, mit denen sie das (weitere) berufsrechtliche Verbot der ärztlichen Suizidhilfe rechtfertigen, nachzuweisen. Denn in einer liberal verfassten Gesellschaft bedürfen nicht Freiheitsrechte, sondern die Einschränkung von Freiheitsrechten der Rechtfertigung. Dieser Nachweis dürfte jedoch angesichts fehlender empirischer Belege schwierig sein. Dementsprechend gilt es, die Konsequenzen zu ziehen und zu fragen, ob es dann Sinn macht, das berufsrechtliche Verbot der Suizidhilfe weiterhin aufrechtzuerhalten und das Ethos des Arztes in der Einzelfallentscheidung weiterhin derart zu beschränken. Zu bedenken wäre, dass es wiederum eine Schwächung des Ethos nach sich ziehen könnte, wenn die Ärzteschaft sich weiterhin den wohl überlegten Patientenwünschen derart entgegenstellt. Letztendlich wächst die Zustimmung zur ärztlichen Suizidhilfe in Deutschland von Jahr zu Jahr. Eine

\footnotetext{
* Bei der Recherche wurde Mitte November 2014 in der Datenbank MEDLINE über PubMed folgende Literatursuche mittels MeSH-Terms durchgeführt: ((("Interpersonal Relations"[Mesh:NoExp]) OR "Professional-Patient Relations"[Mesh:NoExp]) OR "Physician-Patient Relations"[Mesh])) AND "Suicide, Assisted"[Mesh]. Unter den 373 Ergebnissen wurde der Zeitraum auf Artikel ab 1997 (bis 2014) eingegrenzt, denn vorher konnten in keinem Land tatsächliche Erfahrungen mit gesetzlich zugelassener Suizidhilfe studiert werden (in Oregon erfolge 1997 die erste gesetzliche Regelung bzw. Freigabe dieser Handlung). Unter den verbleibenden 243 aufgeführten Artikeln erfolgte ein Screening des Titels und des Abstracts auf der Suche nach Studien der oben genannten Fragestellung. Dabei fand sich keine einzige empirische Studie zum Thema Vertrauensverlust der Bevölkerung/der Patienten in die Ärzteschaft in Ländern mit einer gesetzlichen Freigabe der ärztlichen Suizidhilfe. Auch die auf das Auffinden von Interviewstudien verfeinerte Suchanfrage ((()(("Interpersonal Relations" [Mesh:NoExp]) OR "Professional-Patient Relations"[Mesh:NoExp]) OR "Physician-Patient Relations"[Mesh])) AND "Suicide, Assisted"[Mesh])) AND ((questionnaire) OR interview) ergab unter den 36 Treffern keine relevante Studie. Zudem wurden in der Datenbank ETHMED mit verschieden kombinierten Schlagwortsuchen ebenfalls keine diesbezüglichen Studien gefunden. Eine Suche nach möglichen Querverweisen auf entsprechende Studien in Literaturbeiträgen zu dem Thema blieb ebenso erfolglos.
} 
Umfrage des Infratest dimap Instituts zeigte im Oktober 2014, dass $79 \%$ der Bürger die Frage Sollte es Ärzten erlaubt sein, Schwerstkranken ein tödliches Medikament zur Selbsteinnahme zur Verfügung stellen? bejahten (Infratest dimap 2014). Das Eingehen der Ärzteschaft auf wohl überlegte Patientenwünsche und (unter bestimmten Bedingungen) die Hilfe bei der Umsetzung dieser Wünsche könnte das Vertrauen in die Ärzteschaft sogar stärken. (vgl. Wiesing 2012 b u. Jox 2011)

\subsection{Zusammenfassung und Zwischenergebnis}

Wie in diesem Kapitel der Arbeit deutlich wurde, ist das ärztliche Ethos die unumstößliche Basis der Arzt-Patient-Beziehung, da es ein rollengebundenes antizipatorisches Systemvertrauen des Patienten in seinen behandelnden Arzt ermöglicht. In Kodizes wurde daher über Jahrhunderte versucht, die Werte und Normen zu verankern, welche dieses besondere ärztliche Berufsethos ausmachen, um ärztliches Handeln in moralischer Hinsicht festzuschreiben und medizinethische Probleme zu normieren. Doch angesichts der Komplexität aktueller, medizinethischer Herausforderungen ist dies nun nicht mehr möglich. Folglich ist die aktuelle Debatte um die ärztliche Hilfe zum Suizid prädestiniert dafür, ein Licht auf die Bedeutung des modernen ärztlichen Standesethos innerhalb aktueller, medizinethischer Debatten zu werfen, denn angesichts der seit einigen Jahrzehnten in den Fokus getretenen Betonung der Patientenautonomie und zunehmend komplexeren Fragestellungen ist eine Problemlösung mittels einer Kodifizierung des Ethos nicht mehr möglich. Da dies eine Überforderung des ärztlichen Ethos bedeuten würde, ist es angebracht, medizinethische Herausforderungen nicht mehr nur unter Berufung auf starre Regelkataloge normieren $\mathrm{zu}$ wollen, da dies der Variabilität der Handlungssituationen kaum mehr gerecht wird und Einzelfall-/Gewissensentscheidungen im Rahmen einer tiefgehenden Arzt-Patient-Beziehung schwerlich zulässt. Hier wird deutlich, dass sich das ärztliche Ethos nunmehr auf überzeitliche und allgemein anerkannte Grundprinzipien (Respekt vor der Patientenautonomie, Fürsorge, Nicht-Schaden und Gleichheit/Gerechtigkeit) berufen muss, welche die moralischen Verpflichtungen des Arztes definieren und die es im Einzelfall gegeneinander abzuwägen gilt, um ein Eingehen des Arztes auf den Patienten und seine wohlbegründeten Wünsche zu ermöglichen. 
Im Folgenden galt es die von Gegnern einer ärztlichen Suizidhilfe oft vorgebrachte These zu prüfen, ob eine Freigabe der ärztlichen Suizidassistenz einen Vertrauensverlust in die Ärzteschaft mit einer daraus resultierenden Schwächung des ärztlichen Ethos nach sich ziehen würde. Im Rahmen der konkreten Debatte um die ärztliche Suizidhilfe wird klar, dass diese These allerdings mit Hilfe deontologischer Argumente nicht untermauert werden kann, da es zwar noch ein Standesethos gibt, dieses aber nicht mehr einheitlich gelebt wird. Die ethische Grundausrichtung von Ärzten variiert vielmehr in Abhängigkeit vom zeitgeschichtlichen Kontext, kulturellen und geographischen Gegebenheiten (vgl. beispielhaft die Haltung der SAMW), dem einzelnen Arzt (vgl. Allensbach-Umfrage 2009) und neuerdings scheinbar sogar vom Bundesland (vgl. die verschiedenen BOen auf Länderebene) (Marckmann 2013). Aber auch mittels teleologischer Argumente, die sich auf die (negativen) Folgen einer Zulassung der ärztlichen Suizidhilfe im Sinne eines Vertrauensverlustes der Bevölkerung in die Ärzteschaft berufen, lässt sich die These, dass das ärztliche Ethos im Widerspruch zur ärztliche Suizidhilfe steht, nicht begründen. Neben den Erfahrungen in Nachbarländern, dass ungewollte Auswirkungen bislang nicht eingetreten sind (op. cit.), gibt es derzeit keine empirischen Hinweise auf einen möglichen Vertrauensverlust im Falle einer Liberalisierung des ärztlichen Ethos hinsichtlich der Möglichkeit der Suizidassistenz. 


\section{5 ÄRZTLICH ASSISTIERTER SUIZID - EIN WIDERSPRUCH ZUM ÄRZTLICHEN ETHOS? ZUSAMMENFASSUNG UND AUSBLICK}

Der abschließenden Zusammenfassung der Ergebnisse dieser Arbeit sei ein Fallbeispiel aus den Erfahrungen des bekannten Palliativmediziners Gian Domenico Borasio vorangestellt, das die Brisanz des Themas der (ärztlichen) Suizidhilfe verdeutlicht. Auch wenn dieses Thema aus verschiedenen Blickwinkeln betrachtet werden kann, steht besonders der Mensch mit seinem Wunsch an die Ärzteschaft oder an Organisationen im Zentrum. Auch wenn dieser Wunsch nur von einem kleinen Teil der Patienten geäußert wird, wird er doch zum zentralen Anliegen nach Würde und unbedingter Selbstbestimmung im Sterben.

„Ein junger Patient mit einem sehr aggressiven Tumor und stärksten Schmerzen wurde auf unserer Palliativstation aufgenommen. Die Schmerzen konnten innerhalb einer Woche gut gelindert werden. Der Patient war sehr zufrieden und bedankte sich bei allen Mitarbeitern, wurde nach Hause entlassen und brachte sich dort um. Das Team der Palliativstation war erschüttert und fragte sich: ,Wieso hat er mit uns nicht geredet?' Wir konnten mit der Schwester des Patienten Kontakt aufnehmen, welche die einzige Person war, der er sein Suizidvorhaben vorab mitgeteilt hatte. Die Schwester hatte ihm die gleiche Frage gestellt: ,Weshalb hast du nicht mit den Ärzten gesprochen?` Die erschütternde Antwort des Patienten war: ,Um Gottes Willen. Die Ärzte sind so gut zu mir gewesen, ich konnte sie doch unmöglich in Schwierigkeiten bringen." "(Borasio 2009, S. 240)

In einem einführenden Kapitel wurden die begrifflichen und inhaltlichen Grundlagen für den Fortgang der Arbeit bereitgestellt, aus denen noch einmal zwei Punkte explizit betrachtet werden sollen. Zum einen, dass es sich beim ärztlich assistierten Suizid um die Hilfe zur freiverantwortlichen Selbsttötung eines Patienten handelt, der seinen Wunsch zu sterben über längere Zeit nach einer rationalen Einschätzung seiner Lebensumstände gründlich abgewogen hat. Zum anderen ist essentiell, dass der Suizid, wie auch die Hilfe hierzu in Deutschland straffrei sind und nur für Ärzte gewisse Einschränkungen im Zuge der Garantenpflicht bestehen, wobei die Rechtsprechung der letzten Jahre zunehmend auf eine mögliche Eigenverantwortlichkeit des Suizidenten eingehen. Mit der tabellarischen Übersicht über die Sterbehilfe am Ende des zweiten Kapitels wurde außerdem auf die begriffliche Neuordnung und die berufs-/ und strafrechtliche Bewertung der einzelnen Formen der Sterbehilfe eingegangen.

Im dritten Kapitel wurde aufgezeigt, warum sich nach den anfänglichen Sterbehilfedebatten in den letzten Jahrzehnten die Debatte hierzulande vermehrt auf die Suizidhilfe verlagert hat und 
auf der Basis einer umfangeichen Literaturrecherche drei Anlässe beschrieben, die diese Entwicklung bedingt haben. Dazu gehören die Kontroversen um die Tätigkeit von Schweizer Sterbehilfeorganisationen in Deutschland und dem damit verbundenen Suizidtourismus in die Schweiz, ausgelöst 2005 durch die Eröffnung einer DIGNITAS Zweigstelle in Hannover. Neben der organisierten Sterbehilfe war des Weiteren die gewerbliche, also auf Gewinnerzielung ausgelegte Suizidhilfe Thema der Debatte, vornehmlich durch die Tätigkeit des Vereins Sterbehilfe Deutschland, der einer jährlich steigenden Zahl sterbewilliger Patienten in Deutschland Suizidhilfe leistet. Hinzu kommt die 2011 von der BÄK vorgenommene berufsethische Neubewertung und das im selben Jahr auf dem 114. Ärztetag in Kiel beschlossene berufsrechtliche Verbot der ärztlichen Suizidhilfe im $§ 16$ MBO. Dieses Verbot wurde im Nachgang nicht von allen LÄKen gleichlautend übernommen, denn einige LÄKen gingen einen eigenen Weg mit einer offeneren Formulierung. Daraus resultiert bezüglich der ärztlichen Suizidhilfe ein berufsrechtlicher Flickenteppich auf Länderebene sowie das Paradoxon, dass das Berufsrecht eine im Strafrecht nicht geahndete Handlung verbietet.

In der Vielzahl der aufgezeigten Reaktionen wird deutlich, dass die juristischen und politischen Bestrebungen dahin gehen, die gewerbliche und organisierte Sterbehilfe (wie auch die Werbung hierfür) in Deutschland zu untersagen, wobei die Debatten über einen Gesetzesentwurf diesbezüglich in naher Zukunft stattfinden werden und sicher mit Spannung erwartet werden können. Erste Positionsentwürfe und auch ein Gesetzesvorschlag einer Gruppe Medizinethiker und Juristen liegen bereits vor. Eine Änderung der berufsrechtlichen und -ethischen Bewertung der Suizidhilfe ist allerdings derzeit nicht zu erwarten, trotz der seit Jahren von verschiedenen Gremien und Expertenrunden wiederholt vorgebrachten Forderung, die Suizidhilfe dem Arzt als höchstpersönliche Gewissensentscheidung in begründeten Einzelfällen zuzugestehen. Zudem wurde im Rahmen der Sichtung der Literatur klar, dass die Frage nach der Zulässigkeit der ärztlichen Suizidhilfe derzeit vielfach mit Bezugnahme auf das ärztliche Ethos diskutiert wird, dabei jedoch die Argumentationsweisen und Vorstellungen dieses besondere Berufsethos betreffend stark divergieren und es deshalb ein Kernpunkt der aktuellen Debatte ist, der einer näheren Betrachtung bedarf.

Neben der Darstellung des aktuellen Stands der Diskussion um die Suizidhilfe in Deutschland soll die vorliegende Dissertation genau an dieser Stelle anknüpfen. Daher wurde im vierten Kapitel das ärztliche Ethos im Kontext der ärztlichen Suizidhilfe betrachtet. Grundlegende Anmerkungen verdeutlichen, dass dem Ethos in der Medizin eine besondere Bedeutung zukommt, denn es ermöglicht dem Patienten ein antizipatorisches, rollengebundenes Systemvertrauen in den Arzt und bildet somit die unumstößliche Basis einer funktionierenden 
Arzt-Patient-Beziehung. Dementsprechend wurde über Jahrhunderte hinweg versucht, dieses besondere Ethos in Kodizes festzuschreiben und damit medizinethische Probleme zu normieren. Dieses Vorgehen wird allerdings der Komplexität moderner medizinethischer Probleme nicht gerecht, da es eine Überforderung des ärztlichen Ethos bedeuten würde, das sich vielmehr auf überzeitliche, weithin anerkannte, ethische Grundprinzipien (Fürsorge/ Wohltun, Nicht-Schaden, Gleichheit/Gerechtigkeit und Respekt vor der Autonomie des Patienten) beziehen sollte, die dann im Rahmen der konkreten Einzelfallentscheidung gegeneinander abgewogen und gewichtet werden müssen.

Im Fortgang der Arbeit wurde klar, dass an die Frage nach dem Standesethos weitere Überlegungen anknüpfen, die das ärztlich Ethos zur Grundlage dafür machen, dass der Arzt Suizidhilfe überhaupt erwägen bzw. leisten darf. In diesem Kontext galt es anschließend, die von Gegnern einer ärztlichen Suizidhilfe oft vorgebrachte konsequentialistische These/ Argumentation zu prüfen, ob eine Freigabe dieser Hilfe einen Vertrauensverlust der Bevölkerung in die Ärzteschaft nach sich ziehen würde. Eine Literaturrecherche konnte zeigen, dass es bislang keinerlei retrospektive Studien gibt, die in Ländern, in denen ärztliche Suizidhilfe legal praktiziert wird, einen möglichen Vertrauensverlust belegen. Lediglich einige prospektive Studien in den USA, Deutschland und Schweden geben Auskunft darüber, dass im Falle einer Zulassung der ärztlichen Suizidhilfe kein Vertrauensverlust zu erwarten wäre.

Da, wie aufgezeigt, weder deontologiosche, noch konsequentialistische Argumentationen die Ablehnung der ärztlichen Suizidassistenz im Namen des ärztlichen Ethos untermauern, ist die zentrale Frage der vorliegenden Dissertation, ob ärztlich assistierter Suizid dem ärztlichen Ethos widerspricht, derzeit mit einem klaren Nein zu beantworten. Auch wenn die Antwort gegenwärtig eindeutig ist, ist es angebracht und wünschenswert, diese These anhand in der Zukunft zu erwartender empirischer Studien zum Thema Vertrauensverlust in die Ärzteschaft in Ländern mit einer gesetzlichen Möglichkeit zur ärztlich assistierten Selbsttötung zu prüfen, denn auch wenn bislang keine Hinweise diesbezüglich vorliegen, heißt es nicht, dass diese Gefahr nicht grundsätzlich besteht.

Zudem wird sich sicher auch das berufsrechtliche Verbot der ärztlichen Suizidhilfe der Debatte und einer genauer Überprüfung stellen müssen, da wie bereits erwähnt, in einer liberal verfassten Gesellschaft nicht Freiheitsrechte, sondern eben die Einschränkung von Freiheitsrechten dringend der Rechtfertigung bedürfen. Schließlich wächst die Zustimmung zur ärztlichen Suizidhilfe in Deutschland von Jahr zu Jahr. 


\section{ABKÜRZUNGSVERZEICHNIS}

\begin{tabular}{|c|c|}
\hline AE-StB & Alternativ-Entwurf Sterbebegleitung \\
\hline $\mathrm{BÄK}$ & Bundesärztekammer \\
\hline BGB & Bürgerliches Gesetzbuch \\
\hline $\mathrm{BGH}$ & Bundesgerichtshof \\
\hline $\mathrm{BO}$ & Berufsordnung \\
\hline $\mathrm{CDU}$ & Christlich Demokratische Union Deutschlands \\
\hline CSU & Christlich-Soziale Union in Bayern e.V. \\
\hline DGHS & Deutsche Gesellschaft für Humanes Sterben e.V. \\
\hline DGP & Deutsche Gesellschaft für Palliativmedizin \\
\hline DJT & Deutscher Juristentag \\
\hline FDP & Freie Demokratische Partei \\
\hline GfK & Gesellschaft für Konsum-, Markt- und Absatzforschung e. V. \\
\hline GG & Grundgesetz \\
\hline KNA & Katholische Nachrichten-Agentur \\
\hline LÄK & Landesärztekammer \\
\hline MBO & Musterberufsordnung für die in Deutschland tätigen Ärztinnen und Ärzte \\
\hline SAMW & Schweizerische Akademie der medizinischen Wissenschaften \\
\hline SPD & Sozialdemokratische Partei Deutschlands \\
\hline StHD & Sterbehilfe Deutschland e.V. \\
\hline StGB & Strafgesetzbuch \\
\hline StR & Strafrecht \\
\hline
\end{tabular}




\section{LITERATURVERZEICHNIS}

Hinweis zur Zitation: Bei direkten Zitaten, die Internetdokumenten entnommen wurden, kann bei der nachfolgenden Literaturangabe im Text leider keine Seitenzahl genannt werden.

o. Verf. (2014): Ärzte sollten „Gewissen folgen dürfen“. FOCUS Magazin 14, 42

Bauer A (1993): Hippokratischer Eid: Übersetzung aus dem Griechischen von Axel Bauer. http://www.umm.uni-heidelberg.de/ag/gte/bauer_hippokratischer_eid.pdf (abgerufen am 31.07.2014)

Beauchamp T, Childress J: Principles of Biomedical Ethics; Oxford University Press, New York 2009

Birnbacher D: Suizid und Suizidverhütung - die Sicht eines Ethikers. In: Ethik in der Medizin: Ein Reader; hrsg. v. Wiesing U, 4. Auflage; Reclam Verlag, Stuttgart 2000, 178-182

Borasio GD (2009): Der assistierte Suizid aus palliativmedizinischer Sicht. Zeitschrift für medizinische Ethik 55, 235-242

Borasio GD, Jox R, Taupitz J, Wiesing U (2014): Pressemitteilung anlässlich der Präsentation des Buches Selbstbestimmung im Sterben - Fürsorge zum Leben: Ein Gesetzesvorschlag zur Regelung des assistierten Suizids. http://blog.kohlhammer.de/wp-content/uploads/ Pressemitteilung_Gesetzesvorschlag_assist_Suizid.pdf (abgerufen am 31.01.2015)

Bosshard G (2012): Beihilfe zum Suizid - Medizinische, rechtliche und ethische Aspekte. Praxis $\underline{101}, 183-189$

Bosshard G, Fischer S, Cartwright C, Faisst K, Loefmark R, Miccinesi G, Mortier F, Norup M, Onwuteaka-Philipsen B, van Delden JJ (2009): Should assisted suicide be performed by physicians only? Results of a survey among physicians in six European countries and Australia. Bioethica Forum 2 (Heft 1), 4-9

Bundesärztekammer (2004): Grundsätze der Bundesärztekammer zur ärztlichen Sterbebegleitung. Deutsches Ärzteblatt 101, 1298

Bundesärztekammer (2011): Grundsätze der Bundesärztekammer zur ärztlichen Sterbebegleitung. Deutsches Ärzteblatt 108, 346-348

Bundesärztekammer (2011): (Muster-)Berufsordnung für die in Deutschland tätigen Ärztinnen und Ärzte in der Fassung der Beschlüsse des 114. Deutschen Ärztetages 2011 in Kiel. http://www.bundesaerztekammer.de/downloads/MBO_08_20112.pdf (abgerufen am 27.02.2013)

Bundesärztekammer (2012): Bundesärztekammer - Aufgaben. www.bundesaerztekammer.de (abgerufen am 27.02.2013)

Bundesärztekammer (2014): Mitteilung des Vorstandes: „Ärzte leisten Hilfe beim Sterben, aber nicht Hilfe zum Sterben“. http://www.bundesaerztekammer.de/ page.asp?his=3.71.11855.12511.12533 (abgerufen am 21.12.2014) 
Bundesgerichtshof (1984): Urteil vom 04.07.1984 - 3 StR 96/84.

http://www.servat.unibe.ch/dfr/bs032367.html (abgerufen am 22.11.2014)

Bundesgerichtshof (1996): Urteil vom 15.11.1996 - 3 StR 79/96.

http://www.hrr-strafrecht.de/hrr/3/96/3-79-96.php3 (abgerufen am 22.11.2014)

Bundesgerichtshof (2010): Urteil vom 25.06.2010 - 2 StR 454/09.

http://www.hrr-strafrecht.de/hrr/2/09/2-454-09.php (abgerufen am 22.11.2014)

Bundesministerium für Justiz und Verbraucherschutz (2015): Strafgesetzbuch. http://www.gesetze-im-internet.de/stgb/BJNR001270871.html\#

BJNR001270871BJNG000102307 (abgerufen am 01.02.2015)

Bundesregierung (2012): Gesetzesentwurf 17/11126: Entwurf eines Gesetzes zur Strafbarkeit der gewerbsmäßigen Förderung der Selbsttötung.

http://dipbt.bundestag.de/dip21/btd/17/111/1711126.pdf (abgerufen am 28.06.2014)

Deutsche Gesellschaft für Humanes Sterben (2003): Sterbehilfe und das Vertrauen in den Hausarzt: Vorurteile auf dem Prüfstand: Aktuelle forsa-Umfrage November 2003. http://www.dghs.de/fileadmin/user_upload/Dateien/PDF/Umfrage_November_2003.pdf (abgerufen am 23.08.2014)

Deutsche Gesellschaft für Palliativmedizin (2011): Stellungnahme der DGP zu den überarbeiteten Grundsätzen der Bundesärztekammer zur ärztlichen Sterbebegleitung. http://www.dgpalliativmedizin.de/images/stories/DGP_Stellungnahme_BK_GS_ Sterbebegleitung_25_02_11.pdf (abgerufen am 05.02.2013)

Deutsche Gesellschaft für Palliativmedizin (2014): Ärztlich assistierter Suizid: Reflexionen der Deutschen Gesellschaft für Palliativmedizin. http://www.dgpalliativmedizin.de/ images/stories/140128_\%C3\%A4rztsuizid_online.pdf (abgerufen am 06.09.2014)

Deutscher Bundestag (2013): Dokumentations- und Informationssystem.

http://dipbt.bundestag.de/extrakt/ba/WP17/470/47094.html (abgerufen am 28.06.2014)

Deutscher Ethikrat (2013): Website des Deutschen Ethikrates. http://www.ethikrat.org (abgerufen am 09.09.2014)

Deutscher Ethikrat (2014): Zur Regelung der Suizidbeihilfe in einer offenen Gesellschaft: Deutscher Ethikrat empfiehlt gesetzliche Stärkung der Suizidprävention. Ad-hoc-Empfehlung. http://www.ethikrat.org/dateien/pdf/empfehlung-suizidbeihilfe.pdf (abgerufen am 23.12.2014)

Deutscher Juristentag (2006): Beschlüsse. http://www.djt.de/fileadmin/downloads/ 66/66_DJT_Beschluesse.pdf (abgerufen am 17.10.2012)

DIGNITAS-Deutschland (2013): Informationsbroschüre DIGNIATS-Deutschland. http://www.dignitas.ch/images/stories/pdf/informations-broschuere-dignitas-deutschland.pdf (abgerufen am 20.03.2013)

Emanuel E, Fairclouh D, Daniels E (1996): Euthanasia and physician-assisted suicide: attitudes and experiences of oncology patients, oncologists and the public. Lancet $\underline{347}$, $1805-1810$

von Engelhardt D: Zur Systematik und Geschichte der Medizinischen Ethik. In: Ethik im Alltag der Medizin: Spektrum der Disziplinen zwischen Forschung und Therapie; hrsg. v. von Engelhardt D; Birkhäuser Verlag, Basel 1997, 1-16

Frewer A (2001): Geschichte und Ethik der Euthanasie: Der ,gute Tod“ und die Aufgaben der Medizin. Brandenburgisches Ärzteblatt 11, 375-378 
Ganzini L, Goy E, Dobscha SK (2009): Oregonians' reasons for requesting physician aid in dying. Arch Intern Med 195, 489-492

Gehring P (2011): Soll es noch ein ärztliches Ethos geben? http://www.faz.net/aktuell/ feuilleton/debatten/sterbehilfe-soll-es-noch-ein-aerztliches-ethos-geben-16280.html (abgerufen am 20.08.2012)

Gelhaus P: Medizin und Arztsein. In: Von Arztethos bis Verteilungsgerechtigkeit: Eine Einführung in die Medizinethik; hrsg. v. Lüttenberg B, Muders S; Hirzel Verlag, Stuttgart 2013, 25-36

Gesellschaft für Konsum-, Markt- und Absatzforschung e. V. (2014): Bürgermeister sind die vertrauenswürdigeren Politiker: GfK Verein veröffentlicht internationale Studie zum Vertrauen in Berufe. http://www.gfk-verein.org/files/pm_gfk_verein_vertrauen_in_ berufe_1.pdf (abgerufen am 14.08.2014)

Graber M, Levy B, Weir R (1996): Patients` view about physician participation in assisted suicide and euthanasia. J Gen Intern Med 11, 71-76

Griese K, Högl E (2014): In Würde leben, in Würde sterben - Positionierung zu Sterbehilfe. http://www.spdfraktion.de/sites/default/files/positionierung_sterbehilfe_griese_hoegl_08.10.2 014.pdf (abgerufen am 01.12.2014)

Hall H, Trachtenberg F, Dugan E (2005): The impact on patient trust of legalising physician aid in dying. J med ethics $\underline{31}$, 693-697

Henckel E (2012): Assistierter Suizid kommt auch in Deutschland. www.welt.de/vermischtes/article106435266/Assistierter-Suizid-kommt-auch-inDeutschland.html (abgerufen am 20.05.2014)

Hillebrand I (2009): Sterbehilfe. http://www.drze.de/im-blickpunkt/sterbehilfe (abgerufen am 15.02.2013)

Hintze P, Reimann C, Lauterbach K, Lischka B, Reiche K, Wöhrl D (2014): Sterben in Würde - Rechtssicherheit für Patienten und Ärzte. http://www.dagmar-woehrl.de/ standpunkt/sterben-in-wuerde-positionspapier (abgerufen am 01.12.2014)

Hoppe J (2011): Grundsätze der Bundesärztekammer zur ärztlichen Sterbebegleitung: Vorwort. Deutsches Ärzteblatt $\underline{108}, 346$

Hoppe J, Hübner M (2009): Auf ein Wort: Der ärztlich assistierte Suizid aus medizinethischer und aus juristischer Perspektive. Zeitschrift für medizinische Ethik 55, 303-317

Hoppe J, Lipp V, Simon A (2011): Sterbehilfe: Das ärztliche Ethos bleibt intakt. http://www.faz.net/aktuell/feuilleton/sterbehilfe-das-aerztliche-ethos-bleibt-intakt1625541.html (abgerufen am 20.05.2014)

Infratest dimap (2014): Vier Fünftel der Deutschen für ärztliche Sterbe-Unterstützung. http://www.infratest-dimap.de/umfragen-analysen/bundesweit/umfragen/aktuell/vier-fuenftelder-deutschen-fuer-aerztliche-sterbe-unterstuetzung (abgerufen am 14.11.2014)

Institut für Demoskopie Allensbach (2010): Ärztlich begleiteter Suizid und aktive Sterbehilfe aus Sicht der deutschen Ärzteschaft: Ergebnisse einer Repräsentativbefragung von Krankenhaus- und niedergelassenen Ärzten. http://www.bundesaerztekammer.de/ downloads/sterbehilfe1.pdf (abgerufen am 21.05.2014)

Institut für Demoskopie Allensbach (2013): Hohes Ansehen für Ärzte und Lehrer Reputation von Hochschulprofessoren und Rechtsanwälten rückläufig: Allensbacher Berufsprestige Skala 2013. http://www.ifd-allensbach.de/ uploads/tx_ reportsndocs/PD_2013_05.pdf (abgerufen am 14.08.2014) 
Jonitz G (2013): Sterbehilfe aus ärztlicher Sicht: 42. Symposium für Juristen und Ärzte. http://www.aerztekammer-berlin.de/40presse/20_VortraegePraes/0874_

Sterbehilfe_Jonitz_9_3_13.pdf (abgerufen am 30.06.2014)

Jox R: Sterben lassen: Über Entscheidungen am Ende des Lebens; Edition Körber-Stiftung, Hamburg 2011

Katholische Nachrichtenagentur/aerztblatt.de (2008): Sterbehilfe: Immer mehr nicht tödlich Kranke nutzen Angebote. http://www.aerzteblatt.de/nachrichten/34257/Sterbehilfe-Immermehr-nicht-toedlich-Kranke-nutzen-Angebote (abgerufen am 24.06.2014)

Katholische Nachrichtenagentur/aerztblatt.de (2014): Sterbehilfeorganisation Exit will Suizidbeihilfe ohne ärztliches Gutachten. http://www.aerzteblatt.de/nachrichten/ 58716/Sterbehilfeorganisation-Exit-will-Suizidbeihilfe-ohne-aerztliches-Gutachten (abgerufen am 26.06.2014)

Kern P (2007): Wertewandel und Medizin. Gibt es ethische Argumente, die den assistierten Freitod bis zum „Töten auf Verlangen“ legalisieren? Praxis 96, 287-295

Klinkhammer G (2014): Neuregelung der Sterbehilfe: Kein Geschäft mit der Angst. http://www.aerzteblatt.de/archiv/152943/Neuregelung-der-Sterbehilfe-Kein-Geschaeft-mitder-Angst (abgerufen am 28.06.2014)

Klinkhammer G, Stüwe H (2011): Interview mit Prof. Dr. med. Jörg-Dietrich Hoppe, Präsident der Bundesärztekammer und des Deutschen Ärztetages: „,Die ärztliche Ethik wird von allen ernst genommen“. www.aerzteblatt.de/archiv/80940/Interview-mit-Prof-Dr-medJoerg-Dietrich-Hoppe-Präsident-der-Bundesärztekammer-und-des-Deutschen-Aerzttages-Dieaerztliche-Ethik-wird-von-allen-ernst-genommen?src=search (abgerufen am 20.05.2014)

Kluge F: Etymologisches Wörterbuch der deutschen Sprache, 24. von Seebold, E. durchgesehene und erweiterte Auflage; de Gruyer Verlag, Berlin 2002

Kreß H: Ärztlich assistierter Suizid: Das Grundrecht von Patienten auf Selbstbestimmung und die Sicht von Religionen und Kirchen - ein unaufhebbarer Gegensatz? (Medizinethische Materialien Heft 192), 1. Auflage; Zentrum für Medizinische Ethik, Bochum 2012

Künast R, Sitte P, Gehring K (2014): Mehr Fürsorge statt mehr Strafrecht: Gegen eine Strafbarkeit der Beihilfe beim Suizid. https://www.gruene-bundestag.de/

fileadmin/media/gruenebundestag_de/fraktion/Positionspapier-Sterbehilfe.pdf (abgerufen am 01.12.2014)

Kutzer K (2012): Strafrechtliche Rechtsprechung des BGH zur Beteiligung an einem freiverantwortlichen Suizid. Zeitschrift für Rechtspolitik 45, 135-139

Lindblad A, Löfmark R, Lynöe N (2009): Would physician-assisted suicide jeopardize trust in the medical services? An empirical study among the general public in Sweden. Scand J Public Health $\underline{37}, 260-264$

Lorenz D (2010): Sterbehilfe als Beruf? MedR 28, 823-828

Lücking-Michel C, Brand M, Frieser M (2014): Begleiten statt Beenden - Schutz und Würde am Ende des Lebens. http://www.luecking-michel.de/wp-content/uploads/2014/11/Begleitenstatt-Beenden-Schutz-der-W\%C3\%BCrde-am-Ende-des-Lebens-PositionspapierSuizidbeihilfe-10-11-2014-1109.pdf (abgerufen am 01.12.2014)

Lunshof JE, Simon A: Die Diskussion um Sterbehilfe und Euthanasie in Deutschland von 1945 bis in die Gegenwart. In: „Euthanasie“ und die aktuelle Sterbehilfe-Debatte: Die Historischen Hintergründe medizinischer Ethik; hrsg. v. Frewer A, Eickhoff C; Campus Verlag, Frankfurt/M. 2000, 237-249 
Marckmann G (2013): Ärztlich assistierter Suizid - Der medizinethische Hintergrund: Tagung Medizinrecht im Wandel. http://www.egt.med.uni-muenchen.de/personen/leitung/ marckmann/materialien/vortragsfolien/tutzing-14_11_13.pdf (abgerufen am 16.10.2014)

Meier M (2012): Die Sterbehelferinnen jenseits der Schlagzeilen. Tages Anzeiger, 26. Juli 2012. http://www.tagesanzeiger.ch/leben/gesellschaft/Die-Sterbehelferinnen-jenseits-derSchlagzeilen/story/20892829 (abgerufen am 24.06.2014)

Nationaler Ethikrat (2003): Infobrief: Informationen und Nachrichten aus dem Nationalen Ethikrat. http://www.ethikrat.org/dateien/pdf/ner-infobrief_01-03.pdf (abgerufen am 21.04.2013)

Nationaler Ethikrat (2005): Stellungnahme: Patientenverfügung Ein Instrument der Selbstbestimmung. http://www.ethikrat.org/dateien/pdf/ Stellungnahme_

Patientenverfuegung.pdf (abgerufen am 29.03.2013)

Nationaler Ethikrat (2006): Stellungnahme: Selbstbestimmung und Fürsorge am Lebensende. http://www.ethikrat.org/dateien/pdf/Stellungnahme_Selbstbestimmung_und_Fuersorge_am_ Lebensende.pdf (abgerufen am 29.03.2013)

Nauck F, Ostgathe C, Radbruch L (2014): Hilfe beim Sterben - keine Hilfe zum Sterben. www.dgpalliativmedizin.de/images/stories/20140119_DGP_\%C3A4rztlich_assistierter_suizi d.pdf (abgerufen am 20.05.2014)

Neitzke G, Coors M, Diemer Q, Holtappels P, Spittler J, Wördehoff D (2013): Empfehlungen zum Umgang mit dem Wunsch nach Suizidhilfe. Ethik in der Medizin 25, 349-365

Oduncu FS, Hohendorf G (2011): Der ärztlich assistierte Suizid. Freiheit zum Tode oder Unfreiheit zum Leben? Zeitschrift für medizinische Ethik 57, 230-242

von Oorschot B, Simon A (2008): Aktive, passive oder indirekte Sterbehilfe?: Über subjektive Definitionen und Klassifikationen von Ärzten und Richtern in Entscheidungssituationen am Lebensende. Psychologie \& Gesellschaftskritik $\underline{32}$, 39-53

Petermann H (2008): Der Wunsch nach einem Tod in Würde. Eine Annäherung an den ärztlich assistierten Suizid. Zeitschrift für Evidenz, Fortbildung und Qualität im Gesundheitswesen 102, 171-175

Regionale Kontrollkommissionen für Sterbehilfe (2012): Jahresbericht 2012. http://www.euthanasiecommissie.nl/Images/JV.RTE2012.duDEF2_tcm52-39101.pdf (abgerufen am 17.06.2014)

de Ridder M: Ärztliches Ethos und Suizidhilfe in engen Grenzen. In: Suizidhilfe als Herausforderung: Arztethos und Strafbarkeitsmythos; hrsg. v. Neumann G. (Schriftenreihe der Humanistischen Akademie Berlin 5); Alibri Verlag, Aschaffenburg 2012, S. 73-79

Rübenach S (2007): Todesursache Suizid. https://www.destatis.de/DE/Publikationen/ WirtschaftStatistik/Gesundheitswesen/AktuellSuizid.pdf (abgerufen am 11.02.2013)

Rudat S (2013): Delegierte beschließen Änderung der Berufsordnung. http://www.aerztekammer-berlin.de/50ueberUns/20_Wer_wir_sind/20_DV/50_DV_Berichte/ 432_DV2013_06_12.html (abgerufen am 20.05.2014)

Ryser-Düblin P, Zwicky-Aeberhard N, Gürber R (2009): Hilfe beim oder Hilfe zum Sterben?: Position der VKAS zur Sterbehilfeproblematik. Schweizerische Ärztezeitung $\underline{89}$, 1245-1249 
Salloch S, Vollmann J (2011): Ärztlich assistierter Suizid als Herausforderung für das ärztliche Berufsethos: Kongresspublikation III. Interdisziplinärer Kongress Junge Naturwissenschaft und Praxis - „Chancen und Grenzen (in) der Medizin“ (Hanns Martin Schleyer-Stiftung/Heinz Nixdorf Stiftung). http://www.schleyerstiftung.de/pdf/ pdf_2011/thesen_berlin_10_11/Salloch_Sabine_Vortrag.pdf (abgerufen am 20.02.2013)

Scharfenberg E, Terpe H (2014): Vorschlag für eine moderate strafrechtliche Regelung der Suizidbeihilfe. http://www.gruene-bundestag.de/fraktion/fraktion-aktuell/suizidbeihilfe/ vorschlag-fuer-eine-moderate-strafrechtliche-regelung-der-suizidbeihilfe_ID_4393282.html (abgerufen am 01.12.2014)

Schicktanz S (2013): Vorlesung I: Einführung \& Selbstbestimmung des Patienten/Probanden: Geschichte, Theorie, Ethik der Medizin; Modul 6.1. https://www.studip.uni-goettingen.de/ folder.php?cid=9669ad6c3355c2615210397618602852\&cmd=tree (abgerufen am 23.09.2014)

Schildmann J, Vollmann J (2006): Ärztliche Assistenz zur Selbsttötung - ethische, rechtliche und klinische Aspekte. Dtsch med Wochenschr 131, 1405-1408

Schmidtke A (2012): Suizidales Verhalten in Deutschland: Referat im Rahmen der Plenarsitzung des Deutschen Ethikrats am 27.09.2012 in Berlin. http://www.ethikrat.org/ dateien/pdf/plenarsitzung-27-09-2012-schmidtke.pdf (abgerufen am 11.02.2013)

Schöch H, Verrel T, Bannenberg B, Heine G, Höpfel B, Huber B, Jung H, Lilie H, Maihofer W, Meier B et al. (2005): Alternativ-Entwurf Sterbebegleitung. http://sterberecht.homepage.tonline.de/AE-Sterbebegleitung.pdf (abgerufen am 28.06.2014)

Schöne-Seifert B: Ist Assistenz zum Sterben unärztlich?. In: Das medizinisch assistierte Sterben: Zur Sterbehilfe aus medizinischer, ethischer, juristischer und theologischer Sicht; hrsg. v. Holderegger A; Universitätsverlag Freiburg u. Herder Verlag, Freiburg i. Br. 1999, 98-119

Schöne-Seifert B (2013): Einführung in die Medizinethik: Mini-Skript zum Grundkurs Ethik im Rahmen von GTE. http://campus.uni-muenster.de/fileadmin/einrichtung/egtm/ pbsurvey/SS_2013/BSS/GTE-Ethik-Skript_Stand_SoSe_2013.pdf (abgerufen am 07.11.2014)

Schreiber H: Gesetzliche Regelung der Sterbehilfe?. In: Perspektiven des Medizinrechts im 21. Jahrhundert; hrsg. v. Duttge G; Universitätsverlag Göttingen, Göttingen 2007, 97-110

Schweizerische Akademie der medizinischen Wissenschaften (2004): Betreuung von Patientinnen und Patienten am Lebensende: Medizinisch-ethische Richtlinien der SAMW. www.Lebensende_D_04.pdf (abgerufen am 03.03.2013)

Schweizerisches Strafgesetzbuch: Artikel 115: Verleitung und Beihilfe zum Selbstmord. http://www.gesetze.ch/sr/311.0/311.0_015.htm (abgerufen am 31.01.2015)

Simon A (2010): Einstellung der Ärzte zur Suizidbeihilfe: Ausbau der Palliativmedizin gefordert. Deutsches Ärzteblatt $\underline{107}, 347$

Simon A: Ethische Aspekte medizinischer Entscheidungen am Lebensende. In: Sterben im Krankenhaus: Situationsbeschreibung, Zusammenhänge, Empfehlungen; hrsg. v. George W, Dommer E, Szymczak V; Psychosozial Verlag, Giessen 2013, 137-144

Sterbehilfe Deutschland e.V. (2010): Website von StHD: Angehörige. http://www.sterbehilfedeutschland.de (abgerufen am 31.01.2015) 
Strätling M: Assistierter Suizid grundsätzlich „keine ärztliche Aufgabe“?: Eine Bestandsaufnahme und Kritik: Medizin-Ethik-Recht. In: Suizidhilfe als Herausforderung: Arztethos und Strafbarkeitsmythos; hrsg. v. Neumann G. (Schriftenreihe der Humanistischen Akademie Berlin 5); Alibri Verlag, Aschaffenburg 2012, 82-132

Ulsenheimer K (2008): Ärztliche Hilfe beim bzw. zum Sterben - Gesetzliche Grenzziehung (aus der Sicht des Juristen). Zeitschrift für Evidenz, Fortbildung und Qualität im Gesundheitswesen 102, 176-183

Verrel T: Patientenautonomie und Strafrecht bei der Sterbebegleitung: Gutachten C zum 66. Deutschen Juristentag, Beck Verlag, München 2006

Verrel T (2011): Ehrlich, nicht unethisch: Die Bundesärztekammer und der ärztlich assistierte Suizid. Ärzteblatt Baden-Württemberg $\underline{66}$, 338-340

Verwaltungsgericht Berlin (2012 a): Pressemitteilung: Kein uneingeschränktes Verbot der Überlassung todbringender Medikamente an Sterbewillige (Nr. 17/2012). http://www.berlin. de/sen/justiz/gerichte/vg/presse/archiv/20120402.1455.368295.html (abgerufen am 15.12.2014)

Verwaltungsgericht Berlin (2012 b): Urteil vom 30.03.2012 - VG 9 K 63.09. http://www.berlin.de/sen/justiz/gerichte/vg/presse/archiv/20120402.1455.368295.html (abgerufen am 30.06.2014)

Verwaltungsgericht Hamburg (2009): Beschluss vom 06.02.2009 - 8 E 33001/08. http://rechtsprechung.hamburg.de/jportal/portal/page/bshaprod.psml?doc.id=MWRE0900007 $20 \&$ st=ent \&showdoccase=1\&paramfromHL=true\#focuspoint (abgerufen am 22.03.2013)

Vollmann J (2011): Auf dem letzten Weg: Warum es nicht inhuman ist, wenn sich todkranke Menschen beim Sterben helfen lassen. Süddeutsche Zeitung, 18. November 2011, 1-2

Weltärztebund (1948): Deklaration von Genf. http://www.bundesaerztekammer.de/ downloads/Genf.pdf (abgerufen am 31.07.2014)

Wenker M (2013): Durfte der Kieler Ärztetag den ärztlich assistierten Suizid verbieten? Ja! Zeitschrift für Ethik in der Medizin 25, 73-77

Wiesing U: Ist aktive Sterbehilfe ,unärztlich“?. In: Das medizinisch assistierte Sterben: Zur Sterbehilfe aus medizinischer, ethischer, juristischer und theologischer Sicht; hrsg. v. Holderegger A; Universitätsverlag Freiburg u. Herder, Freiburg i. Br. 1999, 233-246

Wiesing U (2012 a): Der hippokratische Eid; In: Ethik in der Medizin: Ein Studienbuch; hrsg. v. Wiesing U, 4. Auflage; Reclam Verlag, Stuttgart 2012, 38-42

Wiesing U (2012 b): Durfte der Kieler Ärztetag den ärztlich assistierten Suizid verbieten? Nein! Zeitschrift für Ethik in der Medizin 24 (Heft 2), 1-5

Wiesing U, Marckmann G: Medizinethik. In: Handbuch Ethik; hrsg. v. Düwell M, Hübenthal C, Werner M, 2. Auflage; Metzler Verlag, Stuttgart 2006, 274-279

Wiesing U, Marckmann G: Freiheit und Ethos des Arztes: Herausforderungen durch evidenzbasierte Medizin und Mittelknappheit, 1. Auflage; Alber Verlag, Freiburg i.Br. 2009

Zimmermann-Acklin M (2009): Dem Sterben zuvorkommen? Ethische Überlegungen zur Beihilfe zum Suizid. Zeitschrift für medizinische Ethik 55, 221-233 


\section{Danksagung}

An dieser Stelle möchte ich mich bei allen ganz herzlich bedanken, die mich bei der Anfertigung dieser Arbeit unterstützt haben.

Mein besonderer Dank gilt meinem Doktorvater Prof. Dr. Alfred Simon für die freundliche Überlassung dieses interessanten und aktuellen Themas. In vielen Gesprächen hat er die vorliegende Arbeit von Anfang bis Ende mit großem Engagement begleitet, wobei jede Phase an sich von ihm intensiv, professionell und warmherzig begleitet wurde. Seine sachkundige, geduldige und umfassende Dissertationsbetreuung trug wesentlich zum Abschluss dieser Arbeit parallel zum Studium und einer schwierigen privaten Situation bei.

Des Weiteren bedanke ich mich bei Frau Raphael von der Informations- und Dokumentationsstelle Ethik in der Medizin (IDEM) für die freundliche Einführung in die Literaturrecherche sowie bei Frau Drost-Siemon für die tatkräftige Unterstützung bei der Büchersuche in der Institutsbibliothek. 


\section{Lebenslauf von Kirsti Mehling}

Ich wurde am 14. Juni 1987 in Hof im Freistaat Bayern geboren. Von 1993 bis 1997 besuchte ich die Max-Reger Grundschule in Hof und im Anschluss daran das Schiller-Gymnasium Hof. Nach dem Abitur im Sommer 2006 absolvierte ich ab dem Wintersemester 2006/07 ein Studium der Musikwissenschaft und der Kunstgeschichte an der Universität Regensburg, das ich im Frühjahr 2009 mit einer Bachelorarbeit zum Thema „Bach-Rezeption bei Ferruccio Busoni“ (Betreuung: Prof. Dr. W. Horn) erfolgreich abschloss. Im Sommersemester 2009 begann ich an der Universität Göttingen das Studium der Humanmedizin und legte nach dem vorklinischen Studienabschnitt im Frühjahr 2011 den Ersten Abschnitt der Ärztlichen Prüfung ab. Im Wintersemester 2011/2012 begann nach einem ersten Kontakt mit Prof. Dr. Alfred Simon am Institut für Ethik und Geschichte der Medizin der Universitätsmedizin Göttingen die Arbeit an der vorliegenden Dissertation. Nach dem Ablegen des schriftlichen Teils des Zweiten Abschnitts der Ärztlichen Prüfung im April 2014 absolviere ich derzeit an der Universitätsmedizin Göttingen mein Praktisches Jahr (Wahlfach Anästhesie) und werde das Studium der Humanmedizin voraussichtlich Ende des Jahres 2015 abschließen. 